Prepared in cooperation with the Federal Highway Administration

\title{
Statistical Methods for Simulating Structural Stormwater Runoff Best Management Practices (BMPs) With the Stochastic Empirical Loading and Dilution Model (SELDM)
}

Scientific Investigations Report 2020-5136 



\section{Statistical Methods for Simulating Structural Stormwater Runoff Best Management Practices (BMPs) With the Stochastic Empirical Loading and Dilution Model (SELDM)}

By Gregory E. Granato, Alana B. Spaetzel, and Laura Medalie

Prepared in cooperation with the Federal Highway Administration

Scientific Investigations Report 2020-5136 


\title{
U.S. Department of the Interior \\ DAVID BERNHARDT, Secretary
}

\author{
U.S. Geological Survey \\ James F. Reilly II, Director
}

U.S. Geological Survey, Reston, Virginia: 2021

For more information on the USGS - the Federal source for science about the Earth, its natural and living resources, natural hazards, and the environment—visit https://www.usgs.gov or call 1-888-ASK-USGS.

For an overview of USGS information products, including maps, imagery, and publications, visit https://store.usgs.gov/.

Any use of trade, firm, or product names is for descriptive purposes only and does not imply endorsement by the U.S. Government.

Although this information product, for the most part, is in the public domain, it also may contain copyrighted material and images protected by publicity rights. Use of photographs or images may require permission to reproduce copyrighted items or the likeness of a person. Permission must be secured from the copyright owner or person whose likeness is being used. For more information, visit https://usgs.gov/copyright.

Suggested citation:

Granato, G.E., Spaetzel, A.B., and Medalie, L., 2021, Statistical methods for simulating structural stormwater runoff best management practices (BMPs) with the Stochastic Empirical Loading and Dilution Model (SELDM): U.S. Geological Survey Scientific Investigations Report 2020-5136, 41 p., https://doi.org/10.3133/sir20205136.

Data associated with this publication:

Granato, G.E., 2021, Best management practices statistical estimator (BMPSE) version 1.2.0: U.S. Geological Survey software release, https://doi.org/10.5066/P9XBPIOB.

Granato, G.E., Medalie, L., and Spaetzel, A.B., 2021, Statistics for simulating structural stormwater runoff best management practices (BMPs) with the Stochastic Empirical Loading and Dilution Model (SELDM): U.S. Geological Survey data release, https://doi.org/10.5066/P9X3ECTD.

ISSN 2328-0328 (online) 


\section{Acknowledgments}

The authors thank the many people who assisted with this report and the associated digital media. Susan C. Jones of the Federal Highway Administration provided oversight and input that improved the content and presentation of information in this report. Jane Clary, the project manager of the International Stormwater Best Management Practices Database Project, worked closely with the authors to answer questions and resolve a number of issues with data in the December 2019 version of that database as they were uncovered in this analysis. The International Stormwater Best Management Practices Database was developed by Wright Water Engineers, Inc. and Geosyntec Consultants for the Water Research Foundation, the American Society of Civil Engineers' Environmental and Water Resources Institute, the American Public Works Association, the Federal Highway Administration, and U.S. Environmental Protection Agency. The authors thank Lillian C. Jeznach and John C. Weaver, U.S. Geological Survey, for providing thoughtful and thorough technical and editorial reviews of this report and the associated digital media. These reviews improved the content and presentation of information in this report. 



\section{Contents}

Acknowledgments ……...................................................................................................................

Abstract

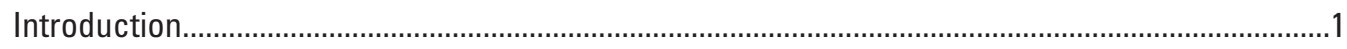

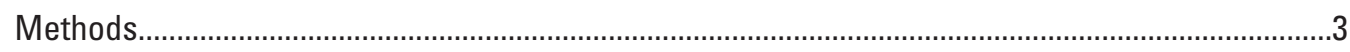

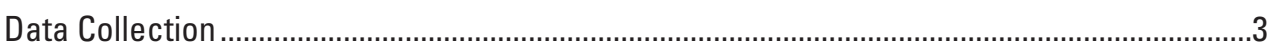

Fitting the Trapezoidal Distribution to Duration and Ratio Data ...............................................

Calculating Rank Correlation Coefficients for Duration and Ratio Data....................................

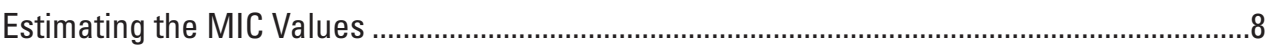

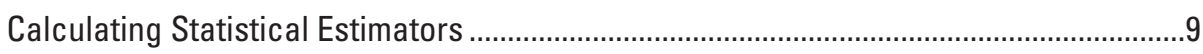

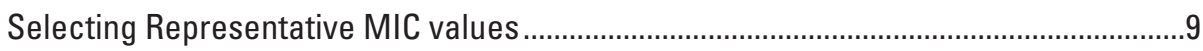

Estimating MIC Values From Inflow-Concentration Statistics ........................................10

Limitations of the BMP Performance Analysis .......................................................................10

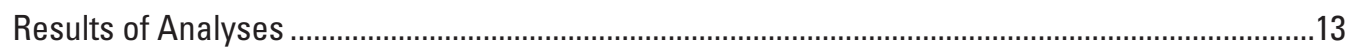

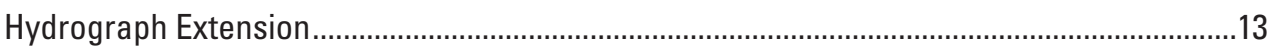

Runoff Volume Reduction .................................................................................................

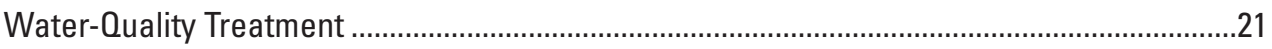

Minimum Irreducible Concentrations ...................................................................................28

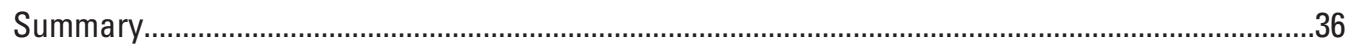

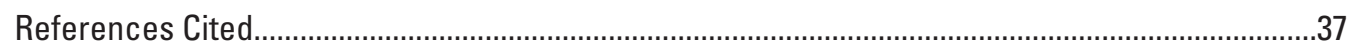

Appendix 1. Water-Quality Treatment Statistics for Individual Constituents ...............................41

\section{Figures}

1. Schematic diagram showing five possible probability density functions of the

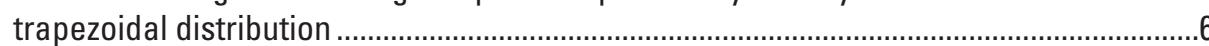

2. Scatter plots of results of a Monte Carlo analysis to demonstrate scatter of paired uniform random-number samples around a one-to-one relation for four different values of the rank correlation coefficient.

3. Line graphs showing fitted cumulative trapezoidal distribution functions of the hydrograph extension statistics.

4. Line graphs showing fitted cumulative trapezoidal distribution functions of the volume reduction ratio statistics...

5. Line graphs showing fitted cumulative trapezoidal distribution functions for the parameter value estimates for sediment, solids, nutrients, minor and trace inorganic, organic, and biological constituents.

\section{Tables}

1. Explanation of selected structural best management practice categories used in the International Stormwater Best Management Practices Database

2. Minimum and maximum ranks of a dataset of a given size that encompass the approximate 95-percent confidence interval for the median based on the binomial distribution 
3. Medians of hydrograph extension statistics for the trapezoidal distribution and Spearman's rank correlation coefficient statistics for structural best management practices, by category.....

4. Medians of stormflow volume reduction statistics for the trapezoidal distribution and Spearman's rho correlation coefficient statistics for structural stormwater runoff best management practices by category

5. Medians of selected stormflow volume reduction statistics for the trapezoidal distribution and Spearman's rho correlation coefficient statistics for structural stormwater runoff best management practices, by category

6. Runoff-quality constituents analyzed with counts of the number of sites, number of International Stormwater Best Management Practice Database categories, and number of paired samples used to analyze structural stormwater runoff best management practices.

7. Medians of selected water-quality treatment statistics for selected parameter groups including the trapezoidal distribution and Spearman's rank correlation coefficient statistics for structural stormwater runoff best management practices, by category

8. Lognormal variate values for the minimum irreducible concentration estimates of selected parameter categories.

9. Correlation between the median of minimum irreducible concentration estimates of selected constituents at individual monitoring sites and the concentration of the associated elements in the top 5 centimeters of soil.

\section{Conversion Factors}

International System of Units to U.S. customary units

\begin{tabular}{lll}
\hline \multicolumn{1}{c}{ Multiply } & By & \multicolumn{1}{c}{ To obtain } \\
\hline centimeter $(\mathrm{cm})$ & 0.3937 & inch (in.) \\
meter $(\mathrm{m})$ & 3.281 & foot $(\mathrm{ft})$ \\
kilometer $(\mathrm{km})$ & 0.6214 & mile (mi) \\
square kilometer $\left(\mathrm{km}^{2}\right)$ & 0.3861 & square mile $\left(\mathrm{mi}^{2}\right)$ \\
liter $(\mathrm{L})$ & 0.2642 & gallon (gal) \\
\hline
\end{tabular}

Temperature in degrees Celsius $\left({ }^{\circ} \mathrm{C}\right)$ may be converted to degrees Fahrenheit $\left({ }^{\circ} \mathrm{F}\right)$ as follows: ${ }^{\circ} \mathrm{F}=\left(1.8 \times{ }^{\circ} \mathrm{C}\right)+32$.

\section{Supplemental Information}

Specific conductance is given in microsiemens per centimeter at 25 degrees Celsius $(\mu \mathrm{S} / \mathrm{cm}$ at $\left.25^{\circ} \mathrm{C}\right)$.

Concentrations of chemical constituents in water are given either in milligrams per liter (mg/L), micrograms per liter $(\mu \mathrm{g} / \mathrm{L})$, or nanograms per liter $(\mathrm{ng} / \mathrm{L})$. Milligrams per liter are equivalent to parts per million, micrograms per liter are equivalent to parts per billion, and nanograms per liter are equivalent to parts per trillion.

For water-quality loads, 1 cubic foot per second ( $\mathrm{ft} 3 / \mathrm{s}$ ) equals 28.32 liters per second (L/s). 


\title{
Abbreviations
}

\author{
BMP best management practice \\ BMPDB International Stormwater Best Management Practices Database \\ BMPSE Best Management Practices Statistical Estimator \\ CDF cumulative distribution function \\ FHWA Federal Highway Administration \\ LBMPV lower bound of the most probable value \\ MIC minimum irreducible concentration \\ MICO minimum of the minimum values of the positive MIC estimates \\ MIC1 25th percentile of the minimum values of the positive MIC estimates \\ MIC2 median of the minimum values of the positive MIC estimates \\ MIC3 median of the median values of the positive MIC estimates \\ MIC4 median of the positive MIC estimates for an individual monitoring site \\ MOLBE modified quantile lower-bound estimator \\ NWIS National Water Information System \\ R Pearson's correlation coefficient \\ $\mathrm{R}(\log ) \quad$ Pearson's correlation coefficient for the common logarithms of concentrations \\ ROS regression on order statistics \\ SELDM Stochastic Empirical Loading and Dilution Model \\ SSC suspended sediment concentration \\ TMDL total maximum daily load \\ TSS total suspended solids \\ UBMPV upper bound of the most probable value \\ USGS U.S. Geological Survey
}





\title{
Statistical Methods for Simulating Structural Stormwater Runoff Best Management Practices (BMPs) With the Stochastic Empirical Loading and Dilution Model (SELDM)
}

\author{
By Gregory E. Granato, Alana B. Spaetzel, and Laura Medalie
}

\section{Abstract}

This report documents statistics for simulating structural stormwater runoff best management practices (BMPs) with the Stochastic Empirical Loading and Dilution Model (SELDM). The U.S. Geological Survey developed SELDM and the statistics documented in this report in cooperation with the Federal Highway Administration to indicate the risk for stormwater flows, concentrations, and loads to exceed userselected water-quality goals and the potential effectiveness of mitigation measures to reduce such risks. In SELDM, three treatment variables - hydrograph extension, volume reduction, and water-quality treatment - are simulated by using the trapezoidal distribution and the rank correlation with the associated runoff variables. This report describes methods for calculating the trapezoidal distribution statistics and rank correlation coefficients for these treatment variables and methods for estimating the minimum irreducible concentration (MIC), which is the lowest expected effluent concentration from a BMP site or a category of BMPs. These statistics are different from the statistics commonly used to characterize or compare BMPs; they are designed to provide a stochastic transfer function to approximate the quantity, duration, and quality of BMP effluent given the associated inflow values for a population of storm events.

Analyses for this study were done with data extracted from a modified copy of the December 2019 version of the International Stormwater Best Management Practices Database. Statistics for volume reduction, hydrograph extension, and water-quality treatment were developed with selected data. The medians of the best-fit statistics for selected constituents were used to construct generalized cumulative distribution functions for the three treatment variables. For volume reduction and hydrograph extension, selection of a Spearman's rank correlation coefficient (rho) value that is the average of the median and maximum values for the BMP category may help generate realistic simulation results in SELDM. The median rho value may be selected to help generate realistic simulation results for water-quality treatment variables.
Water-quality treatment statistics, including trapezoidal ratios and MIC values, were developed for 51 runoff-quality constituents commonly measured in highway and urban runoff studies. Statistics were calculated for water-quality properties, sediment and solids, nutrients, major and trace inorganic elements, organic compounds, and biologic constituents.

Analysis of MIC values provides information to guide professional judgement for selecting values for simulating water quality at sites of interest. The MIC is a lower bound for BMP discharge concentrations and will therefore replace simulated BMP discharge concentrations below the selected value. A new method for estimating MIC values, the lognormal variate of inflow concentrations, was developed in this report and these statistics were calculated for individual constituents and constituent categories. Inflow quality is correlated to MIC values for some constituents, but regional soil concentrations were not strongly correlated to MIC values.

\section{Introduction}

The U.S. Geological Survey (USGS) developed the Stochastic Empirical Loading and Dilution Model (SELDM) in cooperation with the Federal Highway Administration (FHWA) to indicate the risk for stormwater flows, concentrations, and loads to be above user-selected water-quality goals and to evaluate the potential effectiveness of mitigation measures to reduce such risks (Granato, 2013, 2014). SELDM is a stochastic model because it uses Monte Carlo methods to produce the random populations needed to generate the values for each component variable. SELDM simulates the potential effect of mitigation measures by using statistics approximating the net effects of structural and nonstructural best management practices (BMPs). In this report, structural BMPs are defined as the components of the drainage pathway between the source of runoff and a stormwater discharge location that affect the timing, volume, or quality of runoff. Use of the term BMP in this report, and much of the literature on stormwater treatment, does not imply that these mitigation measures represent an optimal solution for any particular site. SELDM can be used to explicitly simulate the effects of structural BMPs on the 
timing, volume, and quality of runoff by using professional judgment or by fitting the trapezoidal distribution to available data (Granato, 2013, 2014). SELDM can be used to implicitly simulate the potential effects of nonstructural BMPs, such as street sweeping, by modifying input statistics to reflect the effect of such measures on the quantity and quality of runoff from the site of interest (Granato, 2013, 2014).

Hydrograph extension is the practice of slowing the discharge of runoff flows and releasing these flows to the receiving water body over an extended period (Granato, 2014). SELDM simulates hydrograph extension times (in hours) from a BMP or series of BMPs as a stochastic variable (Granato, 2013, 2014). In theory, hydrograph extension provides extended treatment time within the BMP. Although SELDM does not alter the water-quality treatment statistics with the hydrograph extension variable, extending the duration of the highway-runoff hydrograph can make a substantial difference in the amount of dilution in a receiving stream, especially in the rising limb of the upstream storm-event hydrograph (Granato, 2013; Granato and Jones, 2014, 2019; Risley and Granato, 2014; Stonewall and others, 2019; Weaver and others, 2019; Jeznach and Granato, 2020). SELDM simulates the potential effects of structural BMPs on the timing of runoff by generating a population of BMP hydrograph extension durations and adding these durations to the runoff duration from the site of interest. SELDM preserves the structure of hydrograph extension monitoring data in simulation results by using the trapezoidal distribution and the rank correlation with the highway stormflow volume (Granato, 2013, 2014).

Volume reduction by BMPs is the practice of retaining, detaining, or routing runoff flows to increase the amount of infiltration, evapotranspiration, or diversion between the pavement and the outfall (Granato, 2014). SELDM simulations indicate that runoff volume reduction can substantially reduce downstream flows and constituent loads to receiving waters (Granato and Jones, 2014, 2017, 2019; Risley and Granato, 2014; Smith and others, 2018; Stonewall and others, 2018, 2019; Weaver and others, 2019; Jeznach and Granato, 2020). SELDM simulates the potential effects of BMPs on the volume of runoff by generating a stochastic population of the ratios of outflow to inflow volumes and applying these ratios to the stochastic population of inflow volumes from the site of interest (Granato, 2013, 2014). SELDM generates these ratios by using the trapezoidal distribution and the rank correlation with the highway stormflow volume. Rank correlation coefficients (Spearman's rho values) are used by SELDM to help generate the volume reduction ratios associated with input runoff volumes, which helps to preserve the structure of BMP monitoring data (Granato, 2013, 2014). Although this variable is described as volume reduction, the BMP may increase storm discharge volumes during some runoff events if there is carryover from one storm to another or if groundwater discharges to the BMP during or between storm events (Granato, 2014). Groundwater discharge is more common for normally wet BMPs, but it can occur intermittently at many sites.
Water-quality treatment is the practice of using physical, chemical, and biological processes in an attempt to reduce the concentration of runoff constituents in stormflow (Granato, 2014). Although the term "concentration reduction" is commonly used to describe these processes, concentrations in outflows can exceed inflows and therefore water quality-treatment ratios may be larger than 1. Outflow concentrations may exceed inflow concentrations if there is carryover in BMP storage from one runoff event to the next; if physical, chemical, or biological processes mobilize constituents between storms; or if flow through the BMP mobilizes previously retained constituents during some events. SELDM simulates the potential effects of BMPs on the concentrations of constituents in runoff by generating a stochastic population of the ratios of outflow to inflow concentrations by using the trapezoidal distribution and rank correlation to inflow concentration and applying these ratios to the stochastic population of inflow concentrations from the site of interest (Granato, 2013, 2014). SELDM simulations indicate that water-quality treatment can substantially reduce constituent loads to receiving waters even if some concentration ratios are greater than 1 (Granato and Jones, 2014, 2017, 2019; Risley and Granato, 2014; Smith and others, 2018; Stonewall and others, 2018, 2019; Weaver and others, 2019; Jeznach and Granato, 2020).

Water-quality treatment by BMPs is limited because there will be some lower limit to the effluent concentrations that can be achieved with normal BMP unit operations (Granato, 2014). The lowest concentration achievable for a well-designed example of each type of BMP is known as the minimum irreducible concentration (MIC). The MIC also has been defined as a background concentration, the lower bound of first-order decay processes, or the intercept of regression equations relating outflow to inflow concentrations (Granato, 2014). In SELDM, the MIC estimate is used to replace concentrations calculated from stochastic influent and concentration-ratio values for simulated events that are lower than the MIC (Granato, 2013, 2014). As such, the MIC provides a lower bound to the simulated population of BMP discharge concentrations.

Granato (2014) used data from the 2012 version of the International Stormwater Best Management Practices Database (BMPDB; Leisenring and others, 2013) to calculate BMP treatment statistics. Those treatment statistics have been used to estimate the risks for adverse effects of runoff on receiving waters and the potential for BMPs to reduce those risks (Granato and Jones, 2014, 2019; Risley and Granato, 2014; Stonewall and others, 2019; Weaver and others, 2019; Jeznach and Granato, 2020). Those treatment statistics also have been used for runoff-loading analyses, which can be used to calculate total maximum daily loads (TMDLs) for watersheds of interest (Granato and Jones, 2017; Smith and others, 2018; Stonewall and others, 2018, 2019). Although the existing statistics have been widely used, Granato (2014) published water-quality treatment statistics for only $12 \mathrm{com}$ monly measured highway and urban runoff constituents. State departments of transportation and municipalities are facing 
TMDL requirements for many more constituents (Lantin and others, 2019), and the December 2019 version of the BMPDB (Wright Water Engineers, Inc. and Geosyntec Consultants, 2019) has been improved and expanded during the period after the analyses in Granato (2014) were complete.

Purpose and scope.-This report documents BMP performance statistics calculated from publicly available data from the December 2019 version of the BMPDB (Wright Water Engineers, Inc. and Geosyntec Consultants, 2019) by using methods developed by Granato (2014). This report provides an updated and expanded set of BMP statistics but does not provide the detailed description of analytical and numerical methods provided by Granato (2014). This study was done by the USGS in cooperation with the FHWA to provide national statistics for stochastic modeling of the timing, volume, and quality of BMP effluent given a stochastic population of inflows from a user-defined site of interest. The purpose of the analyses in this report is to update and expand statistics developed by Granato (2014) by using the expanded and refined December 2019 version of the BMPDB (Wright Water Engineers, Inc. and Geosyntec Consultants, 2019). The data, information, and statistics developed in this analysis are intended to facilitate stochastic planning-level analysis of the potential effects of stormwater runoff on receiving waters at unmonitored sites (or sites with limited monitoring data). The methods and statistics described in this report were designed for use with SELDM but may be used with other methods or models. These methods and statistics are designed to help evaluate the risk for adverse effects of runoff on receiving waters, the potential need for mitigation measures, and the potential effectiveness of such management measures for reducing these risks.

The methods and statistics in this report are not intended to replace accepted methods for evaluating and comparing different types of BMPs. Such methods include the effluent probability method (Strecker and others, 2001; Geosyntec Consultants and Wright Water Engineers, Inc., 2009), regression analysis between influent and effluent concentrations (Taylor and others, 2014), and theoretical-analytical timeseries analyses (Clar and others, 2004; Huber and others, 2006; National Cooperative Highway Research Program, 2006). Existing methods for BMP comparison provide information about BMP performance at previously studied sites, which may or may not represent the volume, timing, and quality of runoff from a site of interest. The methods described in this report, however, provide statistics for estimating expected BMP effluent characteristics and the reduction of risk for adverse effects of runoff in receiving waters given user-defined site properties, runoff quality, BMP performance statistics, and receiving-water characteristics.

\section{Methods}

Granato (2014) developed quantitative methods to estimate values of the trapezoidal distribution statistics, correlation coefficients, and the MIC from available data. The methods and analysis tools were designed to analyze data from the 2012 version of the BMPDB and to replicate the analysis with user-supplied data in the future. Granato (2014) developed a Microsoft Access database application named the Best Management Practices Statistical Estimator (BMPSE) to facilitate retrieval and analysis of data from the BMPDB and potentially other datasets. Granato (2014) also developed spreadsheets to fit BMP monitoring data retrieved from the BMPSE to the trapezoidal distribution. As part of the current study, the BMPSE was improved to facilitate the use and calculation of additional statistics (Granato, 2021). The spreadsheets also were updated and improved to work as macro-enabled Microsoft Excel spreadsheets (Granato and others, 2021).

\section{Data Collection}

The analyses documented in this report were done with data extracted from the December 2019 version of the BMPDB (Wright Water Engineers, Inc. and Geosyntec Consultants, 2019). The BMPDB was selected as the source of data for this analysis because it is extensive and is available to the public for research purposes. The 2019 version of the BMPDB has data for 526 test sites, 771 BMPs, 2,371 monitoring stations, 19,547 runoff events, 30,682 flow measurements, and 374,643 water-quality measurements. The 2019 compilation represents continuing efforts of the BMPDB project team to collect, format, check, and enter data over a 24-year period from 1996 through 2019. In many cases, the data have been vetted for use in various BMP performance summaries (for example, Leisenring and others, 2013, 2020; Clary and others, 2017). Data for BMP sites, monitoring sites, runoff volumes, runoff durations, and constituent concentrations were retrieved from the BMP database using a series of queries that were designed to obtain paired input and output values. Although the outflow for one event may represent the effects of inflows from one or more prior events (Strecker and others, 2001), building a large dataset of paired values for each category should provide the statistics necessary to stochastically generate the wide variations in output values that may occur over a large number of storms.

Data from the December 2019 version of the BMPDB were screened for import into the BMPSE (Granato, 2021), in consultation with the project team that supports and maintains the BMPDB (Wright Water Engineers, Inc. and Geosyntec Consultants, 2019). Modifications included identifying waterquality constituents, making measurement units consistent, identifying paired inflow and outflow values, and converting water-quality values that were set in the BMPDB as half the detection limit back to the detection limit. Total polycyclic 
aromatic hydrocarbon (PAH) values were calculated from individual PAH measurements at sites with enough data to calculate totals. The screened data are available in the BMPSE database application (Granato, 2021).

The results of analyses presented in this report are organized by using the categories specified in the December 2019 version of the BMPDB. This version of the database contains 19 categories of structural BMPs. For this analysis, 12 categories of BMP were selected on the basis of available data and applicability for modeling the quality and quantity of stormwater runoff with SELDM (table 1). Analyses were not done for BMPs listed as "permeable friction course" because of insufficient paired data; BMP data classified as "Other" were not analyzed because statistics for this category would not be meaningful for a set of unrelated BMPs. The selected BMPs are designed to treat the quality and (or) quantity of runoff between the source area and the discharge area. The selected BMPs also are commonly used to treat highway and urban runoff. The December 2019 version of this database also contains 40 subcategories of structural BMPs, but the analysis documented in this report was done using the categories in table 1. Despite the large amount of data in the database, the availability of paired inflow and outflow data from BMP sites for some categories and many subcategories is not sufficient for quantitative characterization of BMP performance.

\section{Fitting the Trapezoidal Distribution to Duration and Ratio Data}

In SELDM, volume reduction ratios, hydrograph extension times, and water-quality treatment ratios are simulated by using the trapezoidal distribution and the rank correlation with the associated highway runoff variables (Granato, 2013, 2014). The trapezoidal family of distributions was selected for modeling BMP performance measures because it can be parameterized by using expert judgment or by fitting the distribution to data if good data are available (Johnson, 1997; Back and others, 2000; U.S. Environmental Protection Agency, 2001; Scherer and others, 2003; Kacker and Lawrence, 2007;

Table 1. Explanation of selected structural best management practice categories used in the International Stormwater Best Management Practices Database.

[The International Stormwater Best Management Practices Database is documented by Leisenring and others (2020). BMP, best management practice]

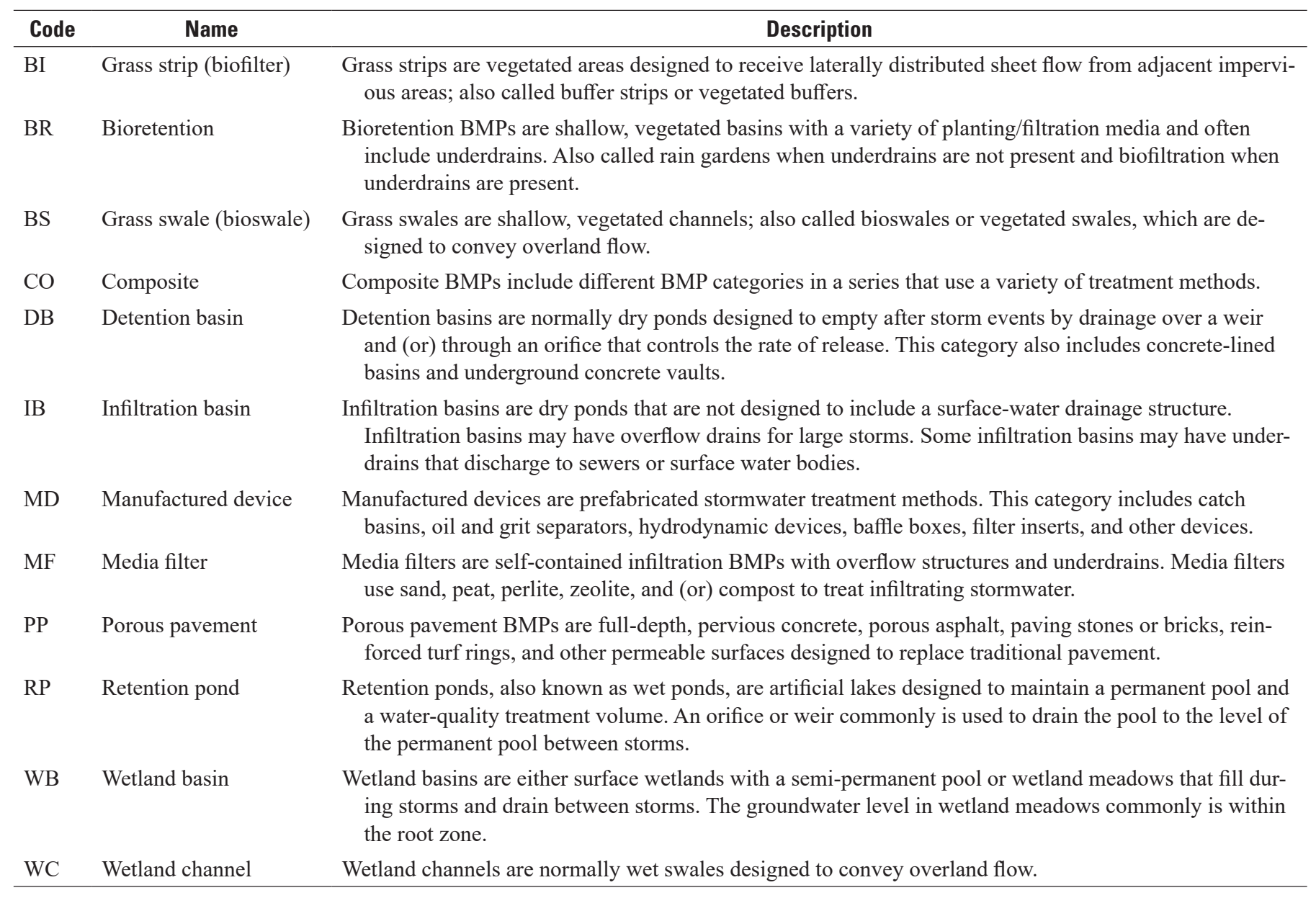


Granato, 2013, 2014). The triangular distribution, which is a special case of the trapezoidal distribution, commonly is suggested when uncertainties in input data that may be used to define a parametric distribution are large (U.S. Environmental Protection Agency, 2001). The trapezoidal distribution is bounded by a selected minimum and maximum value. When data are uncertain or are limited in scope, use of a bounded distribution reduces the chance that unrealistic output values will be generated by extrapolating a distribution beyond the range of available data.

SELDM generates random numbers that follow trapezoidal distributions by using the inverse cumulative distribution function (CDF) with an algorithm developed by Kacker and Lawrence (2007). The trapezoidal distribution is defined by four location variables (fig. 1): the lower bound (the minimum value), the lower bound of the most probable value (LBMPV), the upper bound of the most probable value (UBMPV), and the upper bound (the maximum value). The trapezoidal distribution is very flexible and can assume a variety of shapes, including a positive-skewed triangular distribution, a negative-skewed triangular distribution, a symmetric (isosceles) triangular distribution, and a rectangular (uniform) distribution. SELDM will produce stochastic data that fit the triangular distribution if the LBMPV and UBMPV are specified as being equal. SELDM will produce stochastic data that fit the rectangular distribution if the LBMPV is set equal to the minimum and the UBMPV is set equal to the maximum. The triangular distribution is commonly used in environmental risk analysis, but the rectangular distribution is not (U.S. Environmental Protection Agency, 2001). In the absence of reliable data, it is easier to estimate the parameters of the trapezoidal distribution by using professional judgment than it is to estimate the parameters of other commonly used distributions. Furthermore, it is easier to avoid generation of extreme outliers when large stochastic datasets are generated because the trapezoidal distributions are bounded.

Least-squares optimization was used to fit the BMP monitoring data to the parameters of the trapezoidal distribution (Granato, 2014). The optimal fit to the trapezoidal distribution was calculated by minimizing the least-squares difference between the cumulative distributions of the volume reduction ratios, the hydrograph extension times, and the water-quality treatment ratios. In each case, the data were sorted, ranked, and assigned plotting positions by using the Cunnane (1978) plotting-position formula. The value for each data point was compared with the value of the same plotting position for the theoretical trapezoidal distribution with the input minimum, LBMPV, UBMPV, and maximum values, and the difference and squared difference were calculated. The sum of squared differences was used as the measure of fit.

The Microsoft Excel solver tool available in the analysis tool pack was used to find the optimal fit of the cumulative distribution of a trapezoidal distribution to each dataset (Granato, 2014; Granato and others, 2021). The Microsoft Excel solver tool should be installed with Microsoft Excel, but this tool must be activated using the Microsoft Excel
"Add-Ins" menu. The solver was set up with the generalized reduced gradient nonlinear solving package to minimize the sum of squared errors between the data and the fitted distribution by varying the input statistics. The solver optimized the minimum, LBMPV, UBMPV, and the maximum values. The constraints on the solver were that the values must be greater than or equal to 0 , the LBMPV must be greater than or equal to the minimum, the UBMPV must be greater than or equal to the LBMPV, and the maximum must be greater than or equal to the UBMPV (Granato, 2014). By definition, the maximum must be greater than the minimum; this criterion is not available in the solver, but it represents a trivial solution that was not encountered in this study.

To prepare for optimization, the BMPSE tool was used to sort and rank the data, calculate plotting positions, calculate initial estimates, and calculate potential correlations (Granato, 2014, 2021). For the hydrograph extension and volume reduction variables, initial estimates were calculated by using the approximation equations for the triangular distribution developed by Johnson (1997). These values were adjusted to ensure the minimum was greater than or equal to 0 , the most probable value was greater than or equal to the minimum, the maximum was greater than or equal to the most probable value, and the maximum was greater than the minimum. For the water-quality treatment ratios, initial estimates were calculated from the median ratio because the prior analyses indicated that the estimates based on the Johnson (1997) equations did not facilitate rapid convergence to a final solution (Granato, 2014, 2021).

When fitting the distribution in Microsoft Excel, the solver was restarted with different input values several times for each analysis to find the most optimal solution. In some cases, there are multiple combinations of input variables that may produce what appears to be an optimal fit to the generalized reduced gradient nonlinear solving package. The situation is analogous to the problem of finding the highest peak of a mountain range in the fog by following an uphill gradient (Granato, 2014). Starting in different locations may result in discovery of different peaks; selecting different starting locations should help find the tallest peak. In an effort to find the most optimal fit, the values calculated from the first solution were modified and the solver was rerun. This was done several times and the most optimum solution (having the smallest sum of square errors) was selected. In many cases, there seemed to be only one optimal solution.

For the volume reduction and hydrograph extension ratio solver runs, which were done manually, at least two additional conditions were tested. In one solver run, the minimum was set equal to 0 , the LBMPV minimum was set equal to 50 percent of the average, the UBMPV minimum was set equal to twice the average, and the maximum was set equal to four times the average. In another solver run, the values for the solution with the lowest sum of square errors were adjusted. The minimum was set equal to 0 ; the LBMPV minimum was reduced by 10 to 20 percent of the prior estimate the UBMPV minimum was increased by 10 to 20 percent of the 


\section{A. Symmetrical trapezoid}

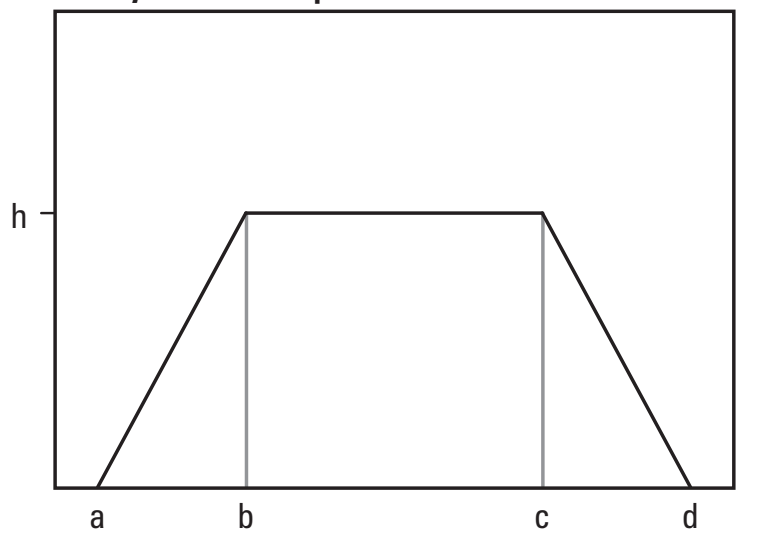

B. Positive-skew triangular

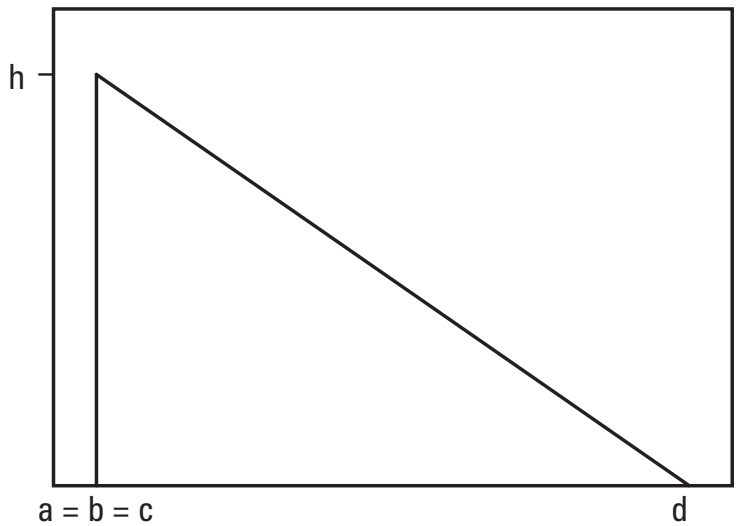

D. Isosceles triangular

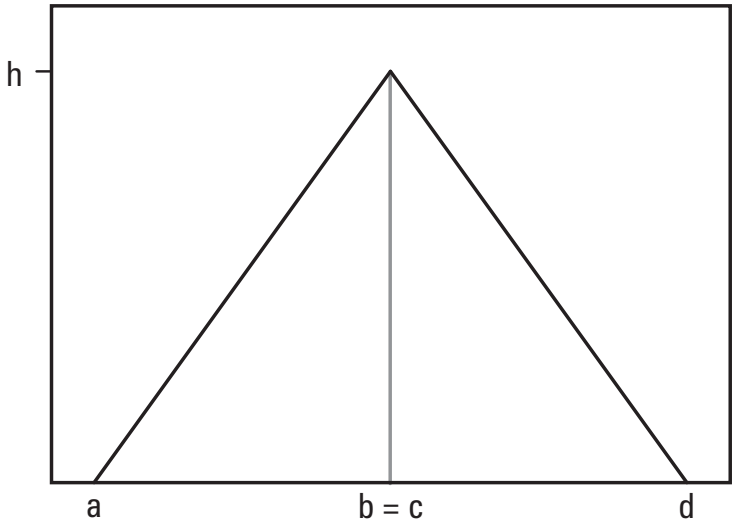

\section{EXPLANATION}

a Lower bound (minimum value)

b Lower bound of the most probable value

c Upper bound of the most probable value

d Upper bound (maximum value)

$h$ Standardized height of the distribution

\section{Negative-skew triangular}

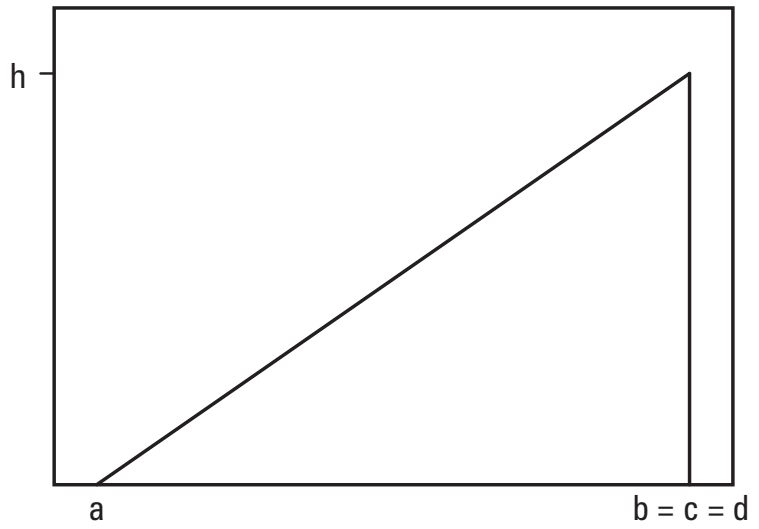

E. Rectangular (uniform)

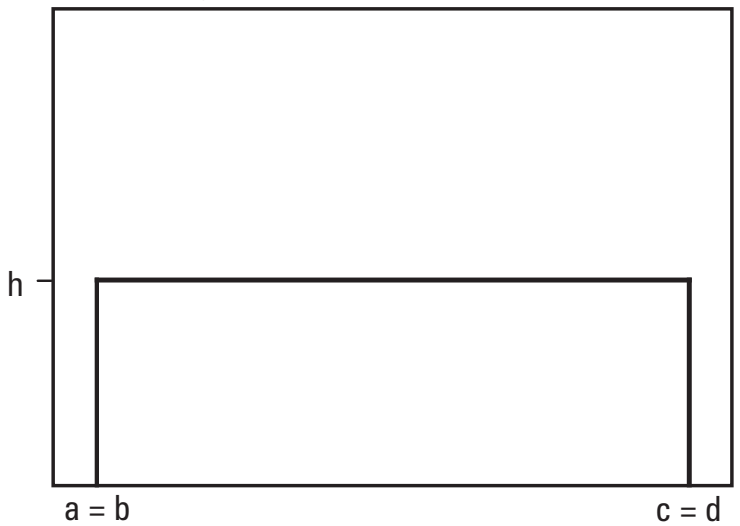

Figure 1. Schematic diagram showing five possible probability density functions of the trapezoidal distribution for simulating structural stormwater runoff best management practices with the stochastic empirical loading and dilution model as defined by the location variables (from Granato, 2014). $A$, symmetrical trapezoid; $B$, positive-skew triangular; $C$, negative-skew triangular; $D$, isosceles triangular; and $E$, rectangular (uniform). The height of each trapezoid is calculated to normalize the area under the probability-density function to equal one (Granato, 2013, 2014). 
prior estimate, and the maximum was increased by 20 percent of the prior estimate. For these variables, the stability of the least-squares solution was evaluated, and the best solution was picked if the results were stable or the starting points were modified if the solution seemed unstable. The solution with the lowest value of the sum of square errors was selected as the final result. The Microsoft Excel spreadsheet used to do these analyses (FitTrapezoidToBMP01v1.0.3.xlsx) is provided in the data release by Granato and others (2021).

In this study, water-quality measurements from 2,017 datasets were optimized to determine trapezoidal fit statistics for concentration ratios for each site within the 10 BMP categories that had sufficient data for analysis for one or more of the 51 highway- and urban-runoff constituents. The trapezoidal-fit spreadsheet for concentration ratios was automated by Granato (2014) to analyze concentration ratios because of the large number of water-quality datasets. The BMPSE generates the input files and the list of filenames for each constituent within the graphical user interface (Granato, 2014, 2021).

For the initial optimization run for the water-quality treatment ratios, the minimum was set equal to one third of the median, the LBMPV minimum was set equal to 65 percent of the median, the UBMPV minimum was set equal to the median, and the maximum was set equal to three times the median. If a solution was reached, then the minimum was set equal to 50 percent of the initial estimate; the LBMPV was reduced to 75 percent of the initial estimate, the UBMPV was increased to 1.1 times the initial estimate, and the maximum was increased to 2 times the initial estimate, and the solver was rerun. If a solution was reached with the second run, then the minimum was set equal to 50 percent of the first-solution minimum, the LBMPV was reduced to 75 percent of the firstsolution LBMPV, the UBMPV was increased to 1.1 times the first-solution UBMPV, and the maximum was increased to 2 times the first-solution maximum, and the solver was run for a third time. In the final trial, the values of the minimum, LBMPV, UBMPV, and maximum were changed to $0,0.75$, 0.75 and 1.5 , respectively. If one of the trial solutions failed to converge, the minimum was set equal to 0 , the LBMPV was set equal to 10 percent of the measured maximum, the UBMPV was set equal to 25 percent of the measured maximum, and the maximum was increased to 1.5 times the measured maximum ratio, and the solver was rerun. The concentration-ratio solver program then sorted results to identify the solution with the smallest sum of squared errors, and this solution was identified as the final result for that monitoring site. The Microsoft Excel spreadsheet used to do these analyses (FitConcentrationRatiov1.1.0.xlsm) is provided in the data release by Granato and others (2021).

\section{Calculating Rank Correlation Coefficients for Duration and Ratio Data}

SELDM uses rank correlation to preserve the structure of inflow and outflow data (Granato, 2013, 2014). The BMPSE (Granato, 2021) calculates the Spearman's rho and Kendall's tau correlation coefficients with their respective 95-percent confidence limits and the probability that each correlation coefficient value is not significantly different from 0 by using standard methods (Fisher, 1924; Haan, 1977; Press and others, 1992; Caruso and Cliff, 1997; Helsel and Hirsch, 2002). If the 95-percent confidence limit values are of the same sign, then the correlation coefficient is statistically different from 0 . The range of the 95-percent confidence limit values, which depends on the strength of correlation and the number of data points, indicates the potential precision of the correlation value. For hydrograph extension, the BMPSE calculates rho and tau between the inflow volume and the hydrograph extension values (Granato, 2014, 2021). For volume reduction, the BMPSE calculates rho and tau between the inflow volume and the ratio of outflow to inflow volumes (Granato, 2014, 2021). For water-quality treatment, the BMPSE calculates rho and tau between the inflow concentrations and the ratio of outflow to inflow concentrations (Granato, 2014, 2021). The BMPSE also calculates rho between the inflow and the outflow concentrations when a water-quality treatment analysis is done.

The rank correlation between the paired inflow volume and the ratio of outflow to inflow volume or the paired inflow concentration and the ratio of outflow to inflow concentration should not be used for statistical inference (Granato, 2014). Because the inflow concentration and runoff are included in the ratios, the correlations are spurious (Haan, 1977). However, these rank correlations can be used in a Monte Carlo analysis to help preserve the structure of the input data (Granato, 2013, 2014). Figure 2 shows the results of an example Monte Carlo analysis to demonstrate the pattern of uniform random numbers generated by using four positive correlation values. These patterns show that as the correlationcoefficient increases, the likelihood that the paired numbers will be similar also increases (fig. 2; Granato, 2013). With positive correlations, higher input values will tend to produce higher ratios. If correlations are negative, then the patterns will be mirrored diagonally from the top left to bottom right of each graph panel. With negative correlations, higher input values will tend to produce lower ratios. Thus, if the rank correlations between inflow volumes and ratios are positive, then large inflows would be associated with large ratios, and small inflows would be associated with small ratios when the performance data are generated. Conversely, if the rank correlations are negative, large inflows would be associated with small ratios, and small inflows would be associated with large ratios when the performance data are generated. The absolute value of the correlation determines the magnitude of the scatter of the points. 


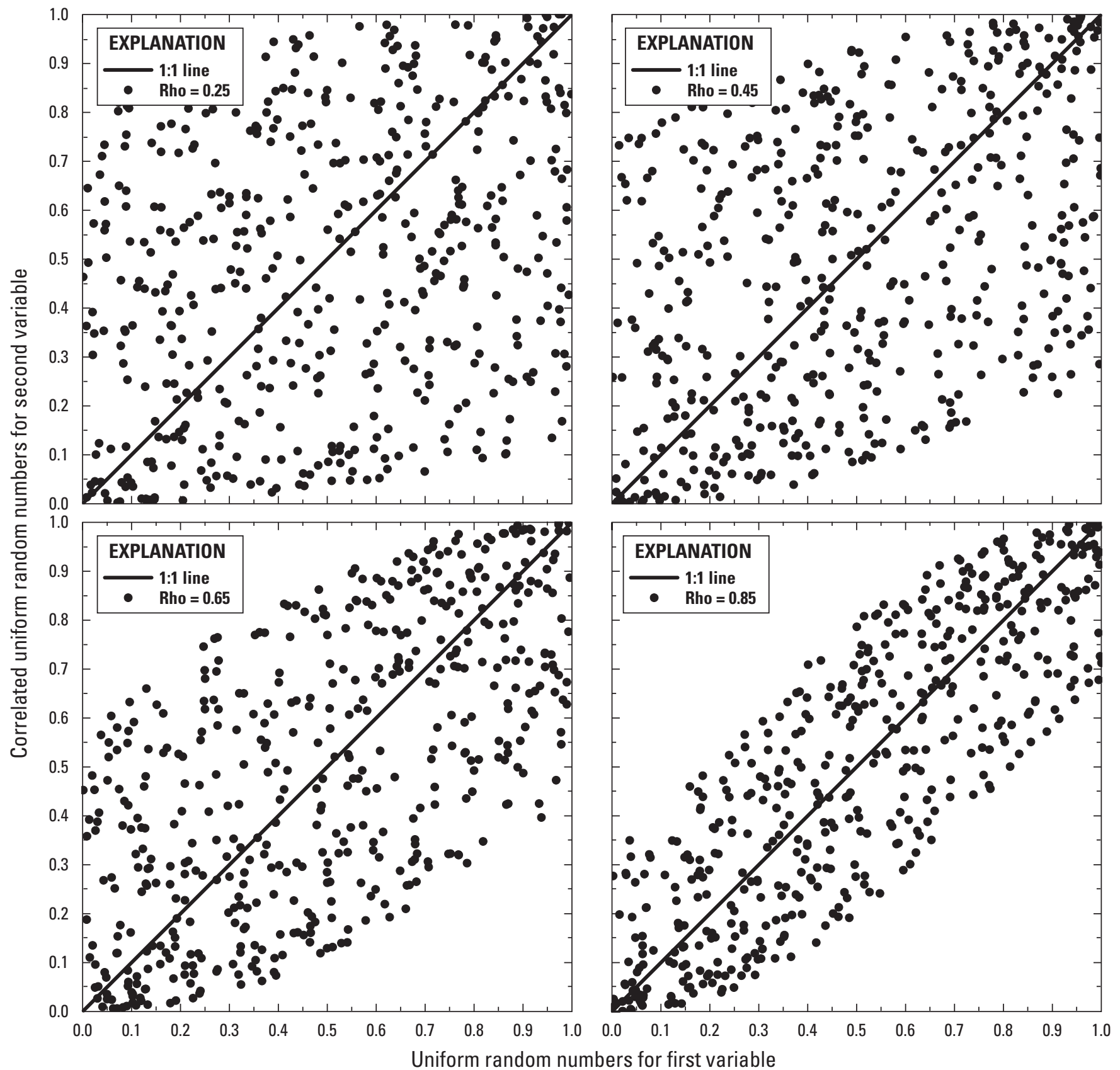

Figure 2. Scatter plots of results of a Monte Carlo analysis to demonstrate scatter of paired uniform random-number samples around a one-to-one relation for four different values of the rank correlation coefficient (Spearman's rho). Each sample consists of 500 paired uniform random numbers in the range between 0 and 1. Modified from Granato (2013).

Sample sizes of seven or more storms per BMP monitoring site were selected for calculating correlation coefficients for the volume reduction ratios, hydrograph extension durations, and concentration ratios (Granato, 2014). This samplesize criterion was applied for selection of datasets to estimate correlation coefficients because Abdel-Megeed (1984) determined that at least five data pairs were necessary to begin to quantify the correlation. A minimum sample size of seven was selected to improve on the minimum estimate of five storms while retaining two or more datasets for each BMP category.

\section{Estimating the MIC Values}

Granato (2014) used four statistical estimators to calculate MICs from available BMP effluent-concentration sample data and then used these estimators to select representative MIC values. These estimators are the measured minimum, the log-triangular lower-bound estimator, Stedinger's quantile lower-bound estimator, and a modified quantile lower-bound estimator. The four lower-bound estimators selected for estimating the MIC in this study are based on the theory that the 
effluent concentrations are approximately lognormal but are not constrained to this assumption. These four different estimators were selected for use because each estimator has several potential advantages and disadvantages. Granato (2014) ranked the estimated MIC values that were greater than 0 and used various percentiles from all sites with sufficient data to provide several MIC values for the constituents of interest that stormwater practitioners could use to simulate BMP discharges to estimate potential effects of runoff on receiving waters or to calculate TMDLs.

\section{Calculating Statistical Estimators}

The measured minimum value is the simplest method for estimating the MIC and is commonly used for this purpose in the literature (Granato, 2014). The measured minimum value is commonly used because it is simple to calculate, it is generally accepted, and it is completely nonparametric. Limitations to the measured minimum value as an estimator for the MIC are that the probability that the measured minimum is representative of the MIC may be low especially if sample sizes are small, and it may not be possible to quantify the measured minimum value because there may be one or more censored values below one or more detection limits. The probability that the measured minimum value is representative of the MIC is low because most BMP monitoring studies collect relatively few samples (Granato, 2014). For example, among sites in the BMPSE from the 2019 dataset with 5 or more samples, about 35 percent of datasets for total suspended solids, total zinc, total copper and total phosphorus have fewer than 10 samples, and about 77 percent of these datasets have fewer than 20 samples (Granato, 2021). In the BMPDB and in many studies, a value of half the detection limit may be substituted if the measured minimum is censored (Granato, 2014). In this study, however, the robust regression on order statistics method was used to estimate values below detection limits for all the MIC estimates. When necessary, the measured minimum value was estimated from the minimum percentile calculated by using the selected plotting-position formula. There is substantial uncertainty in the exact minimum value if estimates are made using regression on order statistics or other methods (Granato, 2014).

The log-triangular lower-bound estimator also is a simple and robust method to estimate a MIC value (Granato, 2014). Although the lognormal distribution is commonly used, the lack of a lower bound in log space may produce estimates that are infinitely close to 0 . Using the log-triangular lowerbound estimator puts a finite lower limit to the estimated MIC. Scherer and others (2003) found that the best fit lower limit could be calculated by subtracting a value of the standard deviation multiplied by the square root of 6 from the mean value. The log-triangular lower-bound estimator is advantageous because it is simple to calculate, it will always produce a value that is greater than 0 , it can be calculated by using accepted standard methods for censored data, and it provides a good fit to the standard normal distribution (Granato, 2014).
For data such as $\mathrm{pH}$, which cannot be simulated using a lognormal distribution, the triangular lower bound estimator can be calculated by using the average and standard deviation of the untransformed data. However, the triangular lower-bound estimator may not be the best estimator if the logarithms of the BMP effluent data are substantially asymmetrical above and below the geometric mean.

Granato (2014) also used Stedinger's quantile lowerbound estimator of the three-parameter lognormal distribution to estimate the MIC. The three-parameter lognormal distribution commonly is used to model environmental data that are well approximated by a lognormal distribution, but do not have a lower-bound value of 0 . Stedinger's quantile lower-bound estimator is simple to calculate and will fit data that are not symmetrical above and below the geometric mean (Granato, 2014). However, this estimate of the MIC is not robust because it can produce a lower-bound value that is less than 0 , it is very sensitive to the presence of data below one or more detection limits because it is calculated using the minimum measured (or censored) value, and the lower-bound estimated using the three-parameter lognormal distribution cannot be adapted to data that cannot be simulated using a lognormal distribution (such as $\mathrm{pH}$, for example).

Because of the limitations of Stedinger's lower-bound estimator, Granato (2014) also used a modified quantile lower-bound estimator (MQLBE) to estimate the MIC. The MQLBE also is simple to calculate and will fit data that are not symmetrical above and below the geometric mean. To avoid MQLBE values that were less than or equal to 0 , Granato (2014) developed an iterative method that would adjust the parameters of the equation until the MIC estimate was greater than 0 . In some cases, however, this method could produce MIC estimates that exceeded the median measured value. Because it uses the average of the smallest measured or censored values, the MQLBE is more robust to the presence of censored values than Stedinger's lower bound estimator but may be affected by a high proportion of censored values. Because it is iterative, the MQLBE is not as easy to calculate as some of the other estimators used by Granato (2014) for MIC values The MQLBE will not produce valid MIC estimates for constituents that cannot be approximated by a lognormal distribution.

\section{Selecting Representative MIC values}

Four statistics (denoted as MIC0 through MIC3) were chosen for selecting representative MIC values from among the four statistical lower-bound estimators (minimum, logtriangular, Stedinger, and MQLBE) for each BMP category. Another statistic, denoted as MIC4, was chosen for selecting a representative MIC for an individual monitoring site from among the four methods for calculating a statistical lowerbound estimate. Only the BMP monitoring sites with five or more samples above the detection limits were used to calculate the four MIC statistics. The first category-level method (MIC0) uses the minimum of the minimum values of the 
positive MIC estimates. The second category-level method (MIC1) uses the 25th percentile of the minimum values of the positive MIC estimates. The third category-level method (MIC2) uses the median of the minimum values of the positive MIC estimates. The fourth category-level method (MIC3) uses the median of the median values of the positive MIC estimates. The median of the positive statistical lower-bound estimators for an individual monitoring site (MIC4) was chosen for selecting a representative MIC for that site because many of the datasets include one or more values below detection limits, which means that an individual minimum MIC estimate may be uncertain for any one site. However, the MIC1 and MIC2 estimates from all available sites were chosen as the primary methods for estimating the MIC for a category or group of BMP sites because the MIC3 estimates may be biased high and the MIC0 may be biased low if the objective is to select a representative MIC for a category of BMPs.

The more conservative MIC estimates based on relatively small sample sizes may not be representative of long-term performance in BMP simulations. SELDM generates stochastic populations with about 800 to 2,300 storms. All BMP effluent concentrations calculated as being below the MIC will be set equal to the MIC. In large long-term simulations, a substantial proportion of effluent concentrations may equal the MIC estimate generated from small short-term studies, which will result in a seemingly unrealistic distribution of effluent concentrations. SELDM was designed with the MIC as a constant variable, whereas further research indicates that it may be a stochastic variable that varies at a site and between sites. Selection of the MIC1 estimate or a lower percentile value should allow for more variation in low-end concentrations. Selection of a lower MIC estimate should reduce the proportion of constant-value low-end concentrations but is not expected to substantially change the proportion of waterquality excursions or total annual loads in most cases because absolute differences in MIC values are small in comparison to the range of BMP effluent concentrations.

\section{Estimating MIC Values From Inflow-Concentration Statistics}

Inflow concentration statistics were used to help inform MIC estimates because inflow concentrations can have a substantial effect on the outflow concentrations (Leisenring and others, 2013; Granato, 2014). The geometric means of inflow concentrations were used to calculate the rank and Pearson's $r$ correlation coefficients for the MIC values (Granato, 2014). The rank and Pearson's $r$ correlation coefficients on the arithmetic and logarithmic values of the geometric mean inflow concentration and the estimated MIC value were calculated to help inform the choice of MIC values and to explore the feasibility of predictive equations for these variables. The geometric means and standard deviations of inflow concentrations also were used to refine MIC estimates based on inflow concentration statistics.
To evaluate the potential for developing quantitative relations between the geometric mean inflow concentration and the MIC values, Granato (2014) defined correlation strengths based on the value of the correlation coefficient. Granato (2014) defined weak correlations as having correlation coefficient values less than 0.5 , moderate correlations having values greater than or equal to 0.5 and less than 0.75 , semistrong correlations having values greater than or equal to 0.75 and less than 0.85 , and strong correlations having values greater than or equal to 0.85 . Granato (2014) found that few constituents had correlations strong enough to provide quantitative relations between geometric mean inflow concentrations and representative MIC values.

Comparisons of the three correlation coefficients can inform the true relations between variables (Granato, 2014). Spearman's rho is a robust estimator of a monotonic relation between two variables that is resistant to outliers (Helsel and Hirsch, 2002). If a rho value is equivalent to one or more of the associated $r$ values, then it may be assumed that the representative linear relation also is robust. If the rho value is greater than one or more of the associated $r$ values, a different transformation of either the geometric mean or MIC estimates (or both) may be assumed to produce a linear relation that corresponds to the rho estimate. However, if one or more $r$ value is substantially greater than the associated rho value, one or more far outliers may be assumed to be responsible for artificially inflating the $r$ values. Using the logarithms of the values tends to decrease the leverage of high outliers, but this increases the leverage of small outliers.

The lognormal variate $(K)$ for the MIC values also were calculated from BMP inflow-concentration statistics to help estimate a site-specific MIC value. The lognormal variate is calculated as follows:

$$
K=\frac{\log (\text { MIC })-\log (\text { GeometricMean })}{\log (\text { GeometricStandardDeviation })}
$$

Once $K$ is estimated from input datasets, it can be used to estimate a MIC value from simulated inflow concentrations at a site of interest with the equation:

$$
\mathrm{MIC}=10(\log (\text { GeometricMean })+K \times \log (\text { GeometricStandardDeviation })) .
$$

The resulting MIC estimate will be an estimate of a constituent concentration or parameter value that is a fraction of the geometric mean of inflow concentrations.

\section{Limitations of the BMP Performance Analysis}

Properly modeling the performance of structural BMPs is a complex endeavor, and there are many explanatory variables that are difficult to quantify, especially with limited monitoring data. For example, Leisenring and others (2013) analyzed the effects of structural BMP design parameters on achievable effluent concentrations by using data from 530 monitoring sites in the BMPDB and found that BMP design variables 
had weak correlation to performance. Leisenring and others (2013) found the strongest correlations were between inflow and outflow concentrations. Few studies provide reliable predictions of treatment performance even with large datasets and complex models (Strecker and others, 2001; Granato, 2014). Uncertainties in volume reduction, hydrograph extension, water-quality treatment, and the MICs arise because of the many categories of BMPs, wide variations in design and construction of BMPs within each category, and wide variations in the operation and maintenance of BMPs once they are installed (Granato, 2014).

Uncertainties in results also are compounded by available sample sizes (Driscoll and others, 1979; Burton and Pitt, 2002; California Department of Transportation, 2009; Granato, 2014; Leutnant and others, 2018). Driscoll and others (1979) recommend the collection of 20 to 40 event mean concentration (EMC) samples to characterize runoff on the basis of the variability of commonly measured runoff constituents. Similarly, Burton and Pitt (2002) indicate that, at a minimum, 25 to 50 EMC samples may be needed. The California Department of Transportation (2009) provides examples in their BMP monitoring handbook that indicate that 50 to 113 paired EMC samples may be needed just to detect differences in mean concentrations. Leutnant and others (2018) determined that 40 EMC samples would need to be collected to characterize total suspended solids (TSS) concentrations. By comparison, the paired data table of the 2019 version of the BMPDB has an average of about 16 samples per BMP for TSS and total phosphorus (TP); the most commonly measured constituents. Only about 6 percent of these BMPs have 40 or more samples for these constituents.

BMP statistics presented in this report are category medians from sites with 7 or more monitoring events: 248 of 446 BMP sites have 7 or more TSS samples, and 319 of 424 BMP sites have 7 or more TP samples. Although this is a seemingly large number of sites, the number of sites per category with sufficient data for analysis can be small for some BMP categories and some BMP performance variables. The category median is selected on the principal of the wisdom of the crowd; the median is selected rather than the mean to reduce the potential effect of far outliers (Granato, 2014; Wallis, 2014). However, the (approximate) 95-percent confidence limit of the median can encompass a large portion of a dataset (table 2).

Professional judgement may be needed to apply analysis of data from short-term studies to long-term simulations. Although the methods described in this report will reproduce the data used for analysis when used to simulate BMP performance, the results of analyses are only as good as the underlying data. The BMPDB includes many small datasets, and many studies do not include the effects of year-round weather conditions. The number of runoff-generating events per year among the 15 U.S. Environmental Protection Agency rain zones defined by the ranges from 17 in arid areas to 62 in areas with wet climates; the average among the rain zones is 40 events per year (Granato, 2010). By comparison, about 36,10 , and 4 percent of studies with paired flow data for 7 or more storms have 20,40, or 60 events, respectively. Similarly, the variation in precipitation volume for most sites approximates typical annual variations but not long-term variations in precipitation volumes. Many datasets have outflow to inflow ratios that greatly exceed 1 ; these values may represent sitespecific conditions or problems in the measurements. Because of the form of the equations for the cumulative distribution function of the trapezoidal distribution (Kacker and Lawrence, 2007), the maximum value has the largest effect on the proportion of ratios that are greater than 1 . As the maximum value increases from 1 to 2 , the percentage of generated values that are greater than 1 increases from 0 to about 40 percent. As the maximum value increases from 2 to 4 , the percentage of generated values that are greater than 1 increases from about 40 to 60 percent. Although the median of at-site statistics should not reflect extreme values from individual sites, the selected medians may be biased upward by the presence of multiple sites with high outliers. These limitations may be overcome by selecting trapezoidal statistics from among selected sites and correlation coefficients that reduce the risk for large ratios with large flows or concentrations.

Planning-level estimates are defined as the results of analyses used to evaluate alternative management measures and are recognized to include substantial uncertainties (Barnwell and Krenkel, 1982; Marsalek and Ng, 1989; Marsalek, 1991; Granato, 2014). The stochastic approach used in SELDM is warranted because there are large uncertainties in available information and the level of effort required to develop detailed simulation models may be beyond the scope of an initial planning-level estimate (Granato, 2013, 2014). Even if data in the BMPDB were more comprehensive, there is always substantial uncertainty when using hydrologic data at one location to estimate conditions at another location. However, if the initial analysis done with SELDM indicates the potential need for mitigation, then detailed simulation or statistical models may be used to develop more refined performance statistics for use with SELDM (Granato, 2014). Furthermore, if the initial analysis without BMP treatment indicates the potential need for mitigation, then SELDM can easily be used to develop the BMP-performance statistics needed to reduce storm loads or the frequencies of water-quality excursions in receiving waters to an acceptable level (Granato, 2014). This analysis can be done by varying BMP treatment statistics to meet water-quality objectives. Such an analysis may indicate that it is impossible in practice to meet water-quality objectives by using the treatment capabilities of feasible BMP designs. 


\section{Statistical Methods for Simulating Structural Stormwater Runoff BMPs With SELDM}

Table 2. Minimum and maximum ranks of a dataset of a given size that encompass the approximate 95-percent confidence interval for the median based on the binomial distribution.

[Equation for the binomial distribution is from Bland (2015)]

\begin{tabular}{|c|c|c|c|c|c|}
\hline \multirow{2}{*}{ Sample size } & \multicolumn{2}{|c|}{ Median value } & \multirow{2}{*}{ Sample size } & \multicolumn{2}{|c|}{ Median value } \\
\hline & Lower-bound rank & Upper-bound rank & & Lower-bound rank & Upper-bound rank \\
\hline 3 & 1 & 3 & 48 & 18 & 31 \\
\hline 4 & 1 & 4 & 49 & 18 & 32 \\
\hline 5 & 1 & 5 & 50 & 19 & 32 \\
\hline 6 & 1 & 6 & 51 & 19 & 33 \\
\hline 7 & 1 & 7 & 52 & 19 & 34 \\
\hline 8 & 2 & 7 & 53 & 20 & 34 \\
\hline 9 & 2 & 8 & 54 & 20 & 35 \\
\hline 10 & 2 & 9 & 55 & 21 & 35 \\
\hline 11 & 3 & 9 & 56 & 21 & 36 \\
\hline 12 & 3 & 10 & 57 & 22 & 36 \\
\hline 13 & 3 & 11 & 58 & 22 & 37 \\
\hline 14 & 4 & 11 & 59 & 22 & 38 \\
\hline 15 & 4 & 12 & 60 & 23 & 38 \\
\hline 16 & 5 & 12 & 61 & 23 & 39 \\
\hline 17 & 5 & 13 & 62 & 24 & 39 \\
\hline 18 & 5 & 14 & 63 & 24 & 40 \\
\hline 19 & 6 & 14 & 64 & 25 & 40 \\
\hline 20 & 6 & 15 & 65 & 25 & 41 \\
\hline 21 & 7 & 15 & 66 & 26 & 41 \\
\hline 22 & 7 & 16 & 67 & 26 & 42 \\
\hline 23 & 7 & 17 & 68 & 26 & 43 \\
\hline 24 & 8 & 17 & 69 & 27 & 43 \\
\hline 25 & 8 & 18 & 70 & 27 & 44 \\
\hline 26 & 9 & 18 & 71 & 28 & 44 \\
\hline 27 & 9 & 19 & 72 & 28 & 45 \\
\hline 28 & 9 & 20 & 73 & 29 & 45 \\
\hline 29 & 10 & 20 & 74 & 29 & 46 \\
\hline 30 & 10 & 21 & 75 & 30 & 46 \\
\hline 31 & 11 & 21 & 76 & 30 & 47 \\
\hline 32 & 11 & 22 & 77 & 30 & 48 \\
\hline 33 & 11 & 23 & 78 & 31 & 48 \\
\hline 34 & 12 & 23 & 79 & 31 & 49 \\
\hline 35 & 12 & 24 & 80 & 32 & 49 \\
\hline 36 & 13 & 24 & 85 & 34 & 52 \\
\hline 37 & 13 & 25 & 90 & 36 & 55 \\
\hline 38 & 13 & 26 & 100 & 41 & 60 \\
\hline 39 & 14 & 26 & 125 & 52 & 74 \\
\hline 40 & 14 & 27 & 150 & 63 & 88 \\
\hline 41 & 15 & 27 & 175 & 75 & 101 \\
\hline 42 & 15 & 28 & 200 & 87 & 114 \\
\hline 43 & 16 & 28 & 250 & 110 & 141 \\
\hline 44 & 16 & 29 & 300 & 134 & 167 \\
\hline 45 & 16 & 30 & 400 & 181 & 220 \\
\hline
\end{tabular}




\section{Results of Analyses}

This study produced statistics for hydrograph extension, volume reduction, and water-quality treatment. The minimum, LBMPV, UBMPV, and maximum of the trapezoidal distribution were calculated for every site in the 2019 version of the BMPDB with seven or more paired events. Correlations between inflow and outflow values also were calculated for these three variables. This report documents the medians of individual statistics because Granato (2014) determined that the median of best-fit statistics would be the most robust approach for selecting BMP-performance statistics after analyzing data from many monitoring sites. Individual at-site statistics for all the sites are listed in Granato and others (2021).

\section{Hydrograph Extension}

In this study, hydrograph extension statistics were developed for 8 BMP categories using data from 44 BMP monitoring sites with 7 or more storm events (table 3 ). The median values of the minimum, LBMPV, and UBMPV of the trapezoidal distributions were equal to 0 for four BMP categories (grass strip, detention basin, manufactured device, and wetland channel) with sufficient data to do the analysis. Therefore, these distributions are the positive-skew triangular distributions shown in figure $1 B$. The grass swale BMP category has values that also produce a positively skewed triangular distribution, and the rest of the BMP categories have values that produce trapezoidal distributions with a vertical lower bound. Hydrograph extension statistics for individual BMP monitoring sites are provided in a runoff hydrograph extension file (USGS-SIR-2020-5136-HydrographExtension-SiteResults. txt) published by Granato and others (2021). The statistics in table 3 also are published in SELDM input file format (SELDM-tblBMPHydraulicsTable.csv) by Granato and others (2021). In comparison to the values developed by Granato (2014), hydrograph extension values increased substantially for detention basins and media filters and decreased substantially for grassy swales. In the 2012 BMPDB, however, which is the version of the BMPDB that was used for the analysis in Granato (2014), grass strips and swales were combined in one category. SELDM users should apply hydrograph extension results carefully, especially for categories with data from only a few monitoring sites. As Granato (2014) indicated, hydraulic design information may help establish the critical upper bound limits for the trapezoidal distribution to be used in SELDM modeling studies, especially since so few studies in the BMPDB have reliably documented hydrograph extension values.

Examination of results for individual BMP sites indicates that there may be large variations in performance within all the categories (fig. 3). Some of these variations may represent limitations in monitoring data, site-specific conditions such as groundwater discharge, or specific design features. For example, the median of the maximum extension values for the grass strip and manufactured device ( 8.63 and 8.58 hours, respectively; table 3 ) are greater than what professional judgement might suggest, but these categories have the largest number of monitoring sites (fig. 3). When results for individual sites are examined, it is apparent that hydrograph extension for the multichambered treatment trains in the manufactured device category are much longer than for the much smaller hydrodynamic devices (Granato and others, 2021). Thus, the medians may straddle different designs within the same BMP category. Although category-median values, which provide robust planning level estimates, are documented in table 3 , some professional judgement may be needed to select statistics from among the individual sites based on design information for the individual sites. The BMPDB, however, does not contain a full set of design values for every BMP, and Leisenring and others (2013) did not find strong correlations between design and performance variables.

In SELDM, the rank correlation between inflow volume and hydrograph extension can be used to condition the stochastic generation of extension values based on the exceedance percentile of flow volume (Granato, 2013; 2014). However, only 7 of the 44 BMP monitoring sites included in the hydrograph extension analyses documented in this report had statistically significant (95th percentile) rank correlations between hydrograph extension and inflow volumes. Among the 44 BMPs with sufficient data, 29 had positive, 14 had negative, and 1 had a 0 -rho value. These rho values ranged from about -0.93 to about 0.71 (table 3 ). This indicates that antecedent conditions rather than within-event runoff volumes may account for a substantial amount of the variability in measured hydrograph extension values (Granato, 2014). Only the detention basin and retention pond, which are designed primarily as storage volumes with specified drain times (Granato, 2014) had consistent correlations between hydrograph extension and inflow volumes. Because hydrograph extension is simulated as a duration in hours rather than being a ratio to an inflow variable, correlation to the inflow value is unlikely to produce anomalous values; therefore, the correlation coefficient is not crucial for simulating reasonable BMP discharge durations.

\section{Runoff Volume Reduction}

In this study, volume reduction statistics were developed for $12 \mathrm{BMP}$ categories using data from $135 \mathrm{BMP}$ monitoring sites with 7 or more storm events (table 4). BMP monitoring sites with equivalent ratios of outflow to inflow volumes across all events were excluded. Volume reduction statistics for individual BMP monitoring sites are provided in a runoff-volume reduction file (USGS-SIR2020-5136-VolumeReduction-SiteResults.txt) published by Granato and others (2021). In comparison to the values developed by Granato (2014), the percent of events with ratios exceeding 1 (outflow volume exceeds inflow volume) increased for grass strips, bioretention, detention basins, and wetland basins; the percent exceedance was about the same 


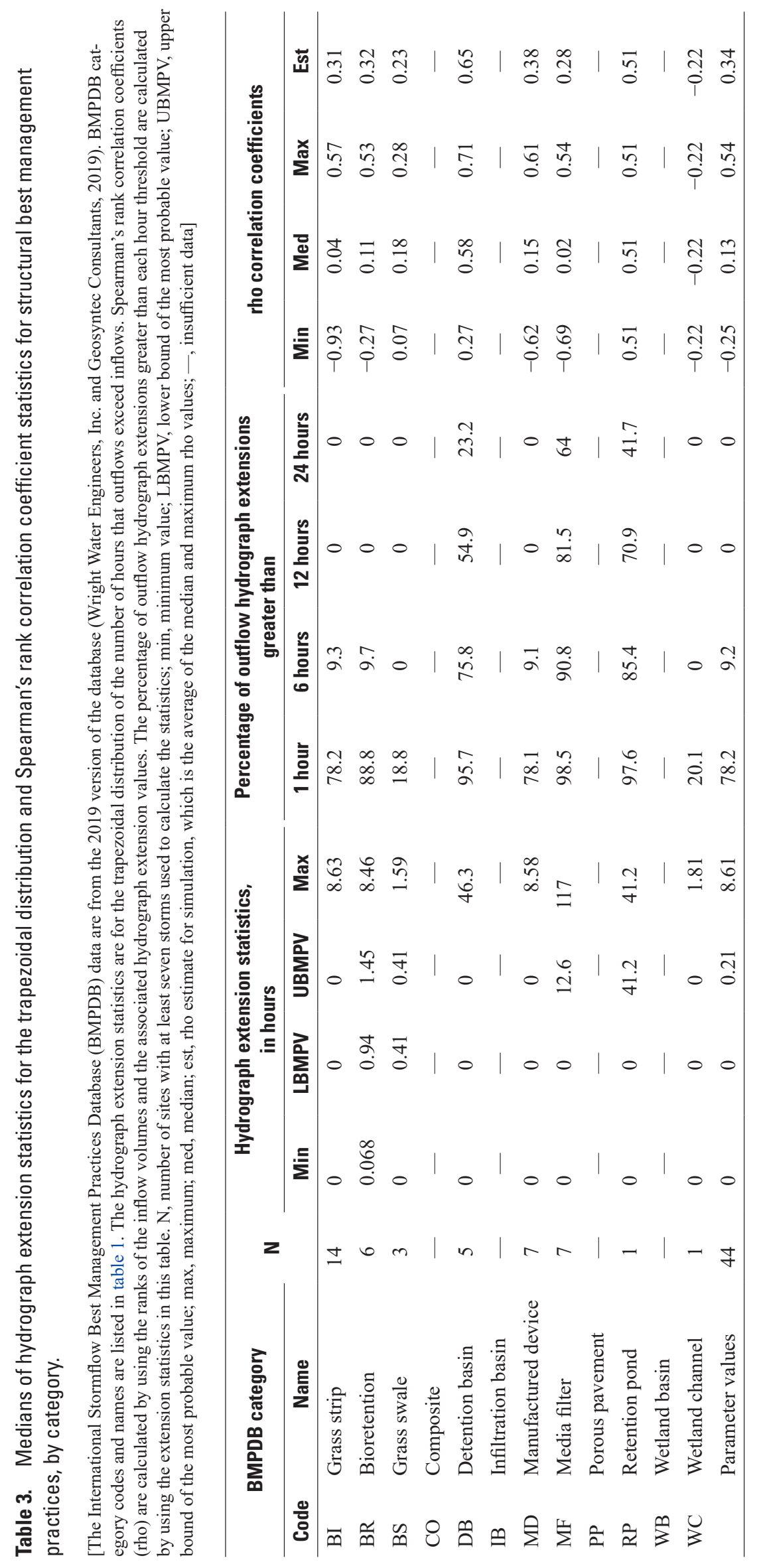


A. BI-Grass strip (biofilter)

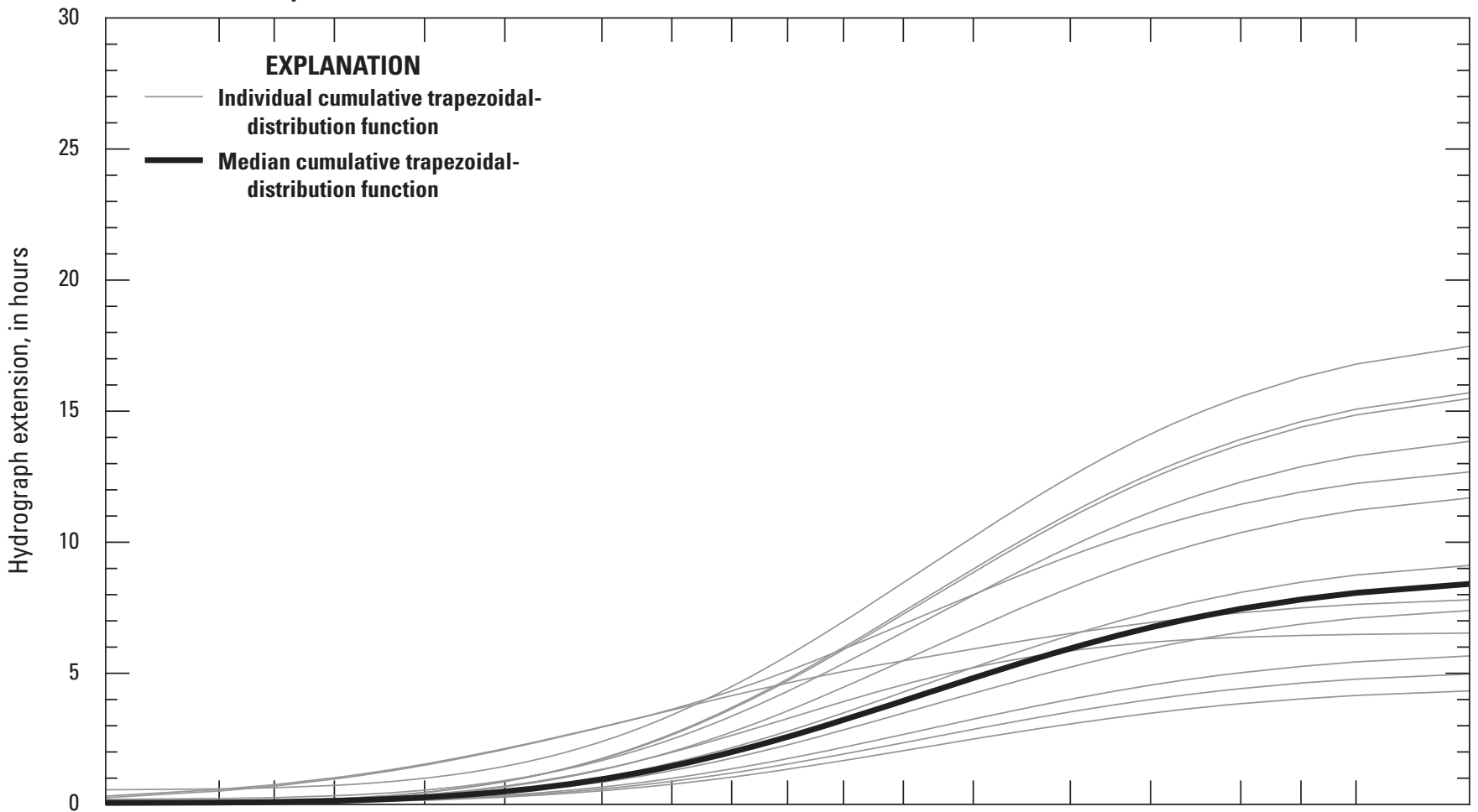

B. BR-Bioretention

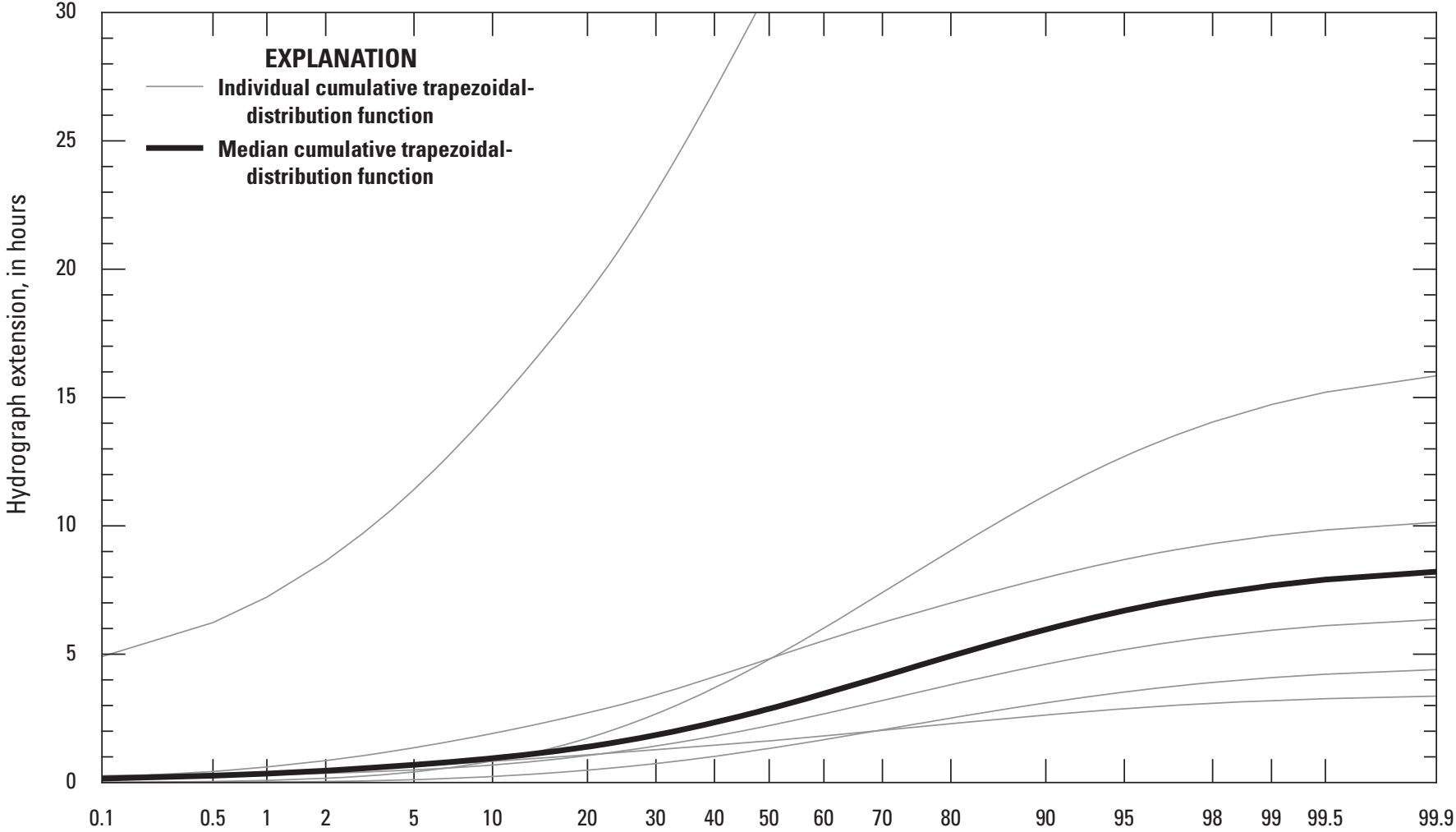

Percentage of storm events with hydrograph-extension durations that are less than or equal to a given value

Figure 3. Line graphs showing fitted cumulative trapezoidal distribution functions of the hydrograph extension statistics for $A$, 14 grass strip (biofilter) monitoring sites, $B, 6$ bioretention monitoring sites, $C, 7$ manufactured device monitoring sites, and $D, 7$ media filter monitoring sites. The graphs also show cumulative distribution functions that are fitted to the median of the hydrograph extension statistics for each category. 
C. MD-Manufactured device
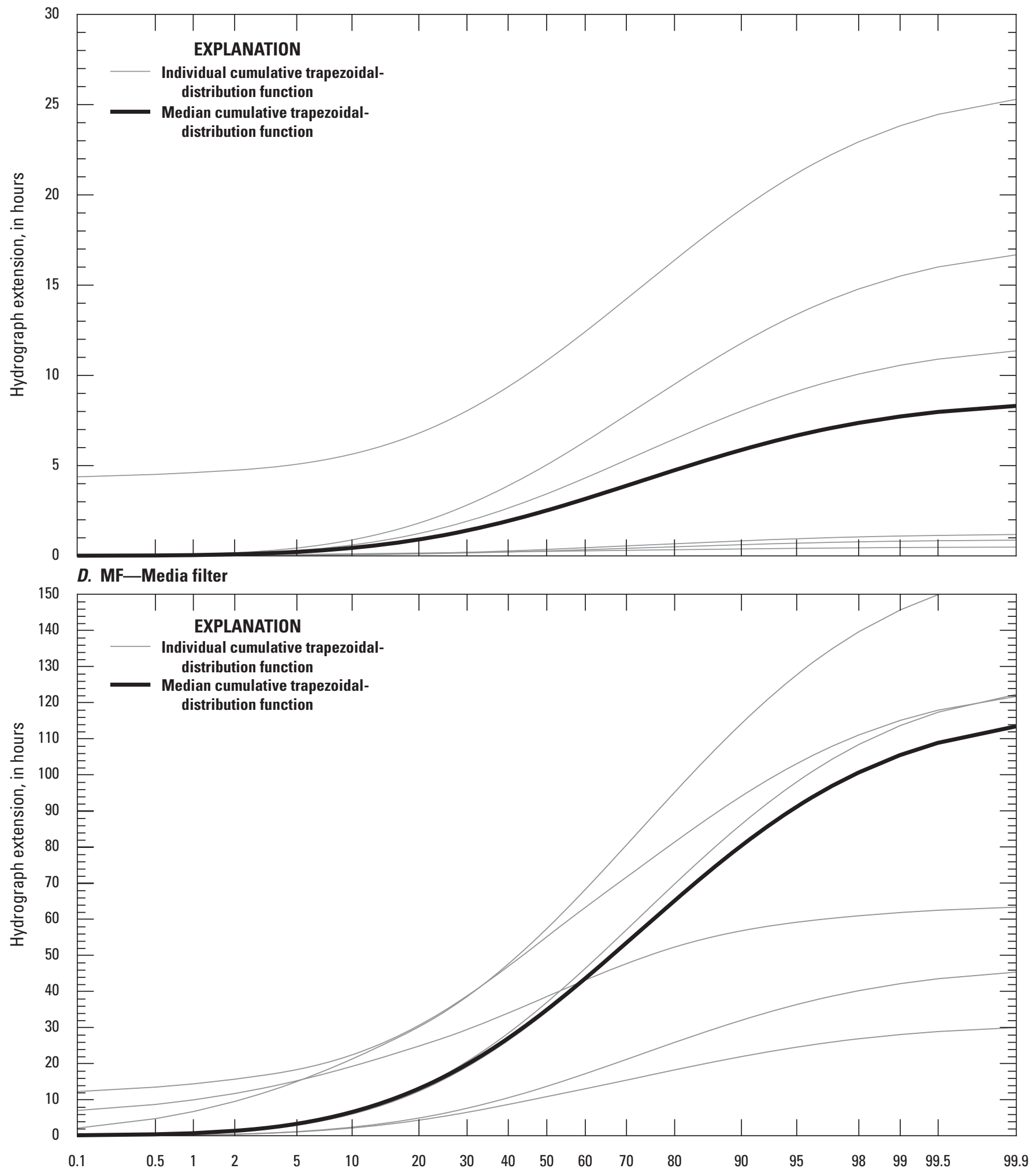

Percentage of storm events with hydrograph-extension durations that are less than or equal to a given value

Figure 3. -Continued 
Table 4. Medians of stormflow volume reduction statistics for the trapezoidal distribution and Spearman's rho correlation coefficient statistics for structural stormwater runoff best management practices by category.

[The International Stormflow Best Management Practices Database (BMPDB) data are from the 2019 version of the database (Wright Water Engineers, Inc. and Geosyntec Consultants, 2019). BMPDB category codes and names are listed in table 1 . The percentage of outflow ratios greater than 1 are calculated by using the volume reduction statistics in this table. The volume reduction statistics are for the trapezoidal distribution of the ratio of outflow to inflow volume. Spearman's rank correlation coefficients (rho) are calculated by using the ranks of the inflow volumes and the associated ratios of outflow to inflow volumes. $\mathrm{N}$, number of sites with at least seven storms used to calculate the median ratio statistics and Spearman's rho statistics; min, minimum; LBMPV, lower bound of the most probable value; UBMPV, upper bound of the most probable value; max, maximum; Pct GT 1, the theoretical percentage of storms in which outflows exceed inflows and thus, the ratio is greater than 1 ; med, median; - , insufficient data]

\begin{tabular}{|c|c|c|c|c|c|c|c|c|c|c|}
\hline \multicolumn{2}{|r|}{ BMPDB category } & \multirow[t]{2}{*}{$\mathbf{N}$} & \multicolumn{5}{|c|}{ Volume reduction statistics, ratio } & \multicolumn{3}{|c|}{$\begin{array}{c}\text { Spearman's rho } \\
\text { correlation coefficients }\end{array}$} \\
\hline Code & Name & & Min & LBMPV & UBMPV & Max & Pct GT 1 & Min & Med & Max \\
\hline $\mathrm{BR}$ & Bioretention & 22 & 0.0043 & 0.0720 & 0.2051 & 1.1318 & 1.49 & -0.70 & 0.27 & 0.78 \\
\hline $\mathrm{BS}$ & Grass swale & 12 & 0.0671 & 0.1969 & 0.6720 & 0.9732 & 0.0 & -0.60 & 0.24 & 0.84 \\
\hline IB & Infiltration basin & 1 & 0.2277 & 1.0584 & 1.0605 & 1.0605 & 14.0 & 0.84 & 0.84 & 0.84 \\
\hline MD & Manufactured device & 8 & 0.3745 & 0.8024 & 0.9502 & 1.3533 & 27.5 & -0.71 & -0.15 & 0.10 \\
\hline MF & Media filter & 6 & 0.2551 & 0.2648 & 0.2746 & 1.3979 & 12.2 & -0.15 & 0.00 & 0.57 \\
\hline PP & Porous pavement & 2 & 0 & 0 & 0 & 0.4008 & 0.0 & 0.28 & 0.53 & 0.77 \\
\hline WC & Parameter values & 135 & 0.1067 & 0.3513 & 0.7814 & 1.4801 & 18.3 & -0.65 & -0.01 & 0.74 \\
\hline
\end{tabular}

as in Granato (2014) for media filters and wetland channels, and smaller for swales and retention ponds. The values for grassy strips and swales may be different because these two categories were separated in the 2019 version of the BMPDB (Wright Water Engineers, Inc. and Geosyntec Consultants, 2019). SELDM users should apply runoff-volume reduction statistics carefully, especially for categories with data from only a few monitoring sites.

The median volume reduction statistics in table 4 indicate that outflows range from about 0.4 percent of inflows (for bioretention) to about 209 percent of outflows (for wetland basins). Only the median for the grass swale and porous pavement category result in BMPs that do not have some outflows that exceed inflows for some storm events. Among the other BMP categories in table 4, the percentage of storms in which outflows exceed inflows ranges from 1.5 percent for bioretention to 56 percent for wetland basins. Outflows may exceed inflows if flows retained during one event are released during a subsequent event, if precipitation on the BMP is a substantial component of flow, if groundwater discharge occurs, if monitoring instruments are miscalibrated, or if flow is otherwise erroneously measured. Groundwater discharge may occur as saturation overland flow, throughflow, or near-channel groundwater ridging (Granato, 2010); these types of flow may be especially prevalent for normally wet BMPs, such as detention ponds or wetland BMPs.
Examples of the CDFs for the trapezoidal distribution of volume reduction ratios for 31 grass strip (biofilter), 22 bioretention, 8 manufactured device, and 6 media-filter sites are shown with the CDFs constructed using the medians of the best fit statistics in figure 4 . The graphs indicate the large range in performance of each type of BMP among the different studies. The BMP categories for the other 68 sites not included in figure 4 also have similar patterns with wide variations in the CDFs within each category and representative CDFs constructed from the median values. The CDF constructed with the medians of statistics have outflows that exceed inflows for about 24 percent of runoff events for the grass strip CDF, about 1 percent of runoff events for the bioretention $\mathrm{CDF}$, about 28 percent for the manufactured device CDF, and about 12 percent of runoff events for the media filter CDF (fig. 4).

The CDFs in figure 4 indicate that the median values provided in table 4 may produce robust estimates for some BMPs but professional judgement may be necessary for selecting statistics for other categories. Although there are 31 grass-strip monitoring sites, many of the CDFs for grass strips indicate the presence of groundwater discharge (Granato, 2010) or other sources of stormflow because outflows greatly exceed inflows for a large proportion of runoff events. If the median of grass-strip values that do not exceed 2 is selected, then the maximum trapezoidal statistic would equal 1.36 , and only about 7 percent of events would exceed a ratio of 1 . Granato 
A. Bl-Grass strip (biofilter)

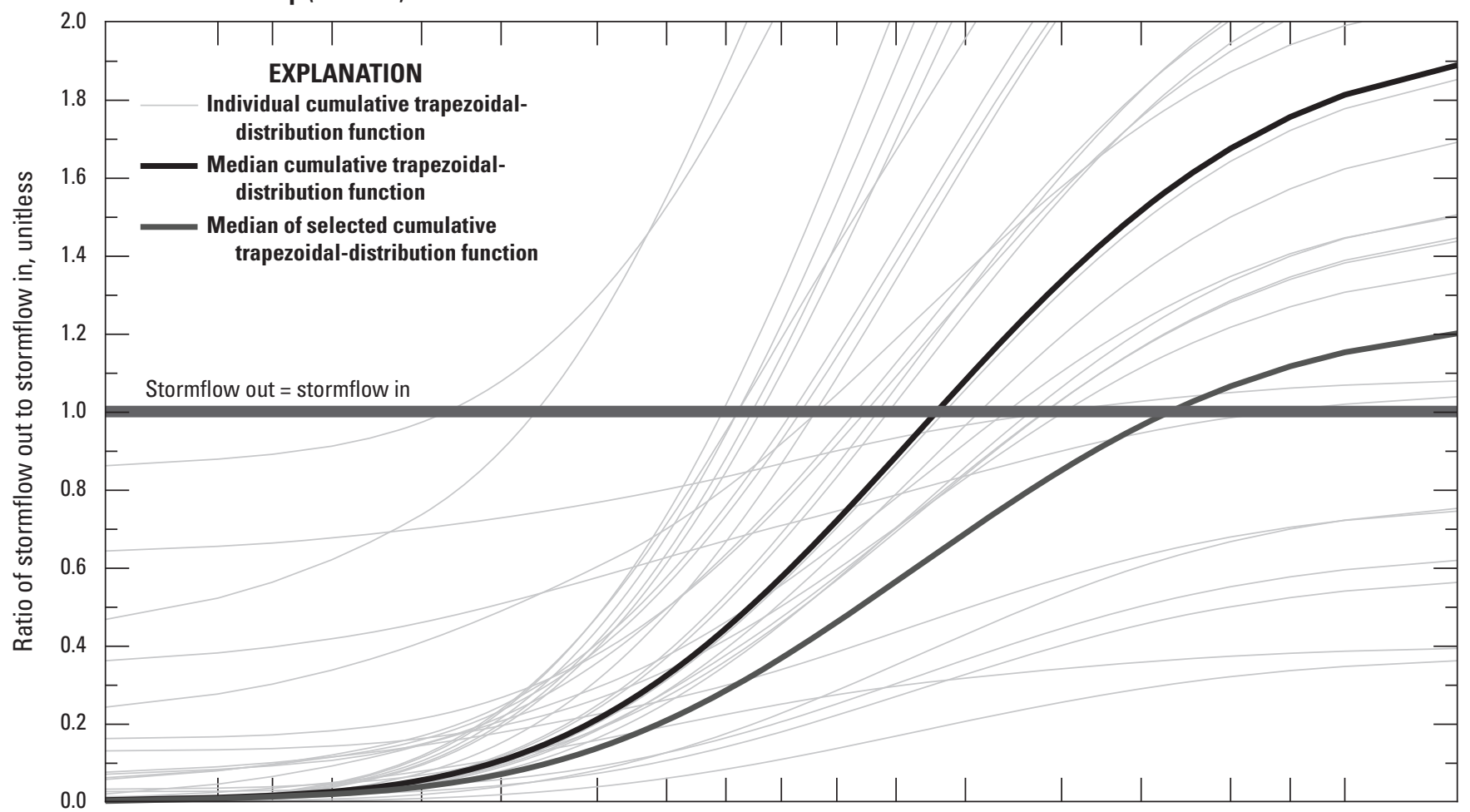

B. BR-Bioretention

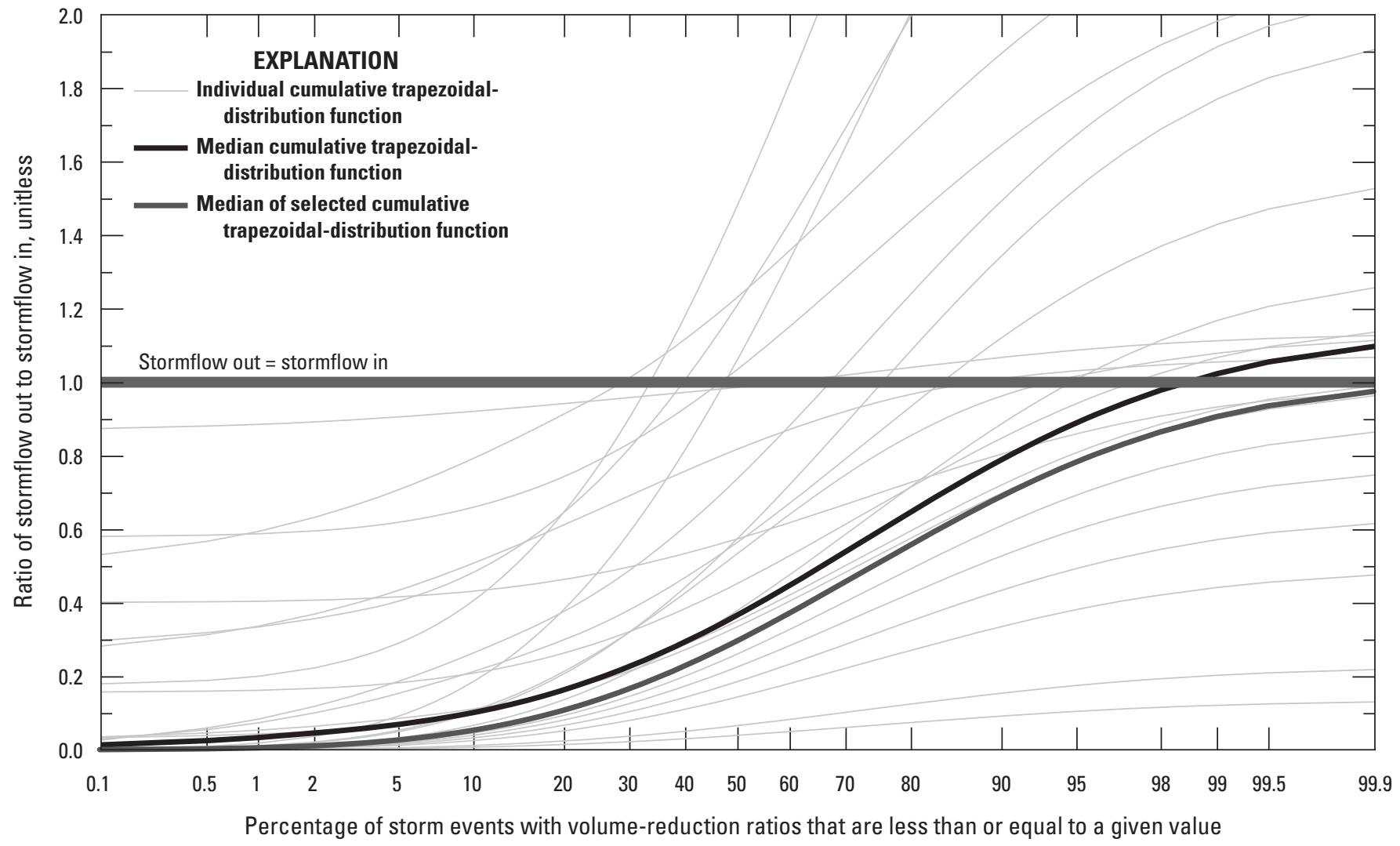

Figure 4. Line graphs showing fitted cumulative trapezoidal distribution functions of the volume reduction ratio statistics for $A, 31$ grass strip (biofilter), $B, 22$ bioretention, $C, 8$ manufactured device, and $D, 6$ media filter monitoring sites. The graphs also show cumulative distribution functions that are fitted to the median and selected-median statistics. 
C. MD-Manufactured device

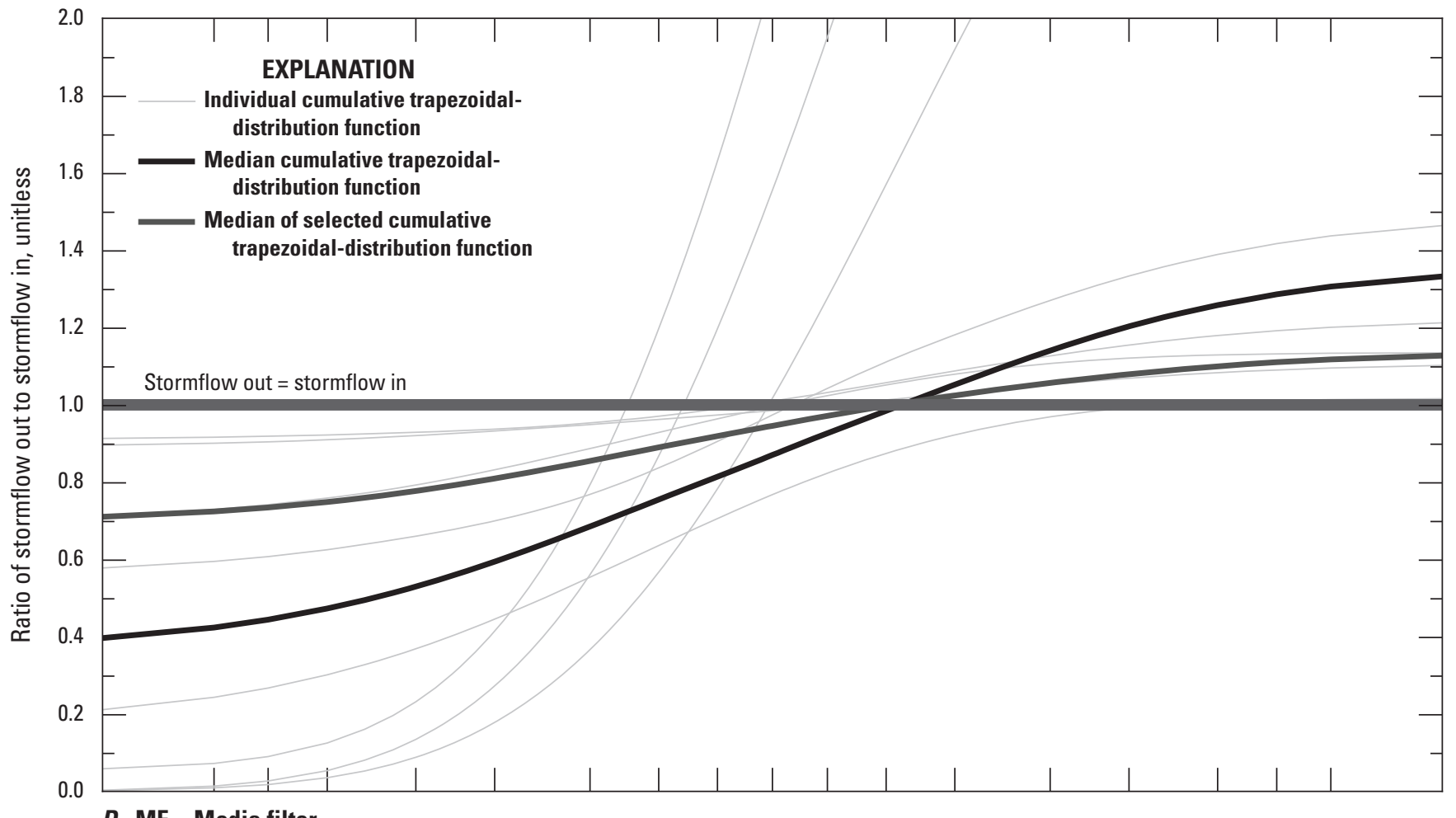

D. MF-Media filter

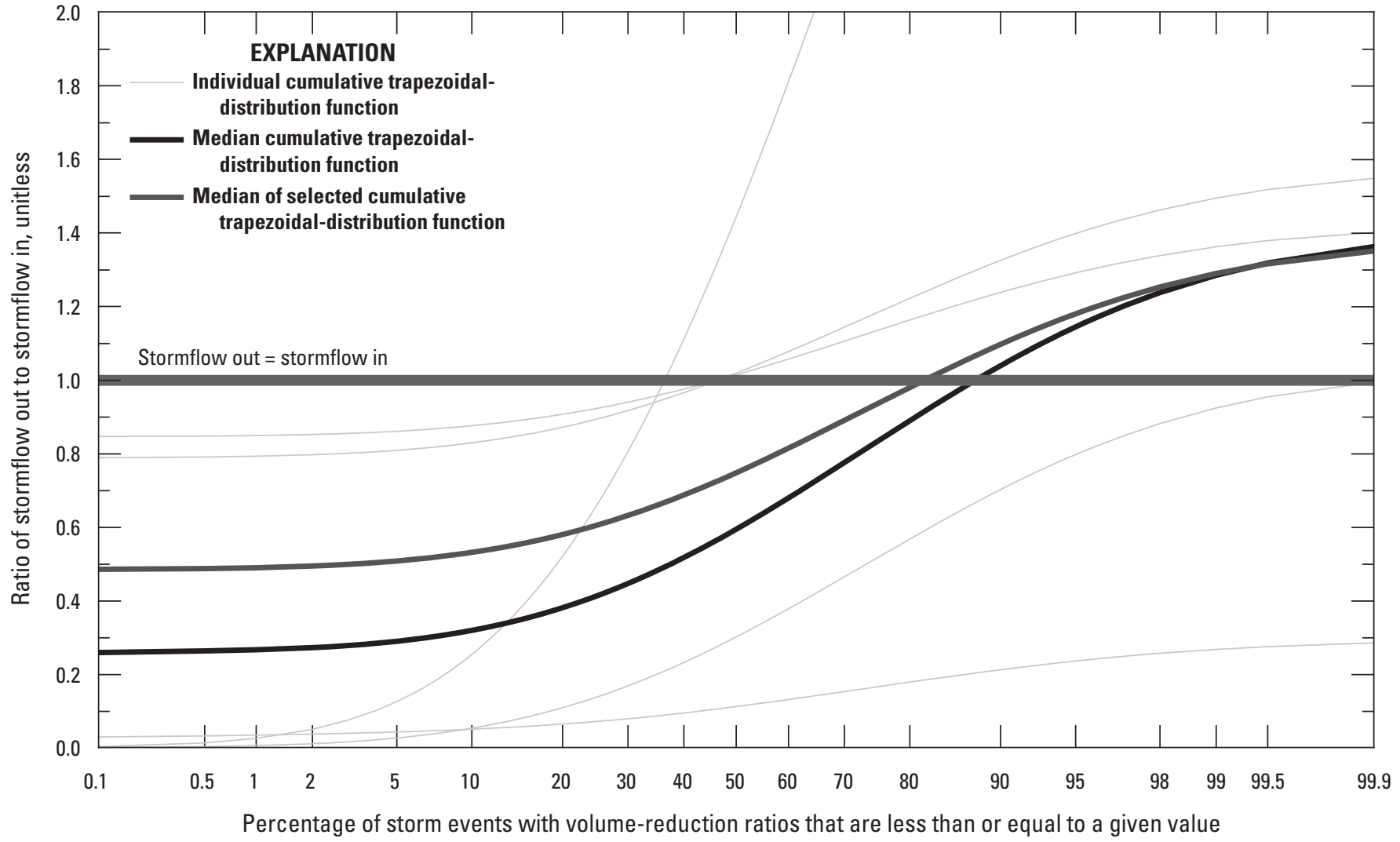

Figure 4. - Continued 
(2014) did not analyze manufactured devices because volume reduction is not a design feature for many of these devices. The CDFs for manufactured device and media filter sites (fig. $4 C$ and $D$ ) indicate the potential for volume changes caused by both infiltration into and leakage from manufactured devices and media filters. Infiltration is evidenced by the CDFs with a substantial percentage of events with ratios that substantially exceed 1 . Leakage is evidenced by the CDFs with a substantial percentage of events with ratios that are substantially less than 1 . Although some evaporation or leakage may be expected from such devices from storm to storm, thereby reducing the outflow from the next event, it may be prudent not to simulate volume reduction for BMPs that are not designed for this purpose. This is because volume reductions observed in the data for some BMPs that are not commonly designed for volume reduction may be the result of sampling artifacts.

To address the potential for simulated mass balance problems for BMPs without unmonitored inflows, median statistics were recalculated by using only the sites with maximum volume reduction ratios that are less than 2 (table 5). Although this resulted in a substantial reduction in the number of sites used in the calculations for several BMPs, it also substantially reduced the risk for exceeding a volume reduction ratio of one and reduced the magnitude for most BMP categories (tables 4 and 5). Results for closed-volume BMPs such as manufactured devices and media filters remain higher than may be expected, but the normally wet BMPs (including retention ponds, wetland basins, and wetland channels) that commonly are in contact with groundwater may reflect the effect of rising groundwater levels during storm events. Using only selected BMPs also reduced the magnitude of excess flows for all BMP categories in these tables. The selected median CDFs in figure 4 can be used to demonstrate the potential effects of the selection criteria on simulated long-term volume reduction populations. The statistics in table 5 also are published in SELDM input-file format (SELDM-tblBMPHydraulicsTable. csv) by Granato and others (2021).

In SELDM, the rank correlation between inflow volumes and the volume reduction ratios can be used to condition the stochastic generation of the ratios based on the exceedance percentile of flow volume (Granato, 2013, 2014). Because volume reduction is simulated as a ratio of the inflow volume, the correlation coefficient can be used to reduce the probability that a small ratio would be applied to a very large runoff volume. A strong positive correlation between inflow volume and the volume reduction ratio would tend to result in low ratios (larger proportional reductions) for small runoff volumes and high ratios (smaller proportional reductions) for large runoff volumes. This is consistent with what would be expected, but strong positive correlations could create large excess flows if the maximum volume reduction value greatly exceeds 1 .

Table 5. Medians of selected stormflow volume reduction statistics for the trapezoidal distribution and Spearman's rho correlation coefficient statistics for structural stormwater runoff best management practices, by category.

[The International Stormflow Best Management Practices Database (BMPDB) data are from the 2019 version of the database (Wright Water Engineers, Inc. and Geosyntec Consultants, 2019). BMPDB category codes and names are listed in table 1 . The medians were calculated by using statistics from sites with maximum ratios that are less than two. The percentage of outflow ratios greater than 1 are calculated by using the volume reduction statistics in this table. The volume reduction statistics are for the trapezoidal distribution of the ratio of outflow to inflow volume. Spearman's rank correlation coefficients (rho) are calculated by using the ranks of the inflow volumes and the associated ratios of outflow to inflow volumes. N, number of sites with at least seven storms used to calculate the median ratio statistics and Spearman's rho statistics; min, minimum; LBMPV, lower bound of the most probable value; UBMPV, upper bound of the most probable value; max, maximum; pct GT 1, the theoretical percentage of storms in which outflows exceed inflows; med, median; est, estimate for simulation, which is the average of the median and maximum rho values]

\begin{tabular}{|c|c|c|c|c|c|c|c|c|c|c|c|}
\hline \multicolumn{2}{|r|}{ BMPDB category } & \multirow{2}{*}{$\mathbf{N}$} & \multicolumn{5}{|c|}{ Volume reduction statistics, ratio } & \multicolumn{4}{|c|}{ Spearman's rho correlation coefficients } \\
\hline Code & Name & & Min & LBMPV & UBMPV & Max & Pct GT 1 & Min & Med & Max & Est \\
\hline $\mathrm{BI}$ & Grass strip & 16 & 0 & 0.0202 & 0.0317 & 1.2428 & 3.9 & -0.61 & -0.06 & 0.90 & 0.42 \\
\hline BR & Bioretention & 16 & 0 & 0 & 0.0492 & 1.0067 & 0.0 & -0.70 & 0.43 & 0.78 & 0.61 \\
\hline BS & Grass swale & 8 & 0.0671 & 0.0671 & 0.4966 & 0.8882 & 0.0 & -0.14 & 0.51 & 0.84 & 0.68 \\
\hline $\mathrm{CO}$ & Composite & 3 & 0 & 0.5561 & 1.0161 & 1.3593 & 20.6 & -0.72 & -0.72 & 0.70 & -0.01 \\
\hline DB & Detention basin & 8 & 0.2486 & 0.3649 & 0.6229 & 0.9973 & 0.0 & -0.76 & -0.04 & 0.48 & 0.22 \\
\hline IB & Infiltration basin & 1 & 0.2277 & 1.0584 & 1.0605 & 1.0605 & 14.0 & 0.84 & 0.84 & 0.84 & 0.84 \\
\hline MD & Manufactured device & 5 & 0.6993 & 0.9320 & 1.0158 & 1.1350 & 29.0 & -0.29 & -0.06 & 0.10 & 0.02 \\
\hline MF & Media filter & 5 & 0.4836 & 0.4836 & 0.5033 & 1.3773 & 17.8 & -0.15 & -0.02 & 0.57 & 0.28 \\
\hline PP & Porous pavement & 2 & 0 & 0 & 0 & 0.4008 & 0.0 & 0.28 & 0.53 & 0.77 & 0.65 \\
\hline $\mathrm{RP}$ & Retention pond & 17 & 0.4150 & 0.8726 & 0.9878 & 1.3992 & 35.2 & -0.72 & 0.07 & 0.79 & 0.43 \\
\hline WB & Wetland basin & 2 & 0.2843 & 0.9028 & 0.9028 & 1.5797 & 38.3 & -0.20 & 0.20 & 0.61 & 0.41 \\
\hline \multirow[t]{2}{*}{ WC } & Wetland channel & 3 & 0.4777 & 0.9530 & 1.1223 & 1.3803 & 46.9 & 0.04 & 0.50 & 0.70 & 0.60 \\
\hline & Parameter values & 86 & 0.2382 & 0.5199 & 0.7629 & 1.1889 & 7.0 & -0.25 & 0.14 & 0.74 & 0.44 \\
\hline
\end{tabular}


Unless there is reason to believe that groundwater discharges are occurring at a site of interest, use of a semistrong-to-strong positive correlation (greater than 0.75 ) with a maximum volume reduction ratio that is much greater than 1 may result in unrealistic mass-balance values for some large events. Use of a negative correlation, however, could lead to excess flows for small runoff volumes and large reductions (small ratios) for large runoff volumes.

Rank correlations calculated from available data in the BMPDB were not definitive indicators of quantitative relations between inflow volumes and volume reduction ratios. Only 35 of the $135 \mathrm{BMP}$ monitoring sites with 7 or more storm events included in the volume reduction analyses documented in this report had statistically significant (95th percentile) rank correlations between volume reduction and inflow volumes. Among the 35 BMPs with statistically significant rho values, 21 had positive and 14 had negative rho values. Among the $135 \mathrm{BMP}$ monitoring sites with data for 7 or more storm events, 68 had positive, 66 had negative, and 1 had a 0 rho value. These rho values ranged from about -0.76 to about 0.90 . These correlation coefficients indicate that a combination of different antecedent conditions, rather than within-event runoff volumes, may account for a substantial amount of the variability in measured volume reduction values (Granato, 2014).

\section{Water-Quality Treatment}

In this study, water-quality treatment statistics were developed for 10 BMP categories by using data from 206 BMP monitoring sites with paired inflow and outflow concentrations from 7 or more storm events (table 6). Waterquality treatment statistics were developed for 51 selected runoff-quality constituents of interest to State departments of transportation. Constituents were selected for inclusion in this report on the basis of available data, potential transferability, and the perceived quality of data in the database. Waterquality treatment statistics from individual BMP monitoring sites for all the water-quality properties and constituents in table 6 are provided in a water-quality treatment file (USGSSIR-2020-5136-WaterQuality-SiteResults.txt) published by Granato and others (2021). Median water-quality treatment statistics, by BMP category, for eight constituent groups are provided in table 7. Median water-quality treatment statistics, by BMP category, for 48 individual water-quality constituents are provided in appendix table 1.1 of this report; these statistics also are published in SELDM input-file format (SELDMtadBMPTreatmentTable.csv) by Granato and others (2021). The constituent-group statistics in table 7 are estimated as the median of statistics from related constituents in table 1.1. There are variations among constituents and groups, but the water-quality treatment statistics in this report are by-andlarge similar to the values developed by Granato (2014). The updated statistics are more robust because the 2012 dataset contained about 80 percent of the sites available in the updated 2019 dataset and the BMPDB team improved the quality of data between 2012 and 2019. The analysis in this report also includes data for many more runoff-quality constituents than Granato (2014).

For many constituent groups (table 7) and constituents (table 1.1), the theoretical percentage of events with waterquality treatment ratios that are greater than 1 is substantial. In some cases, the percentage of events in which the outflow concentrations exceed the inflow concentrations exceed 50 percent. There are many physicochemical processes that may cause increases in concentrations during some events, especially for dissolved constituents that can partition from stormwater solids. Because of the form of the equations for the cumulative distribution function of the trapezoidal distribution (Kacker and Lawrence, 2007), the maximum value has the largest effect on the proportion of ratios that are greater than 1 . As the maximum value increases from 1 to 2 , the percentage of generated values that are greater than 1 increases from 0 to about 40 percent. As the maximum value increases from 2 to 4 , the percentage of generated values that are greater than 1 increases from about 40 to 60 percent. Although the ratios may exceed 1, indicating higher concentrations in the outflows than in the inflows, the negative correlations prevalent for most constituents indicate that small inflow concentrations may tend to increase within the BMPs, whereas large concentrations decrease. Because concentrations of highway and urban runoff commonly vary logarithmically over one or more orders of magnitude, an equivalent percentage change for a low concentration is usually much smaller than for a large concentration (Granato and Jones, 2014, 2019; Risley and Granato, 2014; Smith and others, 2018; Stonewall and others, 2019; Weaver and others, 2019; Jeznach and Granato, 2020).

Tables 7 and 1.1 contain statistics for individual BMP types and for "parameter values." These "parameter values" statistics are estimated from multiple BMP categories for each property, constituent, or constituent group. The trapezoidal statistics are the median of values in the tables for the BMP categories. The cumulative distribution functions for the parameter value statistics in table 7 are shown in figure 5 . The percentages of values exceeding a ratio of 1 for these estimates are the theoretical percent of events calculated by using the trapezoidal parameter value statistics. The rho values for the parameter value estimates were selected as the smallest rho values from among the category values; these minimum of median rho values were selected to minimize simulations in which large concentrations would be paired with large ratios (Granato, 2013, 2014). The probability that this would occur increases as the absolute value correlation coefficient increases (Granato, 2013).

The parameter value statistics may be used as planninglevel estimates of treatment statistics for constituents with insufficient data to produce robust estimates for a given BMP category or for a given constituent. These statistics also may be used to provide planning-level treatment estimates for TMDL analyses in receiving-water basins where multiple BMPs may be in use or for analyses at actual or hypothetical sites without a particular BMP (Granato and Jones, 2017; 
Table 6. Runoff-quality constituents analyzed with counts of the number of sites, number of International Stormwater Best Management Practice Database categories, and number of paired samples used to analyze structural stormwater runoff best management practices.

[The International Stormflow Best Management Practices Database (BMPDB) data are from the 2019 version of the database (Wright Water Engineers, Inc. and Geosyntec Consultants, 2019). Pcode is the water-quality parameter code is denoted by the letter $\mathrm{p}$ and the five-digit identification number from the U.S. Geological Survey (2020) National Water Information System (NWIS); abbreviation is the short name used in tables and figures in this report; name is the constituent name in NWIS; fraction is the sampled fraction (filtered water or unfiltered (whole) water); and number of sites are the sites with seven or more uncensored paired samples]

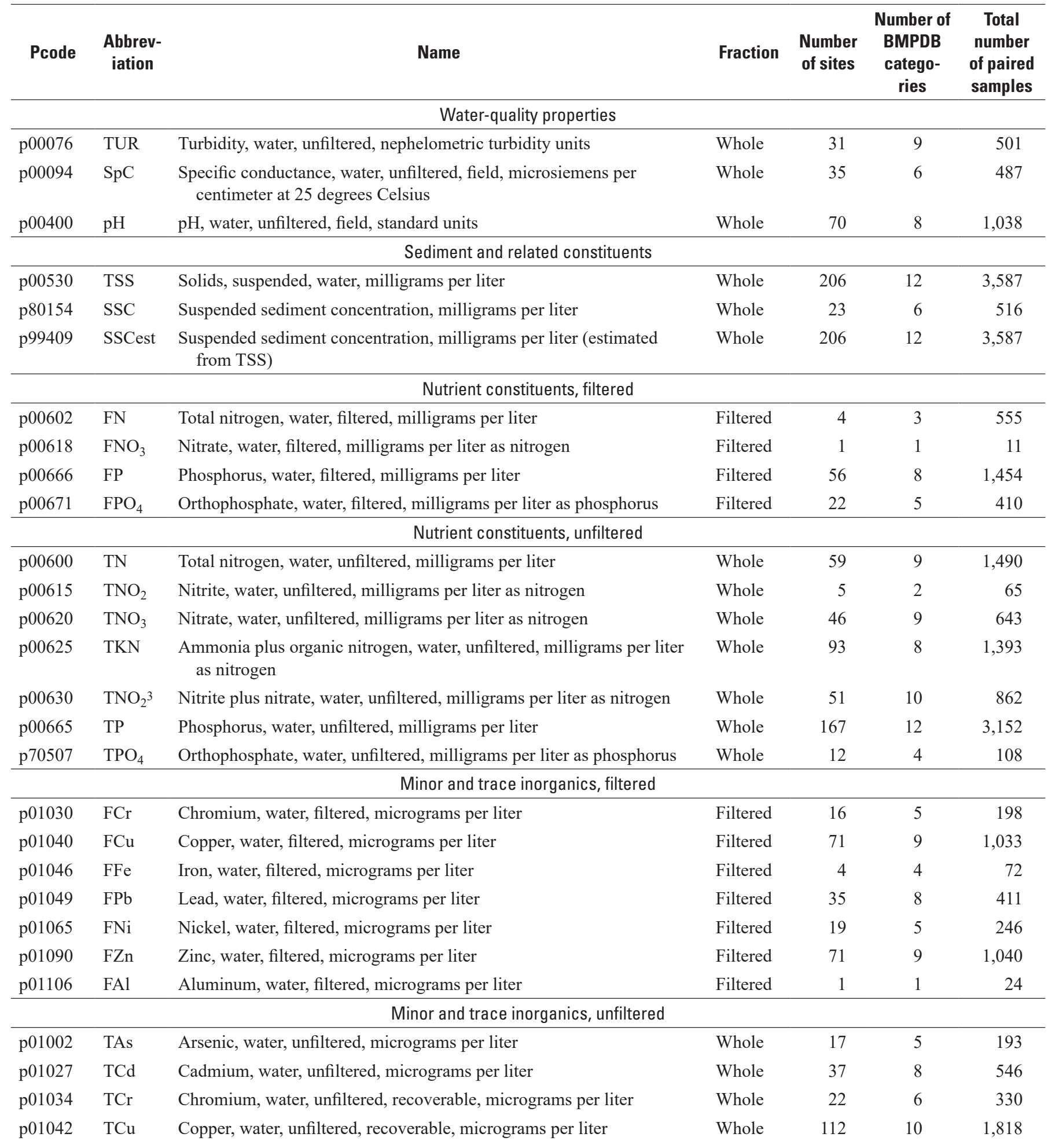


Table 6. Runoff-quality constituents analyzed with counts of the number of sites, number of International Stormwater Best Management Practice Database categories, and number of paired samples used to analyze structural stormwater runoff best management practices.-Continued

[The International Stormflow Best Management Practices Database (BMPDB) data are from the 2019 version of the database (Wright Water Engineers, Inc. and Geosyntec Consultants, 2019). Pcode is the water-quality parameter code is denoted by the letter $\mathrm{p}$ and the five-digit identification number from the U.S. Geological Survey (2020) National Water Information System (NWIS); abbreviation is the short name used in tables and figures in this report; name is the constituent name in NWIS; fraction is the sampled fraction (filtered water or unfiltered (whole) water); and number of sites are the sites with seven or more uncensored paired samples]

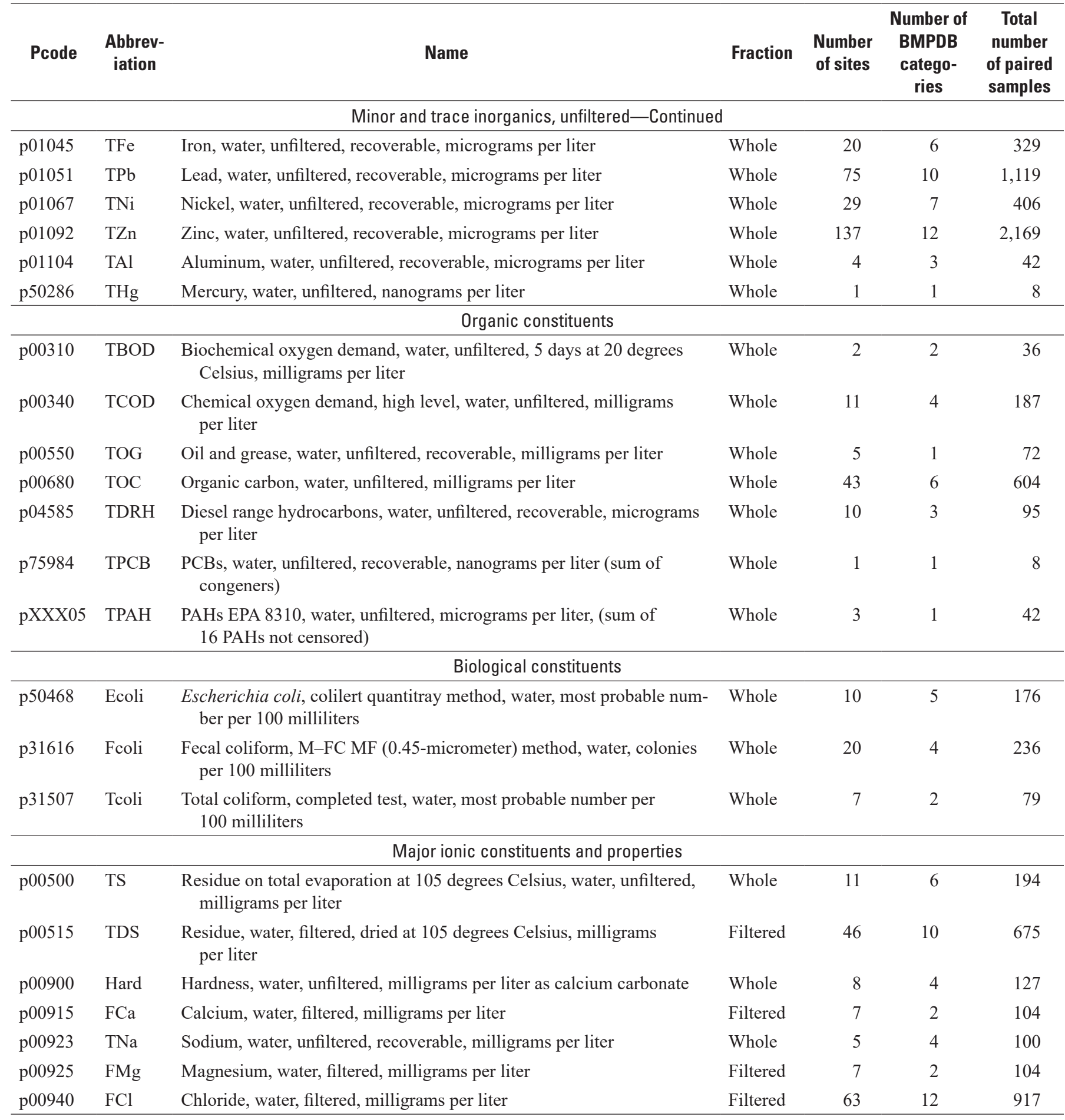


Table 7. Medians of selected water-quality treatment statistics for selected parameter groups including the trapezoidal distribution and Spearman's rank correlation coefficient statistics for structural stormwater runoff best management practices, by category.

[The International Stormflow Best Management Practices Database (BMPDB) data are from the 2019 version of the database (Wright Water Engineers, Inc. and Geosyntec Consultants, 2019). BMPDB category codes and names are listed in table 1. The constituents included in the parameter categories are listed in table 6. The percentage of outflow ratios greater than 1 are calculated by using the treatment statistics in this table. The concentration-reduction statistics are for the trapezoidal distribution of the ratio of outflow to inflow concentration. Spearman's rank correlation coefficients (rho) are calculated by using the ranks of the inflow concentrations and the associated ratios of outflow to inflow concentrations. The selected rho value is closest to minus one among at-site rho values. The water-quality parameter groups are listed and defined in table 6 . N, number of sites with paired inflow and outflow concentrations for at least seven storms used to calculate the median ratio statistics; min, minimum; LBMPV, lower bound of the most probable value; UBMPV, upper bound of the most probable value; max, maximum; Pct GT 1, theoretical percentage of storms in which outflows exceed inflows and thus, the ratio is greater than 1 ; - , insufficient data]

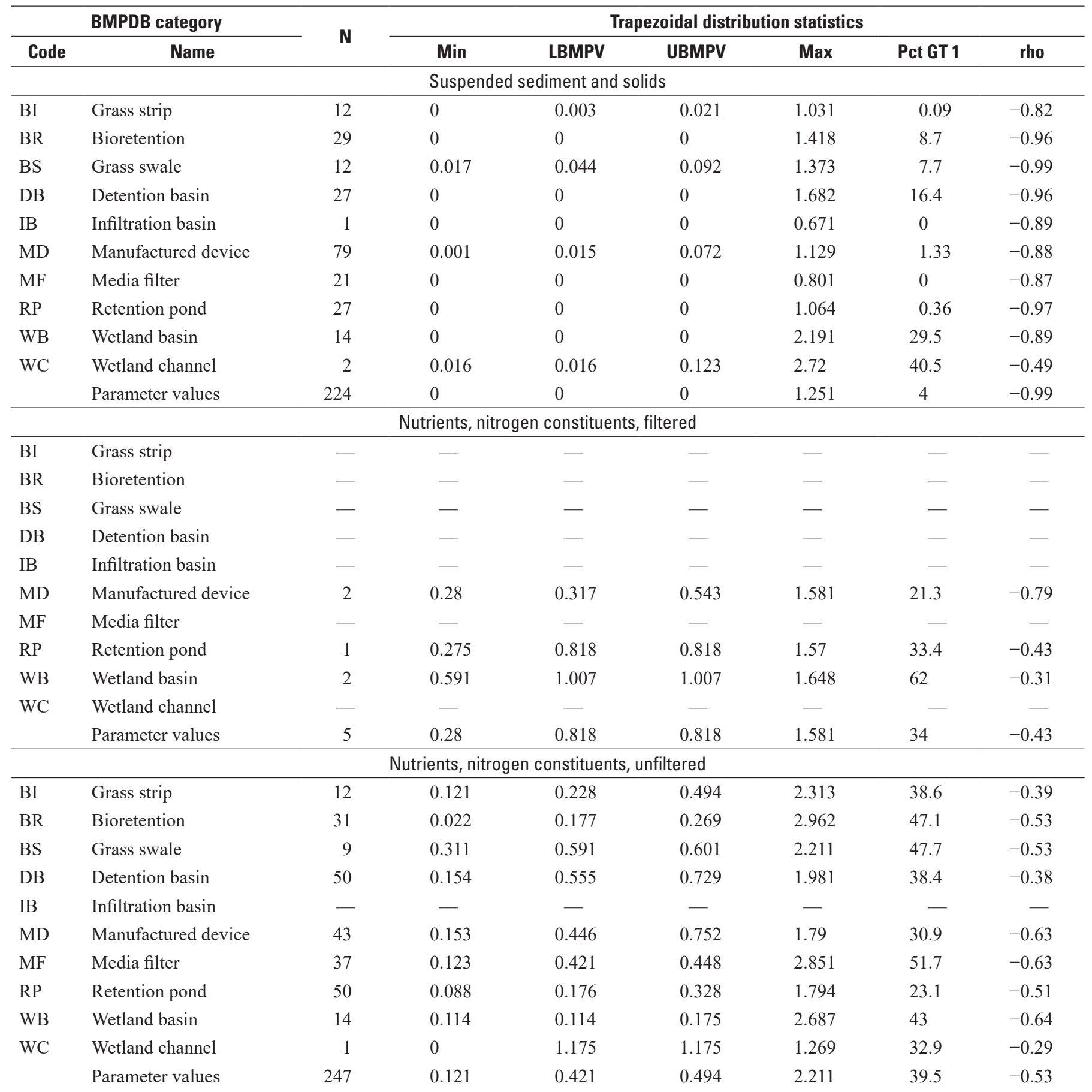


Table 7. Medians of selected water-quality treatment statistics for selected parameter groups including the trapezoidal distribution and Spearman's rank correlation coefficient statistics for structural stormwater runoff best management practices, by category. -Continued

[The International Stormflow Best Management Practices Database (BMPDB) data are from the 2019 version of the database (Wright Water Engineers, Inc. and Geosyntec Consultants, 2019). BMPDB category codes and names are listed in table 1. The constituents included in the parameter categories are listed in table 6. The percentage of outflow ratios greater than 1 are calculated by using the treatment statistics in this table. The concentration-reduction statistics are for the trapezoidal distribution of the ratio of outflow to inflow concentration. Spearman's rank correlation coefficients (rho) are calculated by using the ranks of the inflow concentrations and the associated ratios of outflow to inflow concentrations. The selected rho value is closest to minus one among at-site rho values. The water-quality parameter groups are listed and defined in table $6 . \mathrm{N}$, number of sites with paired inflow and outflow concentrations for at least seven storms used to calculate the median ratio statistics; min, minimum; LBMPV, lower bound of the most probable value; UBMPV, upper bound of the most probable value; max, maximum; Pct GT 1, theoretical percentage of storms in which outflows exceed inflows and thus, the ratio is greater than 1; - , insufficient data]

\begin{tabular}{|c|c|c|c|c|c|c|c|c|}
\hline \multicolumn{2}{|r|}{ BMPDB category } & \multirow{2}{*}{$\mathbf{N}$} & \multicolumn{6}{|c|}{ Trapezoidal distribution statistics } \\
\hline Code & Name & & Min & LBMPV & UBMPV & Max & Pct GT 1 & rho \\
\hline \multicolumn{9}{|c|}{ Nutrients, phosphorus constituents, filtered } \\
\hline $\mathrm{BR}$ & Bioretention & 2 & 0.016 & 0.383 & 0.383 & 1.216 & 4.7 & 0.04 \\
\hline $\mathrm{BS}$ & Grass swale & 4 & 0.256 & 0.382 & 0.418 & 4.899 & 72.5 & -0.62 \\
\hline MD & Manufactured device & 25 & 0.092 & 0.379 & 0.666 & 1.801 & 28.3 & -0.44 \\
\hline MF & Media filter & 6 & 0 & 0.672 & 0.676 & 1.588 & 23.8 & -0.6 \\
\hline $\mathrm{RP}$ & Retention pond & 19 & 0 & 0 & 0 & 2.161 & 28.9 & -0.57 \\
\hline WB & Wetland basin & 8 & 0.184 & 0.248 & 0.302 & 3.817 & 61.2 & -0.3 \\
\hline $\mathrm{BI}$ & Grass strip & 7 & 0.015 & 0.075 & 0.129 & 2.598 & 39.2 & -0.59 \\
\hline $\mathrm{BR}$ & Bioretention & 22 & 0 & 0.01 & 0.077 & 4.433 & 60.1 & -0.64 \\
\hline $\mathrm{BS}$ & Grass swale & 10 & 0.052 & 0.565 & 0.784 & 3.4 & 61.7 & -0.63 \\
\hline DB & Detention basin & 33 & 0.062 & 0.18 & 0.456 & 2.744 & 44.9 & -0.54 \\
\hline IB & Infiltration basin & 41 & 0.207 & 0.521 & 0.569 & 1.568 & 22.9 & -0.34 \\
\hline MD & Manufactured device & 21 & 0.266 & 0.338 & 0.356 & 2.085 & 37 & -0.57 \\
\hline MF & Media filter & 2 & 0.007 & 0.007 & 0.007 & 1.849 & 21.2 & -0.92 \\
\hline $\mathrm{RP}$ & Retention pond & 27 & 0.155 & 0.209 & 0.765 & 2.35 & 41.8 & -0.55 \\
\hline WB & Wetland basin & 12 & 0.09 & 0.157 & 0.212 & 2.489 & 39.7 & -0.47 \\
\hline DB & Detention basin & 30 & 0.2345 & 0.609 & 0.6885 & 1.886 & 37.9 & -0.73 \\
\hline IB & Infiltration basin & 2 & 0.563 & 0.563 & 0.584 & 2.933 & 66.5 & -0.62 \\
\hline $\mathrm{MD}$ & Manufactured device & 79 & 0.225 & 0.765 & 0.8925 & 1.815 & 41.9 & -0.79 \\
\hline MF & Media filter & 39 & 0.183 & 0.544 & 0.89 & 1.44 & 22 & -0.79 \\
\hline $\mathrm{RP}$ & Retention pond & 17 & 0.09 & 0.116 & 0.396 & 2.114 & 31.4 & -0.94 \\
\hline WB & Wetland basin & 4 & 0.198 & 0.371 & 0.371 & 2.289 & 41.4 & -0.86 \\
\hline \multirow[t]{2}{*}{ WC } & Wetland channel & - & - & - & - & - & - & - \\
\hline & Parameter values & 212 & 0.183 & 0.371 & 0.584 & 1.837 & 29.9 & -0.79 \\
\hline
\end{tabular}


Table 7. Medians of selected water-quality treatment statistics for selected parameter groups including the trapezoidal distribution and Spearman's rank correlation coefficient statistics for structural stormwater runoff best management practices, by category.

\section{- Continued}

[The International Stormflow Best Management Practices Database (BMPDB) data are from the 2019 version of the database (Wright Water Engineers, Inc. and Geosyntec Consultants, 2019). BMPDB category codes and names are listed in table 1. The constituents included in the parameter categories are listed in table 6. The percentage of outflow ratios greater than 1 are calculated by using the treatment statistics in this table. The concentration-reduction statistics are for the trapezoidal distribution of the ratio of outflow to inflow concentration. Spearman's rank correlation coefficients (rho) are calculated by using the ranks of the inflow concentrations and the associated ratios of outflow to inflow concentrations. The selected rho value is closest to minus one among at-site rho values. The water-quality parameter groups are listed and defined in table $6 . \mathrm{N}$, number of sites with paired inflow and outflow concentrations for at least seven storms used to calculate the median ratio statistics; min, minimum; LBMPV, lower bound of the most probable value; UBMPV, upper bound of the most probable value; max, maximum; Pct GT 1, theoretical percentage of storms in which outflows exceed inflows and thus, the ratio is greater than 1; - , insufficient data]

\begin{tabular}{|c|c|c|c|c|c|c|c|c|}
\hline \multicolumn{2}{|r|}{ BMPDB category } & \multirow{2}{*}{$\mathbf{N}$} & \multicolumn{6}{|c|}{ Trapezoidal distribution statistics } \\
\hline Code & Name & & Min & LBMPV & UBMPV & Max & Pct GT 1 & rho \\
\hline \multicolumn{9}{|c|}{ Minor and trace inorganics, unfiltered } \\
\hline BR & Bioretention & 35 & 0 & 0 & 0 & 1.529 & 12 & -0.89 \\
\hline BS & Grass swale & 14 & 0 & 0.1275 & 0.2365 & 1.364 & 8 & -0.79 \\
\hline MD & Manufactured device & 136 & 0.1905 & 0.482 & 0.639 & 1.3815 & 14.5 & -0.67 \\
\hline MF & Media filter & 66 & 0.029 & 0.074 & 0.263 & 1.471 & 11.3 & -0.9 \\
\hline $\mathrm{RP}$ & Retention pond & 83 & 0.024 & 0.0765 & 0.1315 & 1.4315 & 9.8 & -0.77 \\
\hline WB & Wetland basin & 11 & 0.019 & 0.07 & 0.07 & 1.895 & 23.4 & -0.89 \\
\hline $\mathrm{BI}$ & Grass strip & 6 & 0.146 & 0.388 & 0.414 & 1.671 & 23.1 & -0.58 \\
\hline $\mathrm{BR}$ & Bioretention & 4 & 0 & 0 & 0 & 1.559 & 12.9 & -1 \\
\hline BS & Grass swale & - & - & - & - & - & - & - \\
\hline DB & Detention basin & 9 & 0.442 & 0.74 & 0.912 & 1.918 & 50.8 & -0.54 \\
\hline IB & Infiltration basin & - & - & - & - & - & - & - \\
\hline MD & Manufactured device & 33 & 0.18 & 0.438 & 0.605 & 1.475 & 17.7 & -0.65 \\
\hline MF & Media filter & 12 & 0.209 & 0.503 & 0.513 & 1.327 & 11.6 & -0.52 \\
\hline $\mathrm{RP}$ & Retention pond & 9 & 0.232 & 0.376 & 0.675 & 1.426 & 16.2 & -0.69 \\
\hline WB & Wetland basin & - & - & - & - & - & - & - \\
\hline DB & Detention basin & 8 & 0 & 0 & 0 & 2.746 & 40.4 & -0.69 \\
\hline IB & Infiltration basin & - & - & - & - & - & - & - \\
\hline MD & Manufactured device & 10 & 0 & 0 & 0 & 2.948 & 43.7 & -0.38 \\
\hline MF & Media filter & 6 & 0 & 0 & 0 & 3.378 & 49.6 & -0.55 \\
\hline $\mathrm{RP}$ & Retention pond & 8 & 0 & 0 & 0 & 3.14 & 46.4 & -0.51 \\
\hline WB & Wetland basin & 1 & 0 & 0 & 0 & 0.711 & 0 & 0.14 \\
\hline \multirow[t]{2}{*}{ WC } & Wetland channel & - & - & - & - & - & - & - \\
\hline & Parameter values & 34 & 0 & 0 & 0 & 2.847 & 42.1 & -0.45 \\
\hline
\end{tabular}




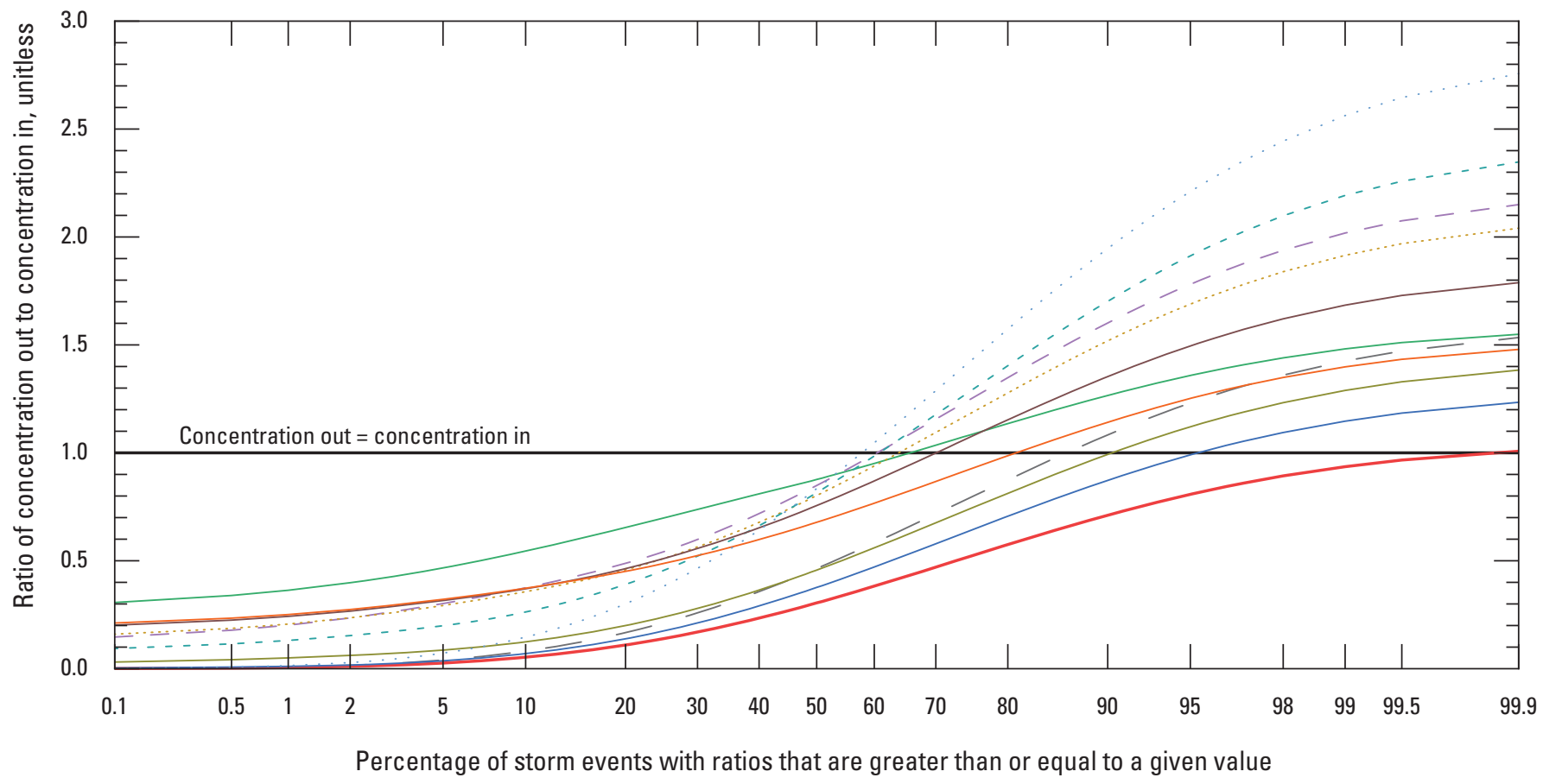

\section{EXPLANATION}
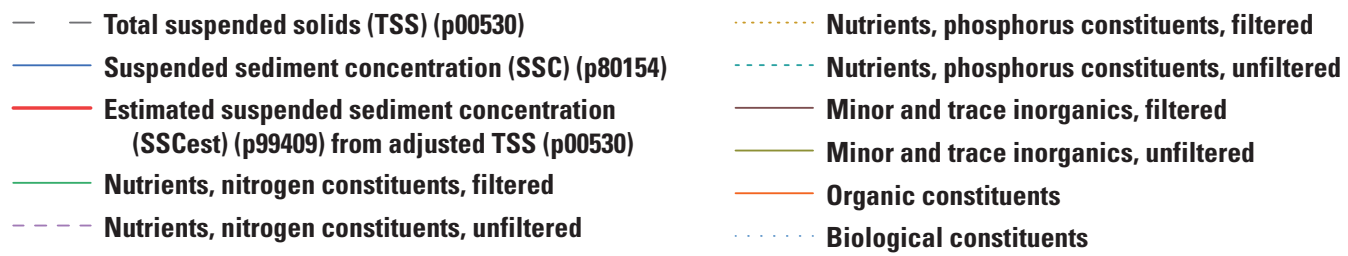

Figure 5. Line graphs showing fitted cumulative trapezoidal distribution functions for the parameter value estimates for sediment, solids, nutrients, minor and trace inorganic, organic, and biological constituents.

Smith and others, 2018; Stonewall and others, 2018, 2019; Jeznach and Granato, 2020). For many constituent groups (table 7) and constituents (table 1.1), these parameter value statistics may be used instead of category-specific statistics for constituents without sufficient data to calculate treatment statistics for one or more BMP categories. Only 4 of 41 constituents analyzed (table 1.1) have sufficient data for all 10 BMP categories. Because of the wide range in BMP performance statistics from site to site that are observed for constituents with plentiful data (such as total suspended solids, total phosphorus, or total zinc), use of the parameter value statistics may be more robust than use of category-specific statistics based on data collected at a small number of monitoring sites.

Granato (2014) estimated water-quality statistics for suspended sediment concentrations (SSCs) from TSS data in the BMPDB because many studies have shown that TSS is an unreliable measure of sediment if sand-sized particles are present. Granato (2014) had used the relation between TSS and SSC developed by Granato and Cazenas (2009) to estimate inflow concentrations of SSC and used TSS effluent concentrations as estimates for concentrations of SSC in BMP outflows based on the assumption that most BMPs could remove the coarse sediment fractions that cannot be effectively measured by using TSS measurement methods. This analysis was repeated with the 2019 data from the BMPDB to refine the SSC treatment statistics with additional data; these results are shown as "SSCest (p99409) from adjusted TSS (p00530)" in table 1.1. These results, when compared to the TSS statistics, demonstrate how use of the TSS analysis method may be underrepresenting the true effectiveness of many BMPs for sediment removal (fig. 5). For example, the parameter values calculated from TSS data indicate that about 14 percent of outflow concentrations may exceed inflow concentrations, but only 0.1 percent of outflow concentrations for the SSC values estimated from TSS may exceed inflow concentrations (table 1.1). This is because the estimated SSC concentrations include the sand-size fraction of SSC in the inflows that are not captured by the TSS method (Granato and Cazenas, 2009). It is difficult to compare the estimated SSC treatment statistics with the measured SSC treatment statistics directly 
because relatively few sites include sufficient SSC data for a definitive comparison. However, only 1.3 percent of measured SSC concentrations exceed inflow concentrations for the only BMP category (manufactured devices) with data from more than one monitoring site. The categorical "Suspended Sediment and Solids" statistics in table 7 are the medians of the TSS, SSC and SSCest statistics.

Summary water-quality treatment statistics for total solids, total dissolved solids, total sodium and filtered chloride are not provided in table 1.1 because these statistics may be misinterpreted when effects of sodium chloride deicing salt are simulated. Statistics for filtered calcium and filtered magnesium, which also are deicing-chemical constituents that are not readily reduced by structural BMPs, are provided to evaluate potential changes in total hardness that may occur as a byproduct of flow through a structural BMP. Total hardness is of special concern because it can affect the partitioning and toxicity of trace elements in the BMP discharge and receiving stream. These treatment statistics should not be used for simulating treatment of deicing chemicals. Treatment statistics from individual BMP monitoring sites for TNa (p00923) and $\mathrm{FCl}$ (p00940) are provided in the water-quality treatment file (USGS-SIR-2020-5136-WaterQuality-SiteResults.txt) published by Granato and others (2021) but should not be used to simulate the effects of structural BMP in deicing-chemical analyses. Analyses for unfiltered selenium (p01147), silver (p01077), dieldrin (p39380), and methylmercury (p50284), which are constituents of concern in TMDLs for the California Department of Transportation, were examined, but not enough uncensored data were available to calculate statistics for a single site. Unless additional data are collected and stored in the BMPDB (Wright Water Engineers, Inc. and Geosyntec Consultants, 2019) and the BMPSE (Granato, 2021), it may be necessary to use statistics for unfiltered minor and trace inorganics to develop planning-level estimates for unfiltered selenium and silver and statistics for unfiltered organic constituents to develop planning-level estimates for dieldrin and methylmercury.

\section{Minimum Irreducible Concentrations}

Granato (2014) calculated MIC values on the assumption that the MIC is a property of the type of BMP, the design and implementation of each type for the local hydrologic conditions, and potentially, the quality of water entering the BMP. The analysis in this report is based on the same assumptions and includes an analysis of background soil chemistry to assess potential effects of this variable on MIC values. In this study, MIC statistics were developed for 51 runoff-quality constituents commonly measured in highway and urban runoff studies (tables 6 and 1.2) by using data from 10 BMP categories and 265 monitoring sites (Granato and others, 2021). Correlations between the geometric mean of inflow concentrations and MIC values were calculated by using data from 164 sites with inflow and outflow concentrations for 7 or more storm events. MIC statistics from individual BMP monitoring sites for all the water-quality properties and constituents in table 6 are provided in a MIC file (USGS-SIR2020-5136-MICs-SiteResults.txt) published by Granato and others (2021). Selected MIC0 values also are published in SELDM input-file format (SELDM-tadBMPTreatmentTable. csv) by Granato and others (2021). However, MIC values for chloride and sodium are not included in this report because these constituents are not changed by commonly used BMP treatment processes, and MIC values for SSCest are not provided because the outflow concentrations were equal to TSS outflow concentrations for the SSCest analyses.

Category-level MIC statistics for individual waterquality constituents are published in appendix 1 of this report. Table 1.2 in appendix 1 lists the category-level MIC0, MIC1, MIC2, and MIC3 estimates; table 1.3 lists the category-level lognormal-variate (K) estimates (eq. 1) for the four MIC estimates (KMIC0, $\mathrm{KMIC} 1, \mathrm{KMIC} 2$, and $\mathrm{KMIC} 3$ ); and table 1.4 lists the correlation coefficients between the geometric mean of inflows and the MIC0 and MIC2 estimates for each constituent. MIC estimates for each type of BMP and parameter estimates, which are the median of the BMP type estimates in the table are provided for each constituent. Only 5 of the 48 runoff-quality constituents have sufficient data (concentrations from 7 or more storm events from 1 or more sites) to calculate MIC values for all $10 \mathrm{BMP}$ categories. The parameter estimates were developed, therefore, to guide professional judgement in the selection of MICs for BMP categories that do not have MIC estimates for a given constituent. There are variations among MIC estimates for different constituents and categories, but the water-quality treatment statistics in this report are by-and-large similar to the values developed by Granato (2014). The updated MIC estimates in this report are more robust because the 2012 dataset contained about 80 percent of the sites available in the newer 2019 dataset and the BMPDB team improved the quality of data in the intervening time. The analysis in this report also includes MIC estimates for many more runoff-quality constituents than Granato (2014).

The lognormal variates (eq. 1; table 1.3) provide information to guide professional judgement for selecting MIC values based on simulated BMP inflow statistics. Use of the lognormal variates is based on the idea that inflow concentrations will reflect the background conditions at a site of interest that may affect the MIC at a given site. A MIC value can be estimated from a lognormal variate by using equation 2 in this report. When used in simulations, this method could reduce the probability that a high proportion of outflow concentrations would be replaced by a single MIC value.

The potential accuracy of the lognormal-variate-based estimates can be inferred from the correlation coefficients in table 1.4. The table includes Pearson's R and Spearman's rho correlations between the selected MIC estimates and the geometric mean of inflow concentrations and Pearson's R correlations between the logarithms of selected MIC estimates and the geometric mean of inflow concentrations. Correlation 
coefficients are calculated when data are available from five or more sites (Abdel-Megeed, 1984). About 11 percent of MIC0 and 14 percent of MIC2 rho values in table 1.4 indicate strong correlations (an absolute value greater than or equal to 0.85 ). About 41 percent of MIC0 and 32 percent of MIC2 rho values in table 1.4 indicate weak correlations (an absolute value less than 0.5). In most cases, therefore, the lognormal-variatebased estimates of the MIC derived from table 1.3 should be viewed as a qualitative rather than a quantitative method for estimating a MIC value for a site of interest.

Lognormal variates also were estimated for nine constituent categories because data were lacking for individual constituents of concern (table 8). These variates were calculated by taking the median of available statistics for each BMP category with one or more constituent values in table 1.2. The categories include sediment, filtered and unfiltered nutrients, filtered and unfiltered minor and trace inorganic constituents, and unfiltered organic and biological constituents. Table 8 also includes a parameter estimate for each constituent category, which is the median of values for each constituent group in table 8 . The lognormal variates (table 8) can be used with BMP inflow statistics to guide professional judgement on the selection of MIC values using equation 2. If the BMPs inflow concentrations are lognormally distributed, then it may be assumed that variate $(\mathrm{K})$ values of $-1,-2,-3$, and -4 would produce MIC estimates that are less than about 84.1, 97.7, 99.987, and 99.997 percent of simulated inflow concentrations, respectively. The percentages of unmodified outflow concentrations that are converted to the MIC value, however, also depend on the water-quality treatment ratios and the rank correlation between inflow concentrations and outflow ratio values.
Potential correlations between the median of MIC estimates of selected constituents and the concentrations of the associated elements in the top 5 centimeters of soil (Smith and others, 2014) were calculated to see if this national-scale soilchemistry dataset could be used with the BMP database data to refine MIC estimates at sites of interest (table 9). This analysis was done because few of the correlations between the MIC values and inflow concentrations were strong and because the MIC has been described as a background concentration in the literature such as Kadlec and Knight (1996), Wong and Geiger (1997), Huber and others (2006), and Granato (2014). The MIC2 values at individual monitoring sites were correlated with the soil concentration calculated as weighted average of concentration values for all data points within 75 kilometers of the center of each 444-square-kilometer grid cell as calculated by Smith and others (2014). No strong correlations emerged from the analysis (table 9), which may be because the coarse resolution of the national-scale soil-chemistry dataset does not capture small-scale variations in concentrations that could affect BMP discharge quality. The soil-chemistry dataset collection effort was designed to characterize natural soils, and thus efforts were made to minimize the local anthropogenic influences on soil chemistry (Smith and others, 2014). These local anthropogenic influences may help define the MIC in BMP discharge at a given site. In the absence of a nationalor international-scale dataset of paired BMP discharge and site-specific soil-chemistry data, the BMP inflow concentrations may have to suffice to guide professional judgement for adjusting local MIC estimates. 
Table 8. Lognormal variate $(K)$ values for the minimum irreducible concentration estimates of selected parameter categories.

[The International Stormwater Best Management Practices Database (BMPDB) data are from the 2019 version of the database (Wright Water Engineers, Inc. and Geosyntec Consultants, 2019); BMPDB category codes and names are listed in table 1. The constituents included in the parameter categories are listed in table 6. The lognormal variates $(\mathrm{K})$ are calculated by subtracting the geometric mean from each minimum irreducible concentration (MIC) estimate and dividing by the geometric standard deviation in logarithmic space (eq. 1). To use the lognormal variate (KMIC) values, add the geometric mean of simulated inflow concentrations to the product of the geometric standard deviation of simulated inflow concentrations in logarithmic space and then retransform the resultant MIC estimate to arithmetic space (eq. 2). KMIC0, the lognormal variate for the minimum of the minimum values of the positive MIC estimates; KMIC1, the lognormal variate for the 25th percentile of the minimum values of the positive MIC estimates; KMIC2, the lognormal variate for the median of the minimum values of the positive MIC estimates; KMIC3, the lognormal variate for the median of the median values of the positive MIC estimates; - , no data]

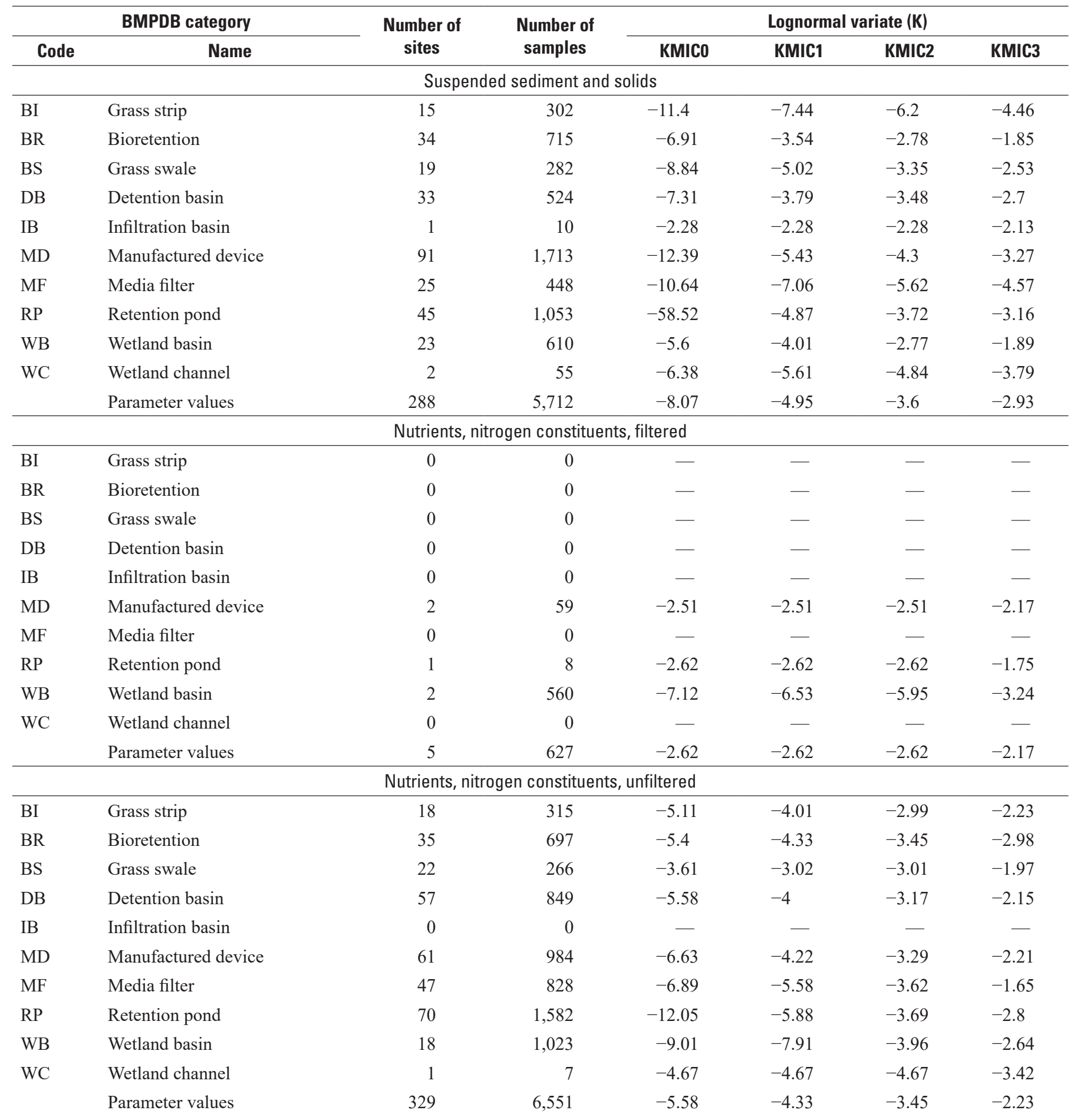


Table 8. Lognormal variate $(K)$ values for the minimum irreducible concentration estimates of selected parameter categories. -Continued

[The International Stormwater Best Management Practices Database (BMPDB) data are from the 2019 version of the database (Wright Water Engineers, Inc. and Geosyntec Consultants, 2019); BMPDB category codes and names are listed in table 1. The constituents included in the parameter categories are listed in table 6. The lognormal variates $(\mathrm{K})$ are calculated by subtracting the geometric mean from each minimum irreducible concentration (MIC) estimate and dividing by the geometric standard deviation in logarithmic space (eq. 1). To use the lognormal variate (KMIC) values, add the geometric mean of simulated inflow concentrations to the product of the geometric standard deviation of simulated inflow concentrations in logarithmic space and then retransform the resultant MIC estimate to arithmetic space (eq. 2). KMIC0, the lognormal variate for the minimum of the minimum values of the positive MIC estimates; KMIC1, the lognormal variate for the 25th percentile of the minimum values of the positive MIC estimates; KMIC2, the lognormal variate for the median of the minimum values of the positive MIC estimates; KMIC3, the lognormal variate for the median of the median values of the positive MIC estimates; - , no data]

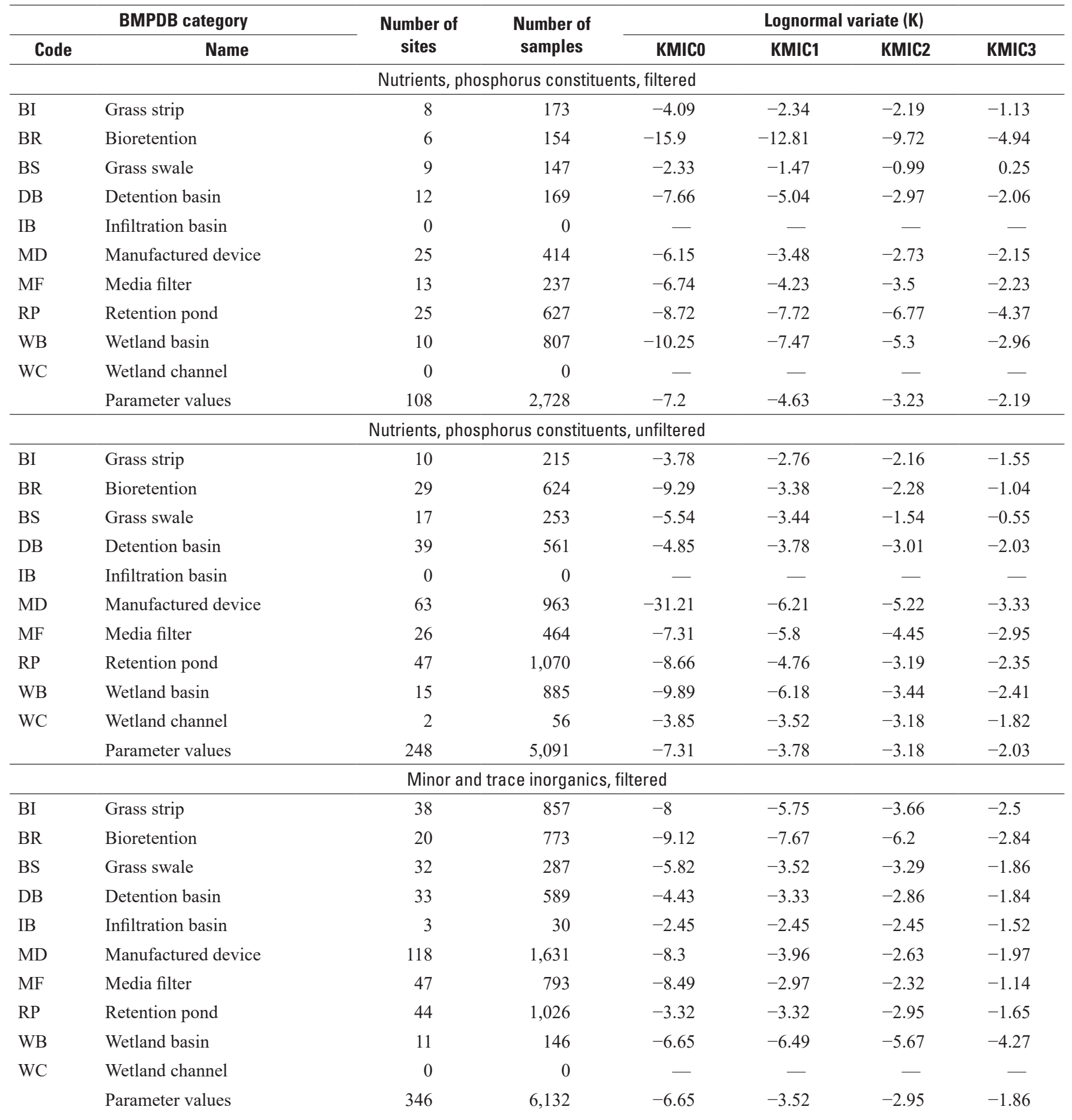


Table 8. Lognormal variate $(K)$ values for the minimum irreducible concentration estimates of selected parameter categories. -Continued

[The International Stormwater Best Management Practices Database (BMPDB) data are from the 2019 version of the database (Wright Water Engineers, Inc. and Geosyntec Consultants, 2019); BMPDB category codes and names are listed in table 1. The constituents included in the parameter categories are listed in table 6. The lognormal variates $(\mathrm{K})$ are calculated by subtracting the geometric mean from each minimum irreducible concentration (MIC) estimate and dividing by the geometric standard deviation in logarithmic space (eq. 1). To use the lognormal variate (KMIC) values, add the geometric mean of simulated inflow concentrations to the product of the geometric standard deviation of simulated inflow concentrations in logarithmic space and then retransform the resultant MIC estimate to arithmetic space (eq. 2). KMIC0, the lognormal variate for the minimum of the minimum values of the positive MIC estimates; KMIC1, the lognormal variate for the 25th percentile of the minimum values of the positive MIC estimates; KMIC2, the lognormal variate for the median of the minimum values of the positive MIC estimates; KMIC3, the lognormal variate for the median of the median values of the positive MIC estimates; - , no data]

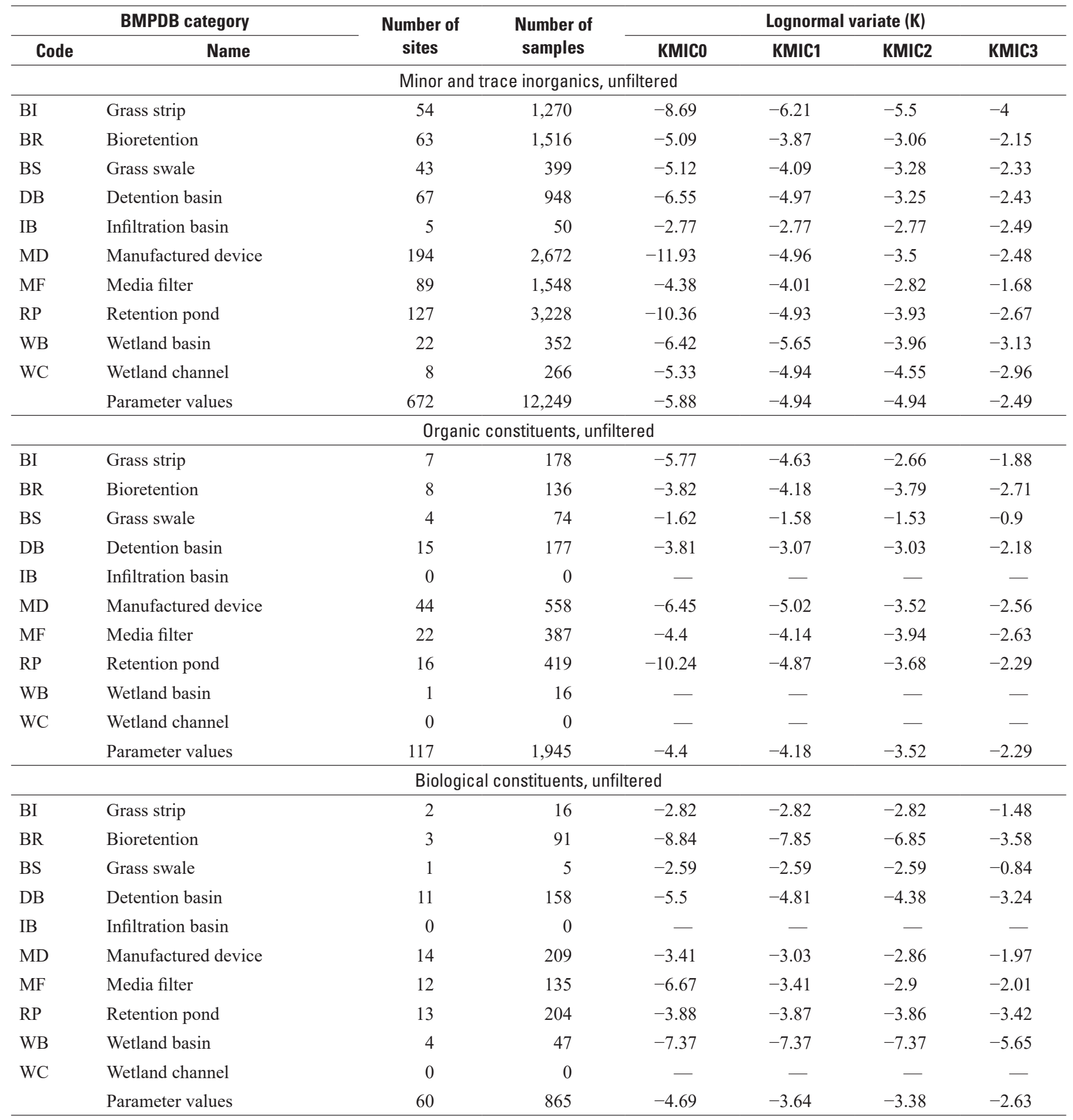


Table 9. Correlation between the median of minimum irreducible concentration estimates of selected constituents at individual monitoring sites and the concentration of the associated elements in the top 5 centimeters of soil.

[The International Stormwater Best Management Practices (BMP) Database (BMPDB) is from (Wright Water Engineers, Inc. and Geosyntec Consultants, 2019). The concentrations of elements in the top 5 centimeters of soil are reported by Smith and others (2014) and are a weighted average of concentration values for all data points within 75 kilometers of the center of a 444-square-kilometer grid cell. The number in parentheses after each constituent is the water-quality parameter code from the National Water Information System and is denoted by "p" followed by a five-digit identification number; parameters are listed in table 6. N, number of sites with sufficient data to calculate the median of the minimum values of the positive minimum irreducible concentration estimate (MIC2) values; R, Pearson correlation coefficient; R(log), Pearson correlation coefficient for the common logarithms of data; Rho, Spearman's correlation coefficient; -, no data]

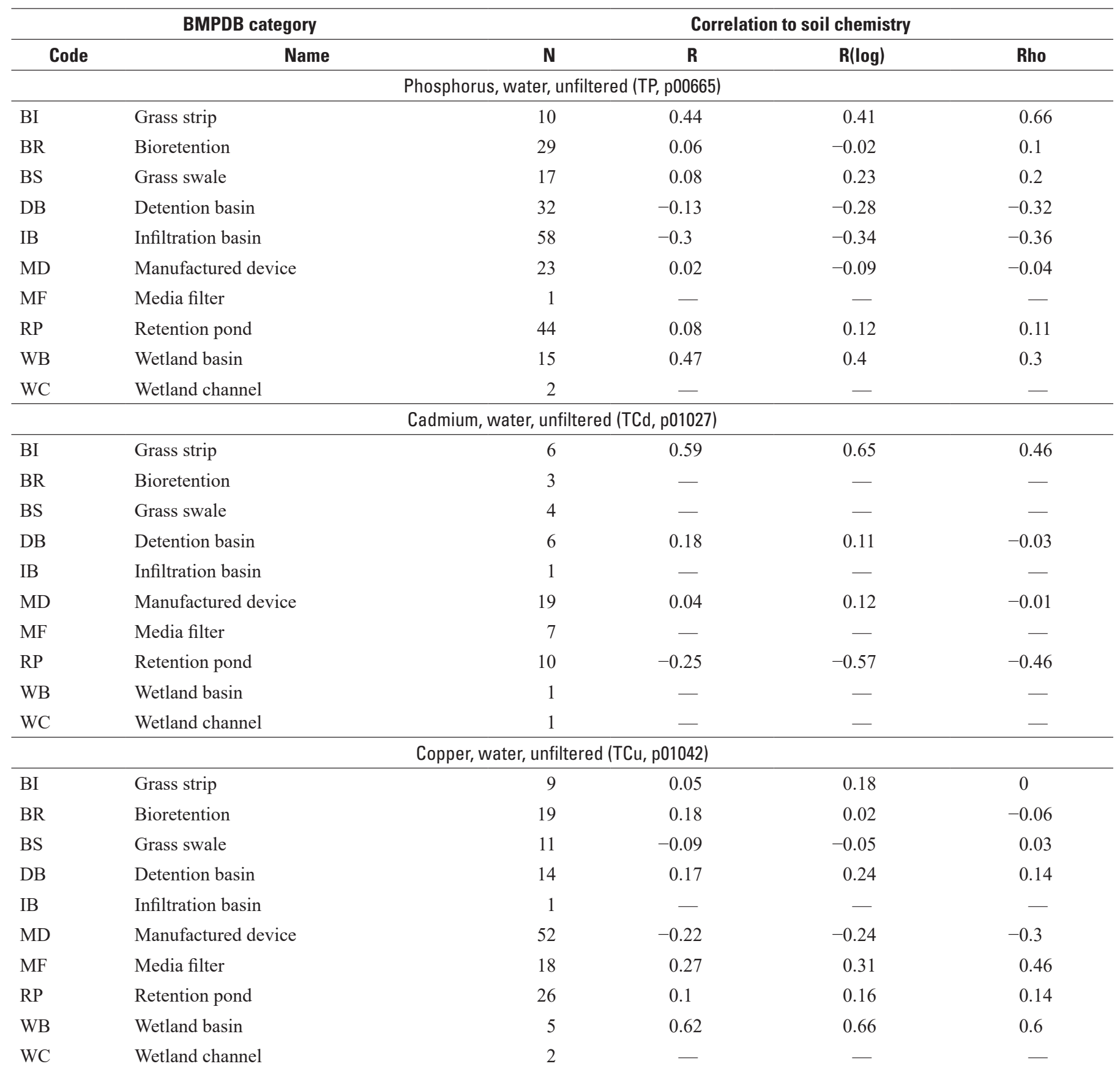


Table 9. Correlation between the median of minimum irreducible concentration estimates of selected constituents at individual monitoring sites and the concentration of the associated elements in the top 5 centimeters of soil.-Continued

[The International Stormwater Best Management Practices (BMP) Database (BMPDB) is from (Wright Water Engineers, Inc. and Geosyntec Consultants, 2019). The concentrations of elements in the top 5 centimeters of soil are reported by Smith and others (2014) and are a weighted average of concentration values for all data points within 75 kilometers of the center of a 444 -square-kilometer grid cell. The number in parentheses after each constituent is the water-quality parameter code from the National Water Information System and is denoted by "p" followed by a five-digit identification number; parameters are listed in table 6. N, number of sites with sufficient data to calculate the median of the minimum values of the positive minimum irreducible concentration estimate (MIC2) values; R, Pearson correlation coefficient; R(log), Pearson correlation coefficient for the common logarithms of data; Rho, Spearman's correlation coefficient; - , no data]

\begin{tabular}{|c|c|c|c|c|c|}
\hline \multicolumn{2}{|r|}{ BMPDB category } & \multicolumn{4}{|c|}{ Correlation to soil chemistry } \\
\hline Code & Name & $\mathbf{N}$ & $\mathbf{R}$ & $\mathbf{R}(\log )$ & Rho \\
\hline \multicolumn{6}{|c|}{ Lead, water, unfiltered (TPb, p01051) } \\
\hline $\mathrm{BR}$ & Bioretention & 8 & -0.67 & -0.43 & -0.65 \\
\hline $\mathrm{BS}$ & Grass swale & 8 & 0.18 & 0.08 & -0.18 \\
\hline IB & Infiltration basin & 1 & - & - & - \\
\hline MD & Manufactured device & 30 & -0.12 & -0.13 & 0.02 \\
\hline MF & Media filter & 14 & -0.36 & -0.48 & 0.11 \\
\hline $\mathrm{RP}$ & Retention pond & 24 & 0.35 & 0.47 & 0.53 \\
\hline WB & Wetland basin & 3 & - & - & - \\
\hline BR & Bioretention & 18 & 0.29 & 0.56 & 0.57 \\
\hline BS & Grass swale & 11 & -0.11 & 0.19 & -0.27 \\
\hline DB & Detention basin & 18 & 0.25 & 0.34 & 0.25 \\
\hline IB & Infiltration basin & 62 & 0.15 & 0.2 & 0.22 \\
\hline MD & Manufactured device & 21 & 0.19 & 0.17 & 0.38 \\
\hline MF & Media filter & 1 & - & - & - \\
\hline $\mathrm{RP}$ & Retention pond & 34 & 0.14 & 0.22 & 0.1 \\
\hline WB & Wetland basin & 9 & -0.06 & 0.11 & 0.08 \\
\hline \multicolumn{6}{|c|}{ Phosphorus, water, filtered (FP, p00666) } \\
\hline IB & Infiltration basin & 25 & -0.13 & -0.06 & -0.05 \\
\hline MD & Manufactured device & 9 & -0.35 & -0.26 & -0.4 \\
\hline MF & Media filter & 0 & - & - & - \\
\hline $\mathrm{RP}$ & Retention pond & 10 & 0.28 & 0.68 & 0.15 \\
\hline WB & Wetland basin & 7 & 0.7 & 0.63 & 0.81 \\
\hline WC & Wetland channel & - & - & - & - \\
\hline
\end{tabular}


Table 9. Correlation between the median of minimum irreducible concentration estimates of selected constituents at individual monitoring sites and the concentration of the associated elements in the top 5 centimeters of soil.-Continued

[The International Stormwater Best Management Practices (BMP) Database (BMPDB) is from (Wright Water Engineers, Inc. and Geosyntec Consultants, 2019). The concentrations of elements in the top 5 centimeters of soil are reported by Smith and others (2014) and are a weighted average of concentration values for all data points within 75 kilometers of the center of a 444-square-kilometer grid cell. The number in parentheses after each constituent is the water-quality parameter code from the National Water Information System and is denoted by "p" followed by a five-digit identification number; parameters are listed in table 6. N, number of sites with sufficient data to calculate the median of the minimum values of the positive minimum irreducible concentration estimate (MIC2) values; R, Pearson correlation coefficient; R(log), Pearson correlation coefficient for the common logarithms of data; Rho, Spearman's correlation coefficient; —, no data]

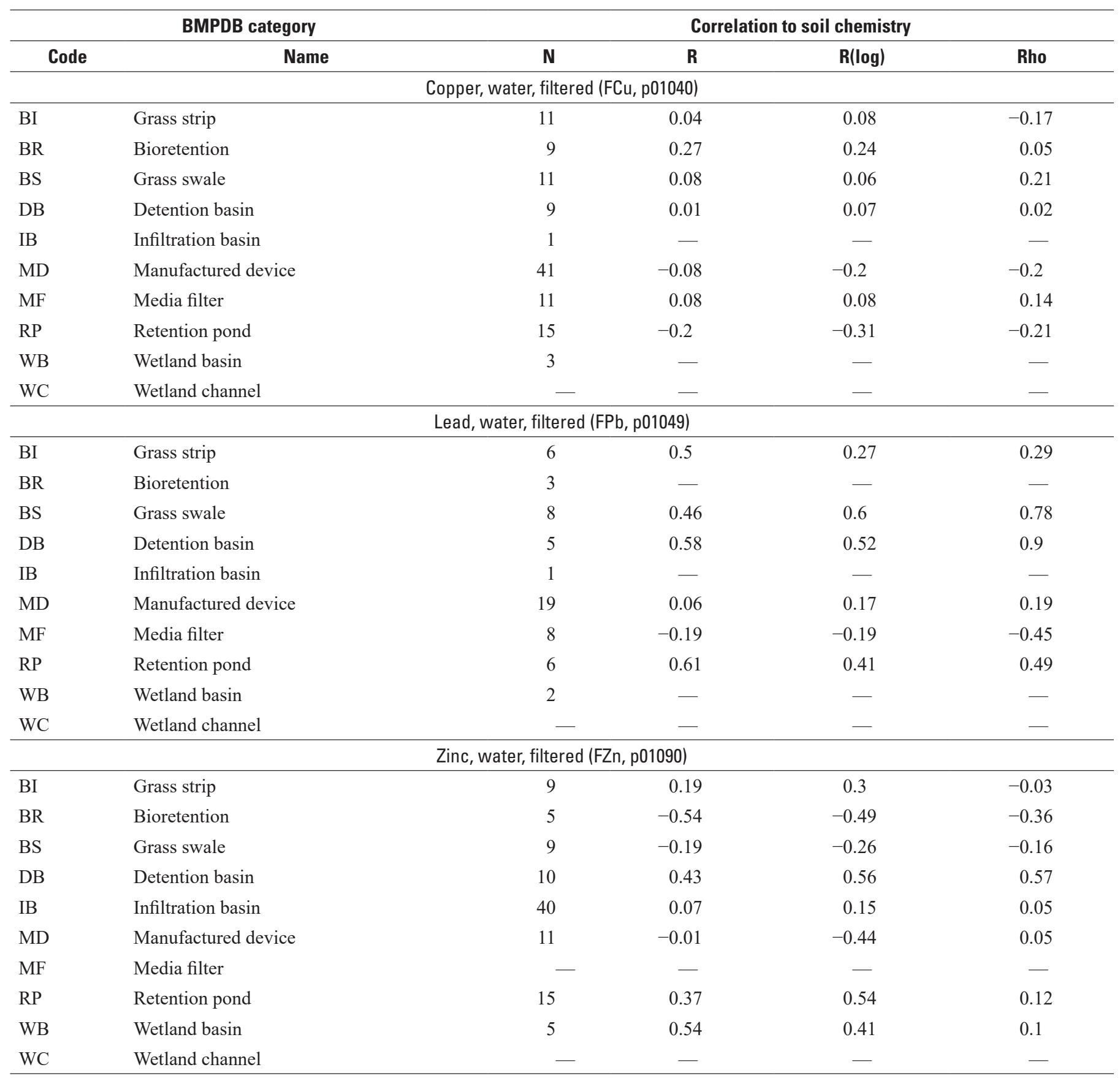




\section{Summary}

Decisionmakers need information to help evaluate the risk for adverse effects of runoff on receiving waters, the potential need for mitigation measures, and the potential effectiveness of such management measures for reducing these risks. Structural stormwater control measures, commonly known as best management practices (BMPs), are used as the primary mitigation measures for reducing adverse effects of runoff on receiving waters. Decisionmakers also need information about the flows and concentrations of runoff and stormwater discharges from BMPs to calculate Total Maximum Daily Loads (TMDLs) for impaired receiving-water basins. In this report, structural BMPs are defined as the components of the drainage pathway between the source of runoff and a stormwater discharge location that affect the timing, volume, or quality of runoff.

The U.S. Geological Survey, in cooperation with the Federal Highway Administration, developed the Stochastic Empirical Loading and Dilution Model (SELDM) to indicate the risk for stormwater flows, concentrations, and loads to be above user-selected water-quality goals and the potential effectiveness of mitigation measures to reduce such risks. SELDM uses a simple stochastic statistical model of BMP performance to develop planning-level estimates of runoff-event characteristics rather than a complex theoretical or physical model. In SELDM, three treatment variables, hydrograph extension, volume reduction, and water-quality treatment are simulated by using the trapezoidal distribution and the rank correlation with the associated highway-runoff variables.

This report documents statistics for simulating structural stormwater runoff best management practices. The trapezoidal-distribution statistics and rank correlation coefficients documented in this report provide a stochastic transfer function to approximate the quantity, quality, and duration of BMP effluents given a population of inflow values. This statistical approach can be used to represent a single BMP or an assemblage of BMPs. If hydrograph extension is specified for a simulated BMP, then the concurrent upstream and downstream flows and loads will be different than those for the untreated runoff because the discharge period will be extended to include more of the upstream flow and loads. If volume reductions are specified but concentration changes are not, then the stormwater-runoff and BMP discharge concentrations will be the same, but the BMP discharge loads and the concurrent downstream loads and concentrations will be different. If BMP water-quality treatment statistics are specified, then BMP discharge concentrations and loads will be affected as well as downstream concentrations and loads. The waterquality treatment statistics also include estimates for the minimum irreducible concentrations (MIC), which represents the lower bound of outflow concentrations that can be achieved with commonly used BMP designs.

In this study, data extracted from a modified copy of the December 2019 version of International Stormwater Best Management Practices Database were used for the analyses.
Sufficient data were available to estimate statistics for 8 to $12 \mathrm{BMP}$ categories by using data from 44 to more than 265 monitoring sites. The medians of the best-fit statistics were used to construct generalized cumulative distribution functions for the three treatment variables. In cases where data are not available for a category of interest or a stream basin with multiple BMPs is being simulated, then the parameter values, which are the medians of categorical medians, may guide professional judgement in these cases.

A parameter value estimate, which represents a generic BMP for watershed-wide simulations, was also calculated for each BMP treatment variable. For hydrograph extension, data were available from 44 monitoring sites with 7 or more storm events; statistics for 8 BMP categories were calculated. For volume reduction, data were available from 87 monitoring sites with 7 or more storm events; statistics for 12 BMP categories were calculated. For water-quality treatment ratios, data were available from 206 monitoring sites with paired inflow and outflow concentrations from 7 or more storm events. Water-quality treatment ratio statistics were calculated for 51 runoff-quality constituents commonly measured in highway and urban runoff studies. Statistics were calculated for water-quality properties, sediment and solids, nutrients, major and trace inorganic elements, organic compounds, and biologic constituents. However, the amount of available data was substantially different for various constituents. Statistics from 1 to 10 BMP categories and parameter-level estimates were calculated for the different constituents and constituent categories analyzed in this report. For the MIC values, data were available from 265 monitoring sites with outflow concentrations from 7 or more storm events. The amount of data available to calculate MIC values also was substantially different for various constituents. Analysis of MIC values indicates that the inflow concentration statistics may be used to guide selection of representative MIC values, but regional soil chemistry is not a strong predictor for this variable. Water-quality statistics for constituent categories are provided in tables within this report; constituent-specific statistics are provided in tables within appendix 1.

SELDM uses rank correlation to the inflow variable to condition the treatment variables to better represent the structure of actual BMP data. For volume reduction and hydrograph extension, interpretation of available data indicates that selection of a Spearman's rho value that is the average of the median and maximum values for the BMP category may help generate realistic simulation results in SELDM. Interpretation of available data also indicates that the median rho value may be selected to help generate realistic simulation results for water-quality treatment ratios and the MIC values.

The planning-level estimates for BMP categories are recognized to include substantial uncertainties when applied to any particular site. Therefore, statistics for individual monitoring sites are available in the U.S. Geological Survey data release by Granato and others (2021) so that analysts may use their own professional judgement to select statistics that are most representative of a particular site of interest. However, 
practitioners may need to combine statistics from multiple sites to represent a site of interest because sample sizes are small, monitoring artifacts are present in many BMP datasets, and previous studies have not demonstrated predictive correlations between BMP design characteristics and BMP performance statistics.

Although site-specific estimates for all 51 constituents are available in the U.S. Geological Survey data release (Granato and others, 2021), summary statistics for constituents in deicing salts (including sodium, chloride, and total solids) were not included in the analyses in this report. Calcium and magnesium, however, were included because statistics for these constituents may be used to estimate the hardness of BMP discharges, which may be used to estimate potential effects of trace elements on receiving-water quality. Statistics for constituents in deicing salts should not be used for analysis of the effects of deicing chemicals on water quality, however, because most datasets do not include deicing-salt data and these constituents are not substantially affected by commonly used BMP treatment methods at concentrations found in winter runoff.

\section{References Cited}

Abdel-Megeed, S.M., 1984, Accuracy of correlation coefficient with limited number of points: Journal of Experimental Education, v. 52, no. 4, p. 188-191. [Also available at https://doi.org/10.1080/00220973.1984.11011891.]

Back, W.E., Boles, W.W., and Fry, G.T., 2000, Defining triangular probability distributions from historical cost data: Journal of Construction Engineering and Management, v. 126, no. 1, p. 29-37. [Also available at https://doi.org/10.1061/(ASCE)0733-9364(2000)126:1(29).]

Barnwell, T.O., Jr., and Krenkel, P.A., 1982, Use of water quality models in management decision making: Water Science and Technology, v. 14, no. 9-11, p. 1095-1107. [Also available at https://doi.org/10.2166/wst.1982.0145.]

Bland, M., 2015, An introduction to medical statistics 4th ed.: Oxford, United Kingdom, Oxford University Press, 427 p.

Burton, G.A., Jr., and Pitt, R., 2002, Stormwater effects handbook-A toolbox for watershed managers, scientists, and engineers: Boca Raton, Fla., CRC Press, 911 p.

California Department of Transportation, 2009, BMP pilot study guidance manual: California Department of Transportation CTSW-RT-06-171.02.1, 368 p.

Caruso, J.C., and Cliff, N., 1997, Empirical size, coverage, and power of confidence intervals for Spearman's rho: Educational and Psychological Measurement, v. 57, no. 4, p. 637-654. [Also available at https://doi.org/10.1177/0013164497057004009.]
Clar, M.L., Barfield, B.J., and O’Connor, T.P., 2004, General considerations, v. 1 of Stormwater best management practice design guide: U.S. Environmental Protection Agency EPA/600/R-04/121, 179 p.

Clary, J., Jones, J., Leisenring, M., Hobson, P., and Strecker, E., 2017, International stormwater best management practices database - 2016 summary statistics: Alexandria, Va., Water Environment \& Reuse Foundation final report, 52 p., accessed June 3, 2020, at https://www.bmpdatabase.org/ Docs/03-SW-1COh\%20BMP\%20Database\%202016\%20 Summary\%20Stats.pdf.

Cunnane, C., 1978, Unbiased plotting positions-A review: Journal of Hydrology (Amsterdam), v. 37, nos. 3-4, p. 205-222. [Also available at https://doi.org/10.1016/0022-1694(78)90017-3.]

Driscoll, E.D., Di Toro, D.M., and Thomann, R.V., 1979, A statistical method for assessment of urban stormwater: U.S. Environmental Protection Agency EPA 440/3-79-023, 436 p. [Also available at https://nepis.epa.gov/Exe/ZyPDF. cgi/2000KZDZ.PDF?Dockey=2000KZDZ.PDF.]

Fisher, R.A., 1924, On a distribution yielding the error functions of several well known statistics: Proceedings of the International Congress of Mathematics, Toronto, Canada, August 11-16, 1924, proceedings, v. 2, p. 805-813. [Also available at https://digital.library.adelaide.edu.au/dspace/ handle/2440/15183.]

Geosyntec Consultants and Wright Water Engineers, Inc., 2009, Urban stormwater BMP performance monitoring: International Stormwater Best Management Practices Database Project, 355 p., accessed March 19, 2020, at https://www.bmpdatabase.org/monitoring-guidance.html.

Granato, G.E., 2010, Methods for development of planninglevel estimates of stormflow at unmonitored sites in the conterminous United States: Federal Highway Administration FHWA-HEP-09-005, 90 p.

Granato, G.E., 2013, Stochastic empirical loading and dilution model (SELDM) version 1.0.0: U.S. Geological Survey Techniques and Methods, book 4, chap. C3, 112 p., accessed June 3, 2020, at https://doi.org/10.3133/tm4C3.

Granato, G.E., 2014, Statistics for stochastic modeling of volume reduction, hydrograph extension, and water-quality treatment by structural stormwater runoff best management practices (BMPs): U.S. Geological Survey Scientific Investigations Report 2014-5037, 37 p., accessed June 3, 2020, at https://doi.org/10.3133/sir20145037.

Granato, G.E., 2021, Best management practices statistical estimator (BMPSE) version 1.2.0: U.S. Geological Survey software release, https://doi.org/10.5066/P9XBPIOB. 
Granato, G.E., and Cazenas, P.A., 2009, Highway-runoff database (HRDB version 1.0) — A data warehouse and preprocessor for the stochastic empirical loading and dilution model: Federal Highway Administration FHWA-HEP-09-004, 57 p., accessed June 3, 2020, at https://pubs.usgs.gov/sir/2009/5269/disc_content_100a_ web/FHWA-HEP-09-004.pdf.

Granato, G.E., and Jones, S.C., 2014, Stochastic empirical loading and dilution model for analysis of flows, concentrations, and loads of highway runoff constituents: Transportation Research Record: Journal of the Transportation Research Board, v. 2436, no. 1, p. 139-147. [Also available at https://doi.org/10.3141/2436-14.]

Granato, G.E., and Jones, S.C., 2017, Estimating total maximum daily loads with the stochastic empirical loading and dilution model: Transportation Research Record: Journal of the Transportation Research Board, v. 2638, no. 1, p. 104-112. [Also available at https://doi.org/10.3141/2638-12.]

Granato, G.E., and Jones, S.C., 2019, Simulating runoff quality with the highway-runoff database and the stochastic empirical loading and dilution model: Transportation Research Record: Journal of the Transportation Research Board, v. 2673, no. 1, p. 136-142. [Also available at https://doi.org/10.1177/0361198118822821.]

Granato, G.E., Medalie, L., and Spaetzel, A.B., 2021, Statistics for simulating structural stormwater runoff best management practices (BMPs) with the stochastic empirical loading and dilution model (SELDM): U.S. Geological Survey data release, https://doi.org/10.5066/P9X3ECTD.

Haan, C.T., 1977, Statistical methods in hydrology: Ames, Iowa State University Press, 378 p.

Helsel, D.R., and Hirsch, R.M., 2002, Statistical methods in water resources-Hydrologic analysis and interpretation: U.S. Geological Survey Techniques of Water-Resources Investigations, book 4, chap. A3, 510 p. [Also available at https://doi.org/10.3133/twri04A3.]

Huber, W.C., Cannon, L., and Stouder, M., 2006, BMP modeling concepts and simulation: U.S. Environmental Protection Agency EPA/600/R-06/033, 166 p., accessed June 9, 2020, at https://cfpub.epa.gov/si/si_public_record_Report.cfm? $\mathrm{Lab}=\mathrm{NRMRL} \&$ dirEntryID $=152387$

Jeznach, L.C., and Granato, G.E., 2020, Comparison of SELDM simulated total-phosphorus concentrations with ecological impervious-area criteria: Journal of Environmental Engineering, v. 146, no. 8, article 04020088, 10 p., accessed June 9, 2020, at https://doi.org/10.1061/ (ASCE)EE.1943-7870.0001763.
Johnson, D., 1997, The triangular distribution as a proxy for the beta distribution in risk analysis: The Statistician, v. 46, no. 3, p. 387-398. [Also available at https://doi.org/10.1111/1467-9884.00091.]

Kacker, R.N., and Lawrence, J.F., 2007, Trapezoidal and triangular distributions for type B evaluation of standard uncertainty: Metrologia, v. 44, no. 2, p. 117-127. [Also available at https://doi.org/10.1088/0026-1394/44/2/003.]

Kadlec, R.H., and Knight, R.L., 1996, Treatment wetlands: Boca Raton, Fla., CRC Press, 893 p.

Lantin, A., Larsen, L., Vyas, A., Barrett, M., Leisenring, M., Koryto, K., and Pechacek, L., 2019, Approaches for determining and complying with TMDL requirements related to roadway stormwater runoff: National Cooperative Highway Research Program Research Report 918, 133 p. [Also available at https://doi.org/10.17226/25473.]

Leisenring, M., Hobson, P., Clary, J., and Krall, J., 2013, International stormwater best management practices (BMP) database advanced analysis - Influence of design parameters on achievable effluent concentrations: International Stormwater Best Management Practices Database, 74 p., accessed June 3, 2020, at https://www.bmpdatabase.org/ Docs/BMPDB_AdvancedAnalysis_Final_2013.pdf.

Leisenring, M., Hobson, P., Pankani, D., Nguyen, L., Clary, J., Rogers, H., Jones, J., and Strecker, E., 2020, Use of the state department of transportation portal to the international stormwater best management practices database: National Cooperative Highway Research Program Project 25-25, Task 120 final report, 102 p., app., accessed April 4, 2020, at http://onlinepubs.trb.org/onlinepubs/nchrp/docs/ NCHRP25-25-120Report.pdf.

Leutnant, D., Muschalla, D., and Uhl, M., 2018, Statistical distribution of TSS event loads from small urban environments: Water, v. 10, no. 6, article 769, 11 p. [Also available at https://doi.org/10.3390/w10060769.]

Marsalek, J.H., 1991, Pollutant loads in urban stormwaterReview of methods for planning-level estimates: Water Resources Bulletin, v. 27, no. 2, p. 283-291. [Also available at https://doi.org/10.1111/j.1752-1688.1991.tb03133.x.]

Marsalek, J.H., and Ng, Y.F., 1989, Evaluation of pollution loadings from urban nonpoint sourcesMethodology and applications: Journal of Great Lakes Research, v. 15, no. 3, p. 444-451. [Also available at https://doi.org/10.1016/S0380-1330(89)71500-8.]

National Cooperative Highway Research Program, 2006, Evaluation of best management practices for highway runoff control: National Cooperative Highway Research Program Research Report 565, 132 p. [Also available at https://doi.org/10.17226/23211.] 
Press, W.H., Flannery, B.P., Teukolsky, S.A., and Vetterling, W.T., 1992, Numerical recipes in Fortran 77-The art of scientific computing ( $2 \mathrm{~d}$ ed.): New York, Cambridge University Press, 992 p.

Risley, J.C., and Granato, G.E., 2014, Assessing potential effects of highway runoff on receiving-water quality at selected sites in Oregon with the stochastic empirical loading and dilution model (SELDM): U.S. Geological Survey Scientific Investigations Report 2014-5099, 73 p., accessed June 3, 2020, at https://doi.org/10.3133/sir20145099.

Scherer, W.T., Pomroy, T.A., and Fuller, D.N., 2003, The triangular density to approximate the normal densityDecision rules-of-thumb: Reliability Engineering \& System Safety, v. 82, no. 3, p. 331-341. [Also available at https://doi.org/10.1016/j.ress.2003.08.003.]

Smith, D.B., Cannon, W.F., and Woodruff, L.G., Solano, F., and Ellefsen, K.J., 2014, Geochemical and mineralogical maps for soils of the conterminous United States: U.S. Geological Survey Open-File Report 2014-1082, 386 p., accessed June 3, 2020, at https://doi.org/10.3133/ ofr20141082.

Smith, K.P., Sorenson, J.R., and Granato, G.E., 2018, Characterization of stormwater runoff from bridge decks in eastern Massachusetts, 2014-16: U.S. Geological Survey Scientific Investigations Report 2018-5033, 73 p., accessed June 3, 2020, at https://doi.org/10.3133/sir20185033.

Stonewall, A.J., Granato, G.E., and Glover-Cutter, K.M., 2019, Assessing potential effects of highway and urban runoff on receiving streams in total maximum daily load watersheds in Oregon using the stochastic empirical loading and dilution model: U.S. Geological Survey Scientific Investigations Report 2019-5053, 116 p., accessed June 3, 2020, at https://doi.org/10.3133/sir20195053.

Stonewall, A.J., Granato, G.E., and Haluska, T.L., 2018, Assessing roadway contributions to stormwater flows, concentrations, and loads by using the StreamStats application: Transportation Research Record: Journal of the Transportation Research Board, v. 2672, no. 39, 9 p. [Also available at https://doi.org/10.1177/0361198118758679.]

Strecker, E.W., Quigley, M.M., Urbonas, B.R., Jones, J.E., and Clary, J.K., 2001, Determining urban storm water BMP effectiveness: Journal of Water Resources Planning and Management, v. 127, no. 3, p. 144-149. [Also available at https://doi.org/10.1061/(ASCE)07339496(2001)127:3(144).]
Taylor, S., Barrett, M., Leisenring, M., Sahu, S., Pankani, D., Poresky, A., Questad, A., Strecker, E., Weinstein, N., and Venner, M., 2014, Long-term performance and life-cycle costs of stormwater best management practices: National Cooperative Highway Research Program Research Report 792, 148 p. [Also available at https://doi.org/10.17226/22275.]

U.S. Environmental Protection Agency, 2001, Process for conducting probabilistic risk assessment, v. III, pt. A of Risk assessment guidance for superfund: U.S. Environmental Protection Agency EPA 540-R-02-002, 385 p.

U.S. Geological Survey, 2020, Search criteria and codes: U.S. Geological Survey National Water Information System web page, accessed April 18, 2020, at https://help.waterdata.usgs.gov/codes-andparameters/codes.

Wallis, K.F., 2014, Revisiting Francis Galton's forecasting competition: Statistical Science, v. 29, no. 3, p. 420-424. [Also available at https://doi.org/10.1214/14-STS468.]

Weaver, J.C., Granato, G.E., and Fitzgerald, S.A., 2019, Assessing water quality from highway runoff at selected sites in North Carolina with the stochastic empirical loading and dilution model (SELDM) (ver. 1.1, July 2019): U.S. Geological Survey Scientific Investigations Report 2019-5031, 99 p., accessed June 3, 2020, at https://doi.org/ 10.3133/sir20195031.

Wong, T.H.F., and Geiger, W.F., 1997, Adaptation of wastewater surface flow wetland formulae for application in constructed stormwater wetlands: Ecological Engineering, v. 9, no. 3-4, p. 187-202. [Also available at https://doi.org/10.1016/S0925-8574(97)10011-8.]

Wright Water Engineers, Inc. and Geosyntec Consultants, 2019, International stormwater BMP database: Water Research Foundation data, accessed December 31, 2020, at https://bmpdatabase.org/. 



\section{Appendix 1. Water-Quality Treatment Statistics for Individual Constituents}

Table 1.1. Median of selected treatment statistics for individual constituents including the trapezoidal distribution parameters and Spearman's rank correlation coefficients for structural stormwater best management practices, by category.

[The table is available for download as a tab-separated value file at https://doi.org/10.3133/sir20205136. The concentration-reduction statistics are for the trapezoidal distribution of the ratio of outflow to inflow concentration. The Spearman's rank correlation coefficients (rho values) are calculated by using the ranks of the inflow concentrations and the associated ratios of outflow to inflow concentrations; selected value is closest to -1 among at-site rho values. The water-quality parameter code in parentheses is denoted by the letter $\mathrm{p}$ and the five-digit identification number, the full name of each parameter is listed in table 6; properties and constituents are listed in parameter-code order. N, number of sites with paired inflow and outflow concentrations for at least seven storms used to calculate the median ratio statistics; ${ }^{*}$, statistic based on values from selected sites; **, statistics based on selected data from the available site(s); LBMPV, lower bound of the most probable value; max, maximum; min, minimum; parameter values are the medians of values in this table; UBMPV, upper bound of the most probable value; Pct GT 1, theoretical percentage of event ratios that may equal or exceed a value of $1 ;-$, insufficient data]

Table 1.2. Estimates of the minimum irreducible concentration for each selected structural stormwater best management practice category for constituents of concern.

[The table is available for download as a tab-separated value file at https://doi.org/10.3133/sir20205136. Each MIC0 estimate is the category minimum of the minimum of positive minimum irreducible concentration (MIC) estimates from available sites. Each MIC1 estimate is the 25th percentile of the minimum of positive MIC estimates from available sites. Each MIC2 estimate is the category median of the minimum of positive MIC estimates from available sites. Each MIC3 estimate is the category median of the median of positive MIC estimates from available sites. International Stormwater Best Management Practices Database (BMPDB) category codes and names are described in table 1; the constituents included in the parameter categories are listed in table 6]
Table 1.3. Estimates of the lognormal variate $(K)$ values of selected minimum irreducible concentrations (MICs) for each selected structural stormwater best management practice category for constituents of concern.

[The table is available for download as a tab-separated value file at https://doi.org/10.3133/sir20205136. The KMIC values are the lognormal variate $(\mathrm{K})$ for the associated minimum irreducible concentration (MIC) values, which are calculated by subtracting the geometric mean from the MIC estimate and dividing by the geometric standard deviation in logarithmic space (eq. 1). To use the KMIC values add the geometric mean of simulated inflow concentrations to the product of the geometric standard deviation of simulated inflow concentrations in logarithmic space and then retransform the resultant MIC estimate to arithmetic space (eq. 2). International Stormwater Best Management Practices Database (BMPDB) category codes and names are described in table 1; the constituents included in the parameter categories are listed in table 6; the MIC values are listed in table 1.2]

Table 1.4. Estimates of correlations between the geometric mean concentration of inflows and selected minimum irreducible concentration (MIC) estimates for each selected best management practices category for constituents of concern.

[The table is available for download as a tab-separated value file at https://doi.org/10.3133/sir20205136. Spearman's rank correlation coefficients (rho) were calculated using the MIC0 and MIC2 estimates and the geometric mean of influents. The MIC estimates for total suspended solids (p00530) are applicable for estimating the MIC of suspended sediment concentration (p80154) because differences in the results of these analytical methods are small once the large grain-size fractions are removed. International Stormwater Best Management Practices Database (BMPDB) category codes and names are described in table 1; the constituents included in the parameter categories are listed in table 6; the MIC values are listed in table 1.2. $R$, Pearson's correlation coefficient; $R(\log )$, Pearson's correlation coefficient for the common logarithms of data, MIC0, the minimum of the minimum values of the positive MIC estimates; MIC2, the median of the minimum values of the positive MIC estimates] 

For more information about this report, contact: Director, New England Water Science Center U.S. Geological Survey 10 Bearfoot Road Northborough, MA 01532

dc_nweng@usgs.gov or visit our website at https://www.usgs.gov/centers/new-england-water

Publishing support provided by the Pembroke Publishing Service Center 


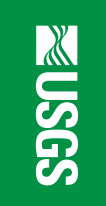

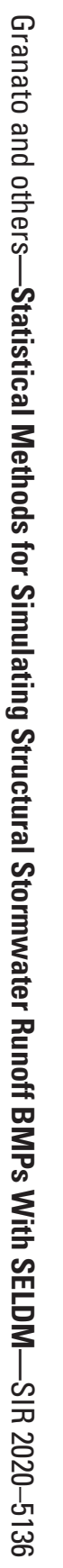

